\title{
Cardiological aspects of pulmonary embolism
}

Citation for published version (APA):

Cheriex, E. C. (1997). Cardiological aspects of pulmonary embolism. [Doctoral Thesis, Maastricht University]. Rijksuniversiteit Maastricht. https://doi.org/10.26481/dis.19970626ec

Document status and date:

Published: 01/01/1997

DOI:

10.26481/dis.19970626ec

Document Version:

Publisher's PDF, also known as Version of record

\section{Please check the document version of this publication:}

- A submitted manuscript is the version of the article upon submission and before peer-review. There can be important differences between the submitted version and the official published version of record.

People interested in the research are advised to contact the author for the final version of the publication, or visit the DOI to the publisher's website.

- The final author version and the galley proof are versions of the publication after peer review.

- The final published version features the final layout of the paper including the volume, issue and page numbers.

Link to publication

\footnotetext{
General rights rights.

- You may freely distribute the URL identifying the publication in the public portal. please follow below link for the End User Agreement:

www.umlib.nl/taverne-license

Take down policy

If you believe that this document breaches copyright please contact us at:

repository@maastrichtuniversity.nl

providing details and we will investigate your claim.
}

Copyright and moral rights for the publications made accessible in the public portal are retained by the authors and/or other copyright owners and it is a condition of accessing publications that users recognise and abide by the legal requirements associated with these

- Users may download and print one copy of any publication from the public portal for the purpose of private study or research.

- You may not further distribute the material or use it for any profit-making activity or commercial gain

If the publication is distributed under the terms of Article $25 \mathrm{fa}$ of the Dutch Copyright Act, indicated by the "Taverne" license above, 
Cardiological aspects of pulmonary embolism 
C E.C. Cheriex, Maastricht 1997

ISBN 90-9010669-3

Vormgeving: E.C.Cheriex

Druk: Datawyse | Universitaire Pers Maastricht 


\title{
Cardiological aspects of pulmonary embolism
}

\author{
Proefschrift
}

ter verkrijging van de graad van doctor aan

de Universiteit Maastricht,

op gezag van de Rector Magnificus, Prof. mr. M.J. Cohen

volgens het besluit van het College van Decanen,

in het openbaar te verdedigen op donderdag 26 juni 1997 om 14.00 uur

door

Emile C. Cheriex 


\section{Promotor:}

Prof. dr. HJJ, Wellens

\section{Beoordelingscommissie:}

Prof. dr. J. de Haan (voorzitter)

Prof. dr. P. Hanrath (Rheinisch-Westfalische Technische Hochschule Aachen)

Prof. dr. J.P. van Hooff

Prof. dr. C.A. Visser (Vrije Universiteit Amsterdam)

Prot. dr. E.F.M. Wouters

De uitgave van de proefschift werd mede mogelijk gemaakt door financiele steun van de Nederlandse Hartstichting en de Stichting RESCAR.

Financiële steun werd verder geleverd door: Asta Medica BV, Bayer BV, Boehringer Mannheim BV, Byk Nederland BV. Hewlett Packard Nederland BV. Lorex Synthélabo BV, Menarini Benelux BV, Merck Sharp \& Dohme BV, Pfizer BV, Roche BV, Sanof Winthrop BV, Solvay Pharma BV. 


\section{Contents}

Chapter 1

Introduction

Chapter 2

Effects of pulmonary embolism on the pulmonary circulation.

Diagnostic methods and strategies.

Chapter 3

Fatal pulmonary embolism in the Maastricht area.

A retrospective, hospital based, study.

Chapter 4

The Maastricht echocardiographic database.

Chapter 5

Cross sectional Doppler echocardiography as the initial technique for the diagnosis of acute pulmonary embolism.

Chapter 6

Value of the 12-lead electrocardiogram at hospital admission in the diagnosis of pulmonary embolism.

Chapter 7

When is echocardiographically detected right ventricular pressure overload suggestive for pulmonary embolism?

Chapter 8

Treatment of acute pulmonary embolism.

Effect of therapy on pulmonary anatomy and pulmonary hemodynamics.

Chapter 9

Summary.

Hoofdstuk 10

Samenvatting.

Nawoord.

Curriculum vitae. 


\begin{tabular}{|l|l|}
\hline \multicolumn{2}{|c|}{ Abbreviations/Acronyms } \\
\hline CABG & Coronary Artery Bypass Surgery \\
INR & International Normalized Ratio \\
V/Q-scan & Ventilation Periusion scan \\
PIOPED & Prospective Investigation Of Pulmonary Embolism Diagnosis \\
CT & Computer Tomography \\
MRI & Magnetic Resonance Imaging \\
TEE & Trans Esophageal Echocardiogram \\
TTE & Trans Thoracic Echocardiogram \\
SPECT & Single Photon Emission Computed Tomography \\
RV & Right Ventricle \\
LV & Left Ventricle \\
RA & Right Atrium \\
LA & Left Atrium \\
IVC & Inferior Caval Vein \\
TR & Tricuspid Regurgitation \\
LVEF & Left Ventricular Ejection Fraction \\
COPD & Chronic Obstructive Pulmonary Disease \\
MRAP & Mean Right Atrial Pressure \\
PAP & Pulmonary Artery Pressure \\
PE & Pulmonary Embolism \\
UPET & Urokinase Pulmonary Embolism Trial \\
USPET & Urokinase Streptokinase Pulmonary Embolism Trial \\
UK & UroKinase \\
SK & Streptokinase \\
UFH & UnFractionated Heparin \\
LMWH & Low Molecular Weight Heparin \\
\hline
\end{tabular}




\section{Chapter 1}

\section{Introduction}

Pulmonary embolism can be the cause of unexpected death and severe morbidity. The earliest possible diagnosis and correct treatment are therefore of obvious importance. Pulmonary embolism may occur under many different circumstances and present with complaints that raise the suspicion of other disorders. It may occur out and inside the hospital and taxes the diagnostic acumen of all kinds of physicians ranging from the general practitioner to a large variety of doctors from different specialties. It is not surprising therefore that the many tests that have been developed to diagnose pulmonary embolism reflect approaches based upon knowledge and understanding by these specialties. In our age of protocolised medicine and cost-consciousness more and more emphasis is placed on uniform approaches when a certain. disease is suspected or diagnosed. In that light it is important to review the approach in the patients with a possible pulmonary embolus. That will be the main theme of this thesis, in which the value of two non-invasive diagnostic techniques: electrocardiography and echocardiography will be studied in particular.

Chapter 2 reviews the pulmonary anatomy and the effect of a pulmonary embolus on pulmonary circulation and the heart. Deep venous thrombosis is usually the cause of the pulmonary embolism and the circumstances promoting the occurrence of thrombo-embolism are discussed. The diagnosis of deep venous thrombosis and the identification of pulmonary embolism requires different non-invasive and invasive tests. The value of these tests and the suggestions from the literature as to when to apply them and in what sequence is discussed in this chapter.

Chapter 3 reports on autopsy findings in the Academic Hospital Maastricht during the years 1986 to 1993 concentrating on the incidence of the finding of pulmonary embolism. The relation of the type of venous thrombosis with pulmonary embolism is discussed on the basis of literature data. The findings in patients with pulmonary embolism are discussed in detail. Emphasis is given to the diagnostic accuracy of physicians in patients dying from pulmonary embolism.

Chapter 4 gives insight in our echocardiographic database. This storage system was initially developed in 1986 and was at that time exceptional in using an early type of mnemonic coding. At present the database contains 47.000 echocardiographic investigations of over 37.500 patients. In this chapter we also discuss possible reasons why not all patients with pulmonary embolism are included in our storage system.

Chapter 5 shows the results in 60 patients with acute clinical symptoms suggestive of pulmonary embolism, in whom echocardiography was used as the initial diagnostic tool. The majority of deaths in acute pulmonary embolism occur due to delays in diagnosis. Of the standard diagnostic tests, ventilation perfusion scans are not sufficiently sensitive, while angiography is invasive and associated with complications. This chapter therefore focuses 
on the value of two-dimensional Doppler echocardiography using acute changes in right ventricular filling pressure, right ventricular function and pulmonary arterial systolic pressure and in relation to pulmonary embolism in a sizeable patient population.

In chapter 6 the 12-lead electrocardiograms of 49 patients presenting with acute symptoms and subsequently proven pulmonary embolism without previous lung disease were studied. All these patients had signs of elevated pressures in the right heart, detected by twodimensional echocardiography. These electrocardiograms obtained on admission to hospital were reviewed in a blinded fashion by different investigators for electrocardiographic features suggestive of right ventricular pressure overload. The objective of this investigation was to determine the value of the electrocardiogram at hospital admission in diagnosing acute right ventricular pressure overload.

Chapter 7 addresses the value of echocardiography in patients with right ventricular pressure overload to make the diagnosis of pulmonary embolism. One hundred patients mainly having echocardiographically detected isolated right sided pressure elevation were studied. In this population also right heart thrombi with or without signs of pressure elevation were incorporated. The objective was to study the value of other clinical and laboratory findings in combination with the echocardiographically detected abnormalities for diagnosing pulmonary embolism.

In chapter 8 the natural history of an embolus in the pulmonary circulation is described. Endogenous lysis and organization of the thrombus are discussed followed by a discussion of the effect of anticoagulation and thrombolytics using the presently available agents. The chapter ends with our present diagnostic and treatment strategy when pulmonary embolism is suspected. 


\section{Chapter 2}

\section{Effects of pulmonary embolism on the pulmonary circulation. Diagnostic methods and strategies}

The respiratory system plays an essential role in the exchange of gases between the atmosphere and the blood in the capillaries of the pulmonary circulation. This interaction between airways and vascular system is not only essential for life but also results in some overlap between two clinical specialties: pulmonology and cardiology. Changes in the respiratory capacity and the tissue structure of the lung will affect the behavior of the vascular system and changes and diseases of the pulmonary vessels will have their effect on gas exchange and respiratory capacity. Not only in cardiovascular disease but also in other systemic diseases, electrolyte and acid-base disorders and during and after surgical interventions appropriate function of the respiratory system is essential. This is the reason that many different medical specialities have to deal with diseases of the lung and the pulmonary circulation, pulmonary embolism being a typical example. A thrombus in one of the larger veins, particularly the leg and pelvic veins, frequently develops in the setting of another disease (cancer, coagulation disorders) or after a surgical intervention leading to immobilization and circulatory changes. This results in the situation that many different medical and surgical specialists are confronted with the occurrence, diagnosis and treatment of pulmonary embolism. To give a complete overview of such a subject is a difficult task. In this chapter we will therefore mainly discuss the cardiovascular effects of pulmonary embolism and how its occurrence can be diagnosed.

\section{Pulmonary anatomy}

To get insight in the pulmonary circulation it is essential to review the anatomy of the lungs, particularly the subdivision of the airways from trachea to alveolus and the pulmonary circulation $^{1,2}$.

The right lung consists of three and the left lung of two lobes. Each lobe is divided into bronchopulmonary segments: This is that part of the lung which is supplied by the terminal branches of a lobar bronchus. The subdivision of the trachea in the two main bronchi is followed by the formation of three lobar bronchi on the right side and two lobar bronchi on the left side. Every lobar bronchus divides into segmental bronchi followed by subsegmental bronchi. These subsegmental bronchi separate dichotomously about five times and continue as small bronchi, still having cartilage to strengthen their structure. These smaller bronchi separate also dichotomously about 15 times and end in bronchioli (without cartilage). The bronchioli will continue into terminal bronchioli and respiratory bronchioli. The respiratory' bronchioli (3-8 generations) will finally end in alveolar ducts and sacs.

The pleura isolates one lobe from another. As a result of that division the lobe is a functional end unit ${ }^{\sharp}$. The main oblique fissure is, however, complete in only about $50 \%$ of subjects. The bronchopulmonary segments are not functional end-units because they are not surrounded 
by connective tissue. Neighboring segments share venous and lymphatic drainage and even air can pass boundaries by collateral ventilation.

The arterial circulation consists of two systems with connections at different levels.

The pulmonary arteries follow in principle the respiratory bronchial divisions; three lobar pulmonary arteries are present on the right side and two on the left side. They divide into 10 segmental arteries (SA) on the right side (figure 1) and 8 on the left side (figure 2):

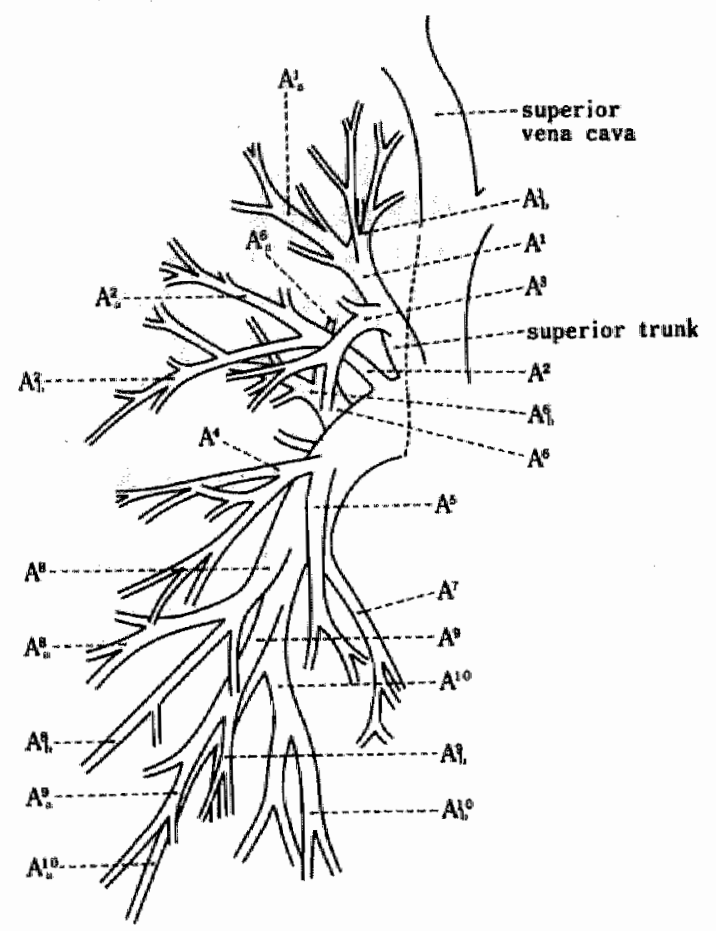

Figure 1: Blood supply to the right ling. Segmental anteries to upper lobe A 1-A3, middle lobe A4-A5 and lower lobe $A 6-A 10$ ( $A_{a}$ and $A_{b}$ " subsegmental arteries). From Nagaish'

Right lung; $\quad$ Superior lobe (3) Apical SA $\left(A^{1}\right)$, Anterior SA $\left(A^{3}\right)$, Posterior SA $\left(A^{2}\right)$

Middle lobe (2) Medial SA $\left(A^{5}\right)$ (not incorporated in Miller"s scoring system of pulmonary angiograms $\left.{ }^{3}\right)$, Lateral SA $\left(A^{4}\right)$

Inferior lobe (5) Superior $\mathrm{SA}\left(A^{6}\right)$, Anterior basal SA $\left(A^{8}\right)$, Medial basal SA $\left(A^{7}\right)$, Posterior basal SA $\left(A^{10}\right)$, Lateral basal SA $\left(A^{g}\right)$ 


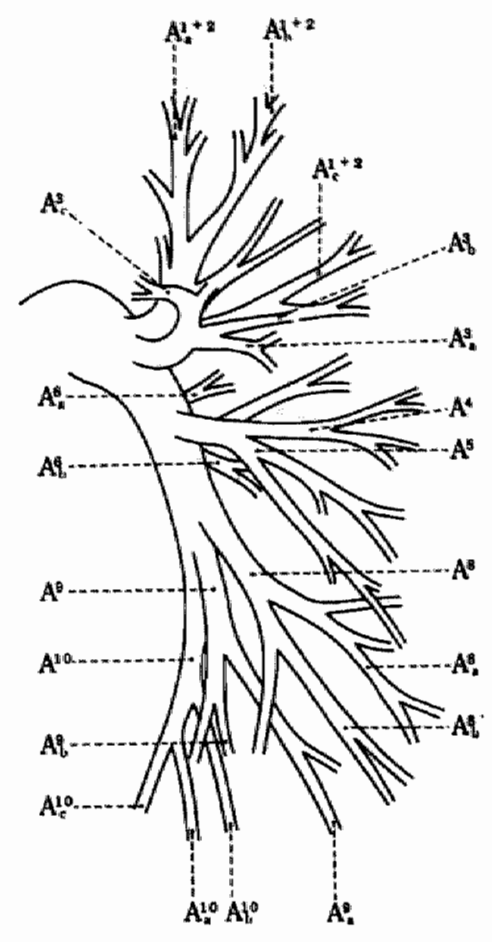

Figure 2. Blood supply to the left ling. A1-A3 superior lobe segmental arteries. A4-A fo inferior lobe segmental arteries. From Nagaishi.

Left Lung;

Superior (4)

Superior (2): Apical posterior SA $\left(A^{1+2}\right)$, Anterior $\mathrm{SA}\left(A^{3}\right)$.

Lingular (2): Superior SA $\left(A^{4}\right)$, Inferior SA $\left(A^{5}\right)$.

Inferior (4)

Superior SA (not inclluded in Miller's scoringsystem $\left.{ }^{3}\right)\left(A^{6}\right)$, Anteromedial basal SA $\left(A^{8}\right)$, Lateral basal SA $\left(A^{9}\right)$, Posterior basal SA $\left(A^{10}\right)$.

The bronchial arteries on the left side take off directly from the descending aorta. The left superior bronchial artery originates from the descending aorta at the level of the thoracic vertebral segment 5 (T5) and the left inferior bronchial artery from level 6 (upper T5 and lower T6) ${ }^{4}$. Sometimes (multiple) take off(s) till level T11 can occur. The right bronchial artery usually arises from an intercostobronchial trunk (which also branches out to the first 3 intercostal arteries; the 3 rd intercostal artery is in fact the first aortic intercostal artery) ${ }^{1,2}$. Common variations are a take off of both left and right bronchial artery from the same superior level of the descending aorta or an origin of the right bronchial artery from the right subclavian artery (the intercostobronchial trunk in general also runs upwards to the subclavian artery). 
These bronchial arteries supply the bronchial tubes, the lung tissue, particularly the central regions and run distally to the pleura ${ }^{5}$. At the precapillary level there are collaterals (under normal circumstances hardly functional) with the pulmonary arteries. At the capillary level there are open collaterals connecting with the capillaries of both pulmonary arteries and veins.

The pulmonary veins transport all the blood from the capillaries from the pulmonary as well as the bronchial system. Only the peri-hilar region is drained by the "true bronchial veins", a region which is only supplied by the bronchial arterial system, which ends in the azygos system.

The lymph ducts of the right lung drain partially via the bronchomediastinal trunk and partially via the scalenus nodes and the deep cervical nodes to the brachiocephalic vein (just below the confluence of the jugular and subclavian veins). The lymph ducts of the left lung initially do the same but develop a large duct (thoracic duct) which runs around the left jugular vein and drains into the left brachiocephalic vein. During congestion of the circulation the size of the lymph ducts also increase considerably and drainage can reverse to abdominal ducts ${ }^{5}$. Whether this can explain differences in pleural fluid development in pure right sided failure is not known.

\section{Effect of pulmonary embolism on the pulmonary circulation}

Initially pathologists were convinced that thrombi found in the pulmonary circulation had developed locally ${ }^{6}$. In 1819 Laennec described a case of pulmonary thrombosis calling it "pulmonary apoplexia". Multiple pulmonary thrombi were described in the atlas "Anatomie pathologique du corps humain" by Cruveilhier (1830-1842).

In 1858 Virchow was the first to suggest the possibility of thrombi developing in veins, spreading metastatically to the lungs. Another important observation made by Virchow was that lung-tissue behind the occluded pulmonary artery did not infarct, what made him conclude that that region was perfused by collaterals. An overview of this subject is given by Chitwood ${ }^{6}$, who mentions the first description of the bronchial arteries by Erasistratos in 270 B.C.. The first drawings of the bronchial arteries are by Leonardo da Vinci $( \pm 1513)$.

Ljungdahl (in 1928) was the first to describe that patients with chronic pulmonary hypertension die as the result of right sided heart failure (with a dilated pulmonary artery and increased right heart size). Post-mortem examination proved the presence of organized thrombotic obstructions. He also observed that vessels distal to the obstruction were normal in size and appeared to have unchanged parenchyma. Daley in 1932 concluded that bronchial arteries enlarge after pulmonary artery obstruction, resulting in increased systemic pulmonary flow and left to right shunting. In 1964 Viamonte, using angiography, proved that the distal pulmonary arteries could be supplied by bronchial arteries ${ }^{4}$. More recently bronchial angiography was performed more routinely in patients evaluated for pulmonary endarterectomy. These angiograms clearly show that the bronchial system is capable of perfusing the pulmonary segments or lobes distal from the obstruction quite adequately. 
Only in distal pulmonary occlusions (small emboli), particularly in patients with other diseases leading to low cardiac output, the lung-tissue will be infarcted. Infarctions can be divided into "reversible" infarctions, referring primarily to intra-alveolar hemorrhage, and completed" infarctions, with necrosis of the parenchyma". Reversible infarction is probably more common and will lead to hemoptysis and pleuritic pain which may last for several hours. A completed infarction may be accompanied by pain for several days.

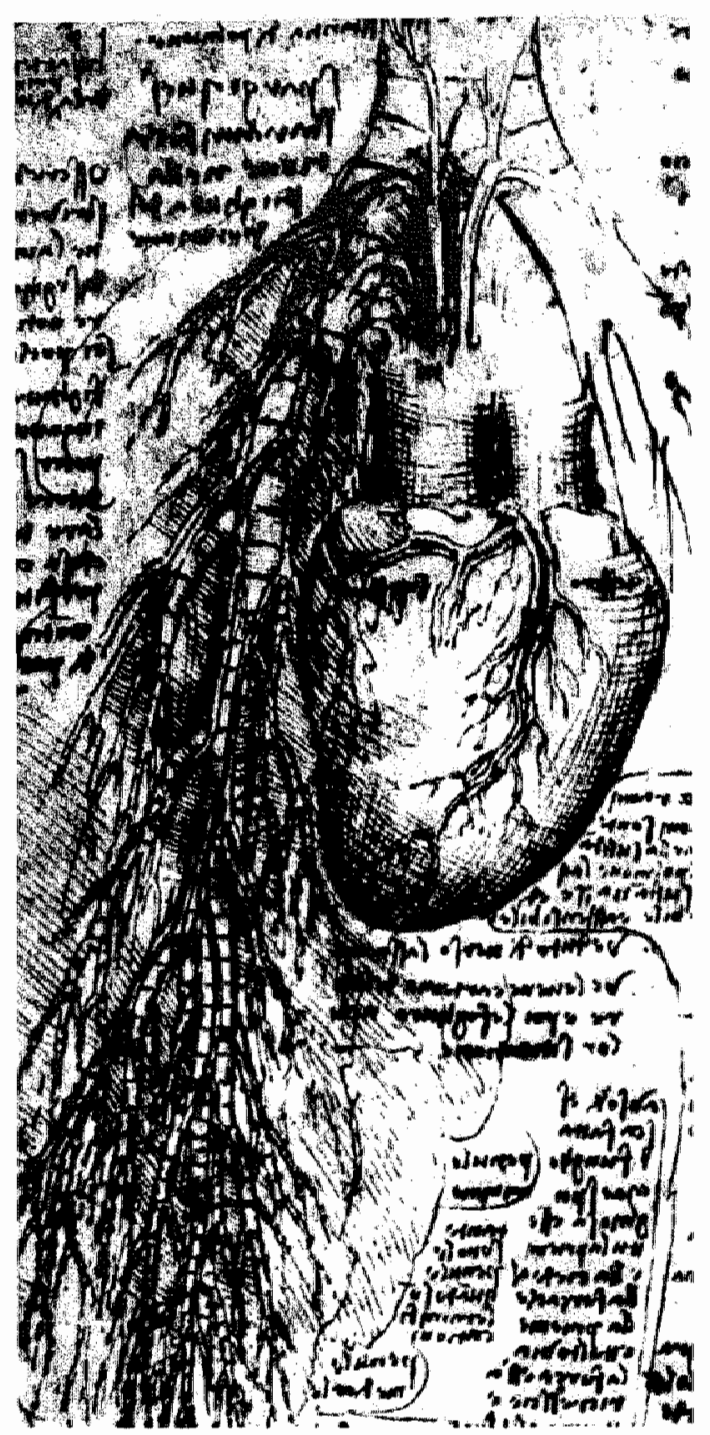

Figure 3: Leonardo da Vinci's drawing of the bronchial arteries arising from the proximal descending aorta and running along the bronchial tree. Note that Leonardo da Winci"s handwriting is running from right to left. He uses a mirror script cipher in Tuscan dialect. 
The fact that lung-tissue in general is reasonably protected by collateral circulation makes endarterectomy of thrombosed vessels feasible. However a progressive reduction in the pulmonary vascular bed can develop gradually as a result of pulmonary hypertensive lesions in the not affected vessels or the partially obstructed vessels (and sometimes even in the obstructed vessels) ${ }^{8}$. An asymptomatic "honeymoon" period after successful initial treatment will in those cases lead to progressive pulmonary hypertension. In cases without collateral circulation there is therefore a contra-indication for endarterectomy ${ }^{9}$.

The collateral circulation between two segments is potentially to a certain degree responsible for the underestimation of the extent of defect size or involved lung area on scintigraphic perfusion scanning ${ }^{10}$. This was studied in more detail by Ryan et al. ". In patients with older organized thrombi, re-canalization may also occur and the perfusion scan, reflecting the distribution of pulmonary resistance, may not give adequate data about pulmonary vascular anatomy. If a segmental-sized perfusion defect exists, the scan can underestimate the amount of affected vessels and severe pulmonary hypertension should be excluded using right heart catheterization and angiography. This is probably not the case in acute pulmonary embolism, although in these cases underestimation may occur because thrombus material is still present in the main pulmonary artery (saddle thrombus), with severe equally diminished blood flow to both lung fields ${ }^{12}$. In chronic pulmonary hypertension changes in the bronchial vessels may also be found as a result of the increased flow ${ }^{8}$.

\section{Hemodynamic effects of pulmonary embolism}

The partial or complete obstruction to blood flow in the pulmonary vessels will increase afterload to the right ventricle. The pressure in the central pulmonary artery will increase and the right ventricular output will decrease. As a result the right ventricle will dilate. This increase in right sided pressures will also effect diastolic pressures, the right sided one now exceeding the left sided diastolic pressure. This will lead to a diastolic shift of the interventricular septum to the left ${ }^{13}$. This phenomenon is called "diastolic bulging" of the interventricular septum. The elevated diastolic pressure will lead to an elevated mean right atrial pressure. Pre-load increases to compensate for the decrease in output. The net effect is congestion in the large systemic veins, affecting organs which are particularly influenced by venous pressure elevation, such as the liver.

The pulmonary circulation normally operates at approximately $20 \%$ of the systemic arterial pressure $^{14}$. In that situation, under normal resting conditions, the pulmonary vascular bed perfusion is partially collapsed in the upper fields, acts as a waterfall in the mid-field and has elevated interstitial pressures and distension in the lower fields. When output increases recruitment and distension of vasculature play an important role in the decrease of pulmonary vascular resistance relative to flow ${ }^{14}$. The normal values for pulmonary artery pressures are 18-25 $\mathrm{mmHg}$ peak-systolic and 6-10 $\mathrm{mmHg}$ end-diastolic, with mean pressures of 12-16 $\mathrm{mmHg}^{15}$. With aging the pressures increase to maximal mean values of $20 \mathrm{mmHg}$ ( $16 \pm 3$ $\mathrm{mmHg}$ ) and systolic pressure of $26 \pm 5 \mathrm{mmHg}^{16}$. During exercise systolic pulmonary arterial pressures can reach values of around $30-35 \mathrm{mmHg}$ (triathlon athletes at that time having a cardiac output of $20 \mathrm{l} / \mathrm{min}$ ) with mean pressures not exceeding $25 \mathrm{mmHg}$. A mean arterial pressure at rest exceeding $25 \mathrm{mmHg}$ is generally accepted to indicate pulmonary 
hypertension. Exercise related mean arterial pressures of more than $30 \mathrm{mmHg}$ are considered to indicate pulmonary hypertension ${ }^{14}$.

How much obstruction is needed before a substantial change in pressure and cardiac output occurs? Hypoxemia, or respiratory compensated hypoxemia, is present in $90 \%$ of patients with obstructions of more than $10 \%$ of the pulmonary circulation. In acute circumstances not only the thrombotic obstruction, but also the hypoxemia and the vasoconstriction mediated by serotonin, released from platelet-rich thrombi, will increase pressures. Also the endothelin levels are high in patients with pulmonary embolism, causing vasoconstriction not only in the pulmonary circulation but also in the coronary circulation ${ }^{17,18}$. There is some relation between systemic hypoxemia, amount of obstruction and mean arterial pressures. In patients without prior cardiopulmonary disease acute pulmonary obstruction exceeding 25 $\%$ of the pulmonary circulation will lead to increased pressures in the pulmonary artery. Larger (acute) obstructions will lead to a greater increase in pulmonary pressures but mean pulmonary artery pressure will not exceed $40 \mathrm{mmHg}^{19}$. The systolic pulmonary pressure, however, can reach values of $50-60 \mathrm{mmHg}$. This is of importance because echocardiographic evaluation of right sided pressures is mainly derived from measurements of tricuspid incompetence velocity. The pressure measurements, calculated from these velocities, represent the systolic pressure difference between the right ventricle and right atrium. Using estimated mean right atrial pressures added to the calculated pressure difference between right ventricle and right atrium only leads to estimated peak systolic pressures. Mean right atrial pressures will normally start to rise when the obstruction of the pulmonary circulation exceeds $30-35 \%$. Cardiac index decreases, although severe hypoxia (5.2-7.9 kPa), leading to a marked increase in cardiac sympathetic discharge, can increase the cardiac index ${ }^{7}$. The abnormal septal motion, present in important obstructions, will also affect diastolic filling of the left ventricle and have its adverse effect on cardiac function.

\section{Deep venous thrombosis is the main cause for pulmonary embolism}

Pulmonary emboli can arise from a number of sources: The most important source is deep venous thrombosis (1). Thrombi can develop in the right atrium (2) or can be the consequence of septic embolization (e.g. intravenous drug users, tricuspid endocarditis etc)(3). Tumors leading to metastatic embolization (4), amniotic fluid (5), fat, air and bone marrow emboli (6) complete the list of causes of pulmonary embolization ${ }^{20}$.

Deep vein thrombosis as a result of post-operative immobilization is very frequent despite heparinization. In patients over 40 undergoing general surgery $25 \%$ will develop deep vein thrombosis without prophylaxis and $7 \%$ with the use of low dose heparin ${ }^{21}$ and even lower when using low molecular weight heparin ${ }^{22}$. Incidence of venous thrombosis is much higher in patients undergoing orthopedic (hip-)surgery and patients having cancer. Apparent nonfatal pulmonary embolism is present in $2 \%$ of the population undergoing general surgery and $0,8 \%$ will develop fatal pulmonary embolism ${ }^{23}$. Also in patients undergoing CABG around $20 \%$ of patients will develop deep vein thrombosis despite prophylaxis (heparin and/or intermittent pneumatic leg-compression $)^{24}$. Clinically apparent pulmonary embolism in this CABG population was present in around $0.6 \%{ }^{24}$. Also in non-surgical patients who are bedridden (because of unstable angina or myocardial infarction) deep venous thrombosis 
is found to be present in $13 \%{ }^{25}$. Patients with deep venous thrombosis and immobilization (e.g. paraplegic patients) are less prone the develop pulmonary embolism than nonimmobilized (post-operative) patients ${ }^{26}$.

Monreal et al. showed that most patients with deep venous thrombosis had proximal deep venous thrombosis and that $22 \%$ of patients with deep venous thrombosis had scintigraphic evidence of pulmonary embolism. Only $54 \%$ of these patients had clinical symptoms or signs although prospectively and systematically analyzed ${ }^{26}$. Also Huisman et al. found an unexpectedly high prevalence $(51 \%)$ of silent pulmonary embolism in patients with clinically suspected deep venous thrombosis ${ }^{27}$. These patients were all anticoagulated for one week. In some studies, however, patients with pulmonary embolism with transient risk factors for deep venous thrombosis, as patients after orthopedic surgery, were left untreated with good results (no death during follow up) ${ }^{28}$.

In general in patients with symptomatic acute deep venous thrombosis the long term risk for recurrent venous thromboembolism is $17.5 \%$ after 2 years, $24.6 \%$ after 5 years and $30.3 \%$ after 8 years. Cancer and impaired coagulation inhibition increase this risk. Patients after surgery or recent trauma have a lower long term risk because of more transient risk factors ${ }^{29}$. A venous post-thrombotic syndrome was seen in $29.1 \%$ after 8 years and survival after 8 years was $70,2 \%$ (with an increased risk in patients with cancer). Death was related to cancer in $58 \%$ of cases. Other causes of death were anticoagulant-related hemorrhage ( $2.2 \%)$, myocardial infarction (2.2\%), heart failure (3.3\%) and stroke (11.1\%). Only $10 \%$ died as a result of pulmonary embolism. All patients were treated with oral anticoagulation for 3 months (INR between 2.0 and 3.0) after the initial event. Another study showed that $42 \%$ of patients with acute deep venous thrombosis died within 6-8 years. Fifteen percent of patients did show recurrence of venous thromboembolism within 6-8 year, a percentage that was much higher in patients younger than 65 years with a prior history of recurrent thromboembolism $(34 \%)^{30}$.

It is clear that an adequate diagnosis of deep venous thrombosis and pulmonary embolism is essential. Treatment can not be withheld in patients with proven deep venous thrombosis or pulmonary embolism. Strategies using diagnostic tests for deep venous thrombosis in combination with tests for pulmonary embolism are being developed and their costeffectiveness tested ${ }^{31-35}$. A short review of these strategies will be given after discussing the most important diagnostic procedures.

\section{Diagnosing deep venous thrombosis}

\section{During the last years 3 tests are used most widely:}

1. Contrast phlebography. Contrast angiography is considered to be the most accurate test for detecting deep venous thrombosis ${ }^{36}$. Complications are; extravasation of contrast, with necrosis of the skin, post-phlebography syndrome (temporary redness, swelling and pain in the leg) in $1.5 \%{ }^{37}$ and post-phlebographic thrombosis in $1 \%$ of patients ${ }^{36}$. In some cases allergic reactions can occur. In $20 \%$ of patients no adequately analyzable phlebogram can be made ${ }^{38}$. 
2. Impedance plethysmography. In the past excellent correlations with phlebograms have been shown ${ }^{32}$. Recent articles, however, show that a "positive" test has a sensitivity of only $65-66 \%{ }^{39,40}$. Probably smaller clots are missed by plethysmography and users of this method have to be aware that the negative predictive value may be unacceptably high, particularly in patients with a high clinical suspicion of deep venous thrombosis ${ }^{41}$.

3. Ultrasound. The use of this method as diagnostic tool to study thrombosis in the leg veins is increasing. The proximal leg veins are easily accessible for ulltrasound. The distal veins are less easily visuallized.

The ultrasound investigation can be used in three ways: Compression of the veins, which shows a sensitivity of $93-98 \%$ and a positive predictive value of $96-100 \%$. Doppler evaluation of (absence of) flow, with a sensitivity of $95-100 \%$ and positive predictive value of $99-100 \%$. Visualization of thrombus was a sensitive finding in $87 \%$ with a positive predictive value of $100 \%{ }^{42,43}$. Also the sensitivity of ultrasound tests is criticized in a metaanalysis by Wells et al.4. The article shows that the bias of the investigator has high implications for the funal result. One must realize, however, that ultrasound is improving in quality every year. Also Doppler enhancement using intravenous contrast agents (given intravenously in the arm veins) are potentially of value in the future.

\section{Diagnosing pulmonary emboli}

\section{Pulmonary angiography}

Pulmonary angiography is regarded as the gold standard for diagnosing pulmonary embolism ${ }^{45}$. Different procedures have been developed during the past years. First a peripheral contrast injection was used with low diagnostic yield. By 1969 selective catheterization of the right and left pulmonary artery was being performed. The safest way to make a pulmonary angiogram, preventing catheter perforation is by using a pigtail catheter, as first used by Grollman et al. in $1970^{46}$. Oblique projections may improve diagnostic accuracy. The true sensitivity and diagnostic accuracy of the angiogram is hard to determine. In fact only studies with patients dying just after an angiogram could be used to correlate the anatomy with the angiogram. There are only a few small studies and case reports showing a good correlation.

Patients with a negative pulmonary angiogram are reported to have small emboli at postmortem examination which could have been missed in an earlier made angiographic examination. Again only a small number of studies are available because in general patients having a negative angiogram do not die as the result of a missed pulmonary embolus ${ }^{45}$. As a rule pulmonary intraluminal defects or an abrupt cut off in a large to medium sized vessel ( $22.5 \mathrm{~mm}$ ) are suggestive for thrombus formation (figure 4). Vessel pruning, oligemia, altered vessel distribution, lack of filling of small vessels are non-specific ${ }^{47}$.

The complications of the procedure (using a pigtail catheter to avoid perforation) is partially related to the overall condition of the patient and the use of contrast material. Goodman reported $0.2 \%$ death in 4209 procedures in 15 centers and $0.2 \%$ cardiac arrests without 


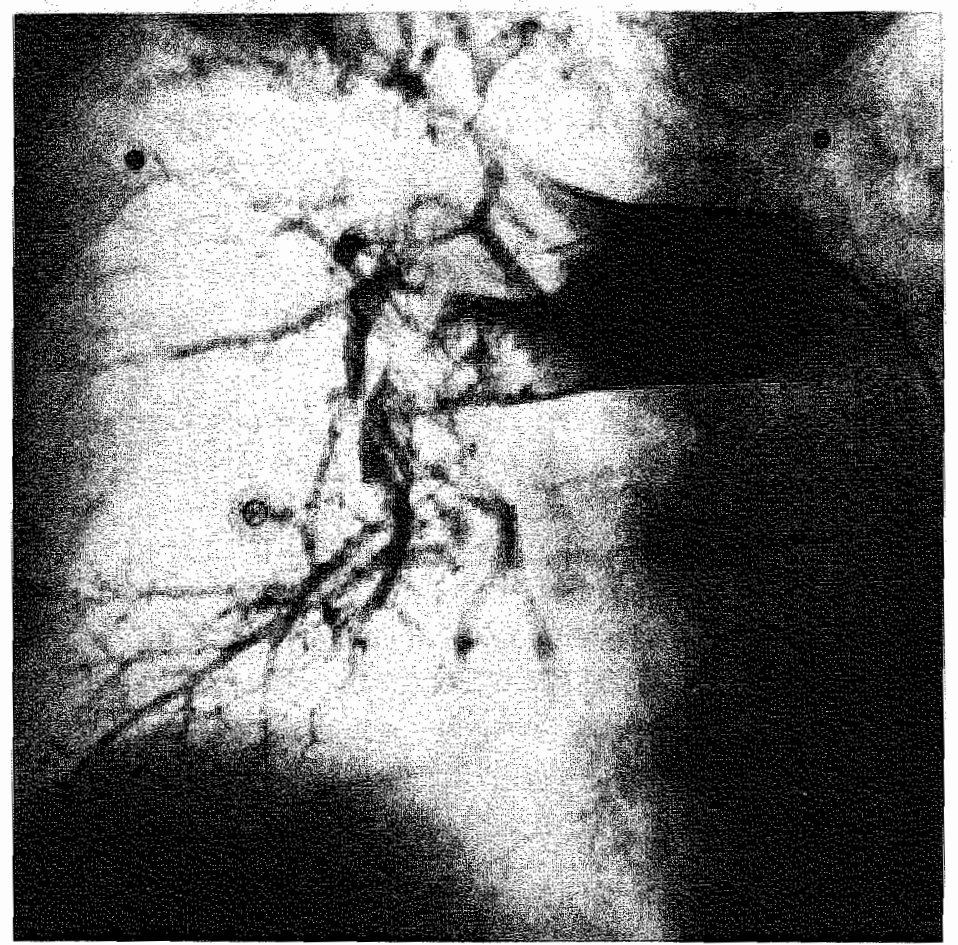

Figure 4: Selective angiography of the right pulmonary antery, using a pigtait catheter, demonstrating large intratuminal defects. The perfusion to the segmental arteries is severely diminished. The only well perfused segment in this patient was the segmental antery to the left upper lobe $\left(A^{t+2}\right.$ in figure 2$)$, making the Miller score 26 (for explanation, see figure 5).

death $^{45}$. In the PIOPED-study 2 patients undergoing angiography died as result of the procedure $(0.3 \%)^{48}$.

Digital subtraction imaging using peripheral contrast injections is a technique that could detect embolism in 75-85 percent of cases. The technique is strongly depended on the breathholding capability of the patient, which can be a major problem in the critically ill. A catheter pliced in the pulmonary artery could improve the resolution. In general, smaller more peripherally located emboli can be missed by this procedure.

The angiographic scoring systems used to quantitate pulmonary embolism are the Walsh scoring system ${ }^{4}$, mainly used in the United States, and the Miller index, commonly used in Europe ${ }^{y}$. A more recent scoring system has been developed by Simon ${ }^{50}$. The Walsh index does not take into account the impairment of peripheral perfusion and the Simon method is rather complex and has not been used in any large trial. The Miller index could overestimate vascular obstruction" "The Miller index scores the presence of emboli in 9 of the lobar branches in the right lung and 7 lobar branches in the left lung. In the presence of a filling defect proximal to the takeoff of a number of segmental vessels all distal segmental branches are scored (so a main right pulmonary artery thrombus scores 9 involved vessels). Each 
involved vessel scores one point. Each lung is divided in 3 zones (upper/middle/lower). The flow to each zone can be scored as absent ( 3 points), severely reduced ( 2 points) or mildly reduced ( 1 point), normal flow being zero points. The maximal total score can be 34 points ( 16 branches and 6 zones with each 3 points) indicating absent fow in all zones (figure 5 ).

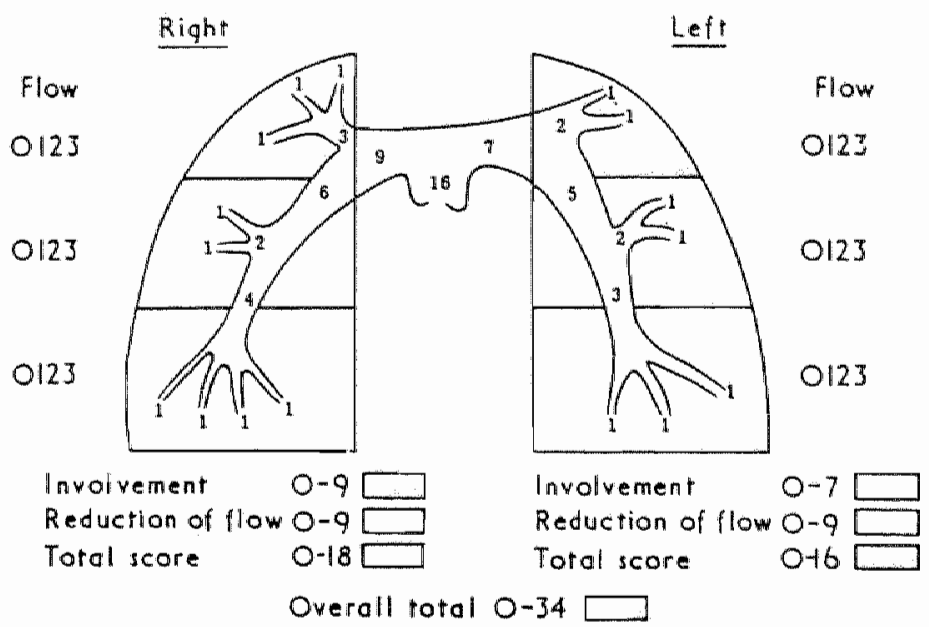

Figure 5: Miller score? Form used to grade the severity of pulmonary embolism based on the angiographic abnormalities. See text for further explanation. Reprinted with permission from the British Medical Association (Brit Med/1971,2,682).

\section{Pulmonary scintigraphy}

Another method to study the presence of pulmonary embolism is the combination of a scintigraphic perfusion scan with a ventilation scan. Technetium ${ }^{99 m}$ labeled albumin is injected intravenously. The albumen particles do not pass the capillary net of the lungs allowing the measurement of capillary function. The ventillation scan is made by inhaling Xenon $^{133}$ particles. The distribution of these particles gives insight in lung-ventilation.

In the PIOPED study 5 categories of ventilation-perfusion scans (V/Q-scan) were recognized ${ }^{48}$ :

1. A normal scan:

$\Leftrightarrow$ Normal distribution of technetium labeled albumin. A ventilation scan is not necessary.

2. A very low-probability scan:

$\rightarrow \leq 3$ small segmental perfusion defects with a normal chest X-ray. 


\section{VENTILATIE}

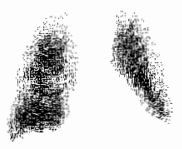

ANT

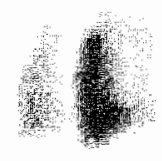

RPO

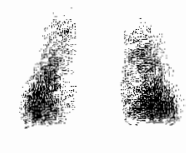

POST

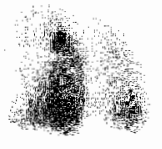

LPO

Figure 6: High probability ventilation pertusion scan (VENTILATIE) showing near normal pertusion of both lungs in the anterior (ANT), posterior (POST), right oblique (RPO) and left posterior oblique (LPO) projection.

Pertusion scan (PERFUSIE) showing a large perfusion defect of the right upper lobe, right middle tobe, left lower lobe, anterior segment and lingular part of the left upper lobe.

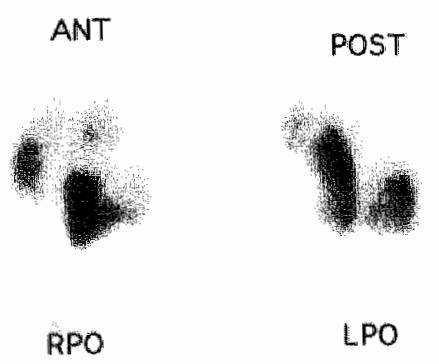

3. A low probability scan:

$\rightarrow$ Non-segmental perfusion defects (e.g. elevated diaphragm, large aortic knob, elevated diaphragm).

$\Rightarrow$ Single moderate mismatched segmental perfusion defect with normal chest X-ray.

$\Rightarrow$ Any perfusion defect with a substantially larger chest X-ray abnormality.

$\Rightarrow 3$ segments in 1 lung region with matching ventilation defects.

$\Leftrightarrow>3$ small segmental defects ( $<25 \%$ of a segment) with a normal chest X-ray.

4. An intermediate probability scan (indeterminate):

$\Rightarrow$ Not falling in/borderline/difficult to categorize as low or high. 
5. High probability scan:

$\Rightarrow \geq 2$ larger perfusion defects ( $>75 \%$ of a segment) with normal ventilation (V/Q mismatch) or normal chest roentgenogram (figure 6).

$\Rightarrow \geq 2$ moderately large ( $\geq 25 \%$ and $\leq 75 \%$ of a segment) plus 1 large segment, with normal ventilation or chest roentgenogram.

$\Rightarrow \geq 4$ moderately large defects with normal ventilation scan or normal chest roentgenogram.

The ventilation-perfusion scan method has been much debated in recent years. The PIOPED study showed that in 255 patients with an angiographically proven pulmonary embolism the V/Q-scan showed high probability in only $41 \%{ }^{48}$. If only high probability scans were used to make the diagnosis, $59 \%$ of patients would not have been recognized. One should, however, look to the PIOPED not only in this way. If clinical probability was taken into account, patients with a clinical probability of $80-100 \%$ or $20-79 \%$ respectively and a high probability scan had a $96 \%$ and $88 \%$ chance respectively of having pulmonary embolism on angiography. Still there is a high subset of patients needing a pulmonary angiogram to make a definitive diagnosis.

The clinical probability impressions in the PIOPED study did not use standardized algorithms. A new study of the same type has been conducted recently in Pisa (Italy). The PISA-PED study again investigated patients with a clinical probability, however, this time with defined clinical findings ${ }^{52}$. The first level of clinical suspicion was the presence of dyspnea and/or chest pain. The second level was blood gas analysis, electrocardiogram and $X$-ray and the third level consisted of both previous levels reevaluated after 24 hour. There were four categories of scan interpretation possible (normal, near normal, abnormal (PE+), abnormal not compatible with pulmonary embolism (PE-) $)^{53}$. In this study the preliminary results show a higher diagnostic yield than was shown by the PIOPED investigators. Only in $21 \%$ of patients clinical data and perfusion scan were discordant.

Categories like indeterminate and low-probability scan should not be used any more in diagnosing pulmonary embolism ${ }^{54}$. According to most researchers there are only normal and high probability scans. The rest is non-diagnostic.

\section{Computed Tomography, MRI and SPECT, ${ }^{123}$ I-YPACK-TPA scanning}

Cross-sections of the body obtained by X-ray computed tomography (CT) and magnetic resonance imaging (MRI) allow direct visualization of thrombi in the pulmonary vessels (figure 7). Spiral CT is successfully used in the diagnosis of acute and also chronic pulmonary embolism ${ }^{55}$. Excellent images of pulmonary emboli indicating the diagnostic potential of this technique were shown by Blum et all. These authors also demonstrated the detection of thrombi and abnormal flow in the main pulmonary artery using MRI ${ }^{56}$. Not only the evaluation of pulmonary arteries but also the evaluation of bronchial artery anatomy and dilatation in pulmonary hypertension due to chronic pulmonary embolism could be of value to predict the effect of pulmonary endarterectomy ${ }^{57}$. Contrast-enhanced electron-beam CT has been used in comparison with pulmonary angiography and V/Q-scanning and showed better results than V/Q-scanning in detecting pulmonary emboli ${ }^{58}$. Recentlly also the first 


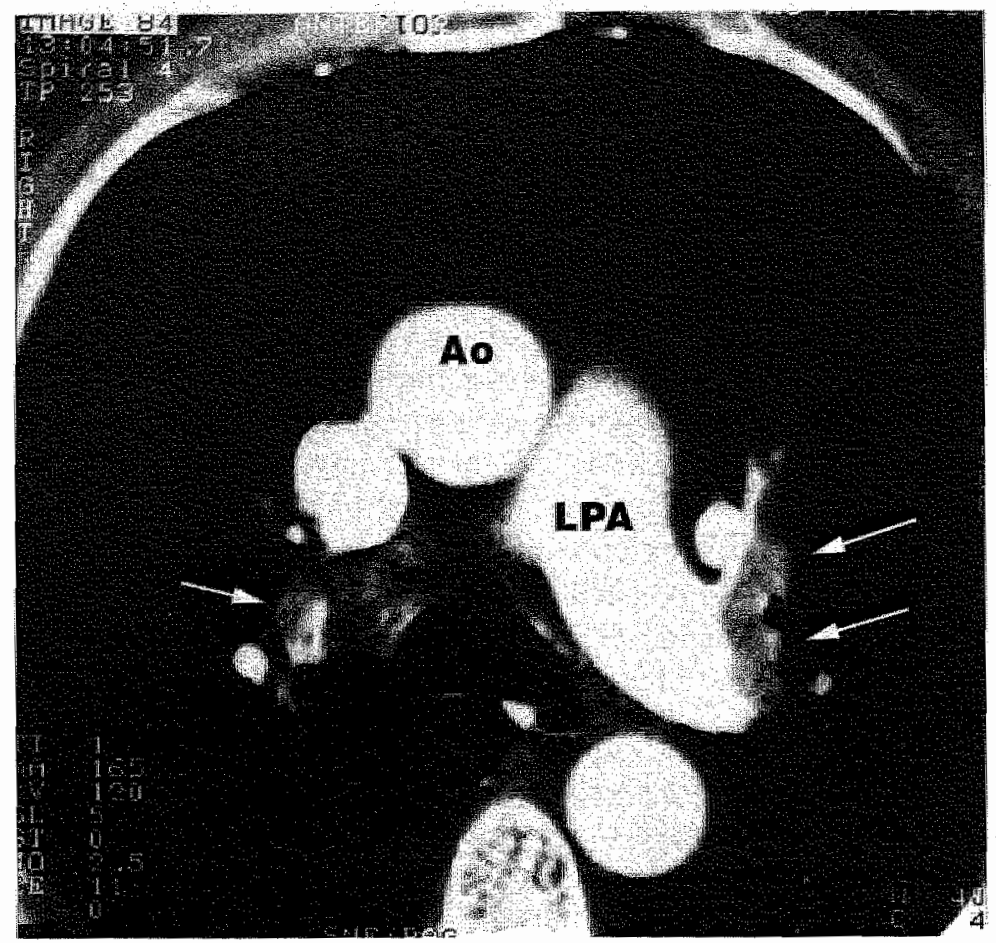

Figure 7: Contrast CT-scan of the patient with the large thrombi in the pulmonary arteries and a high probability lung scan (see figure 6) showing a thrombus in the distal right segmental artery and a large thrombus in the left puimonary artery (arrows). $\angle P A=$ Left Pumonary Artery, $A O=$ Aorta.

study comparing trans-esophageal echocardiography (TEE) with spiral CT did show excellent results in diagnosing central pulmonary artery thrombi in patients with suspected pulmonary embolism and right ventricular overload (compared to a high probability scan or pulmonary angiography or surgery/autopsy). CT detected in $89 \%$ and TEE in $79 \%$ of patients (43) central pulmonary artery thrombi ${ }^{59}$ (figure 8 ).

Axial single photon emission computed tomography (SPECT) perfusion scans have been compared with $\mathrm{CT}$ scanning to study regional hypoperfusion and areas of decreased lung attenuation in patients with chronic pulmonary thromboembolism ${ }^{60}$. A recently introduced scintigraphic tool to visualize thrombi in pulmonary arteries is 123 -labeled, enzymatically inactivated tissue-type plasminogen activator. Using SPECT thrombi could be adequately visualized in animals within $40-120$ minutes after injection of this tracer ${ }^{61}$.

\section{Diagnostic strategies using leg evaluation for deep vein thrombosis, pulmonary $V / Q$-scanning and pulmonary angiography}

Cost effective strategies based on sensitivity and specificity of diagnostic tests as the V/Qscan, the ultrasound examination or impedance plethysmographic examination of the leg veins have been developed to prevent patients from undergoing invasive pulmonary angiography. These strategies accept as proven that 14-30\% of the patients with low 


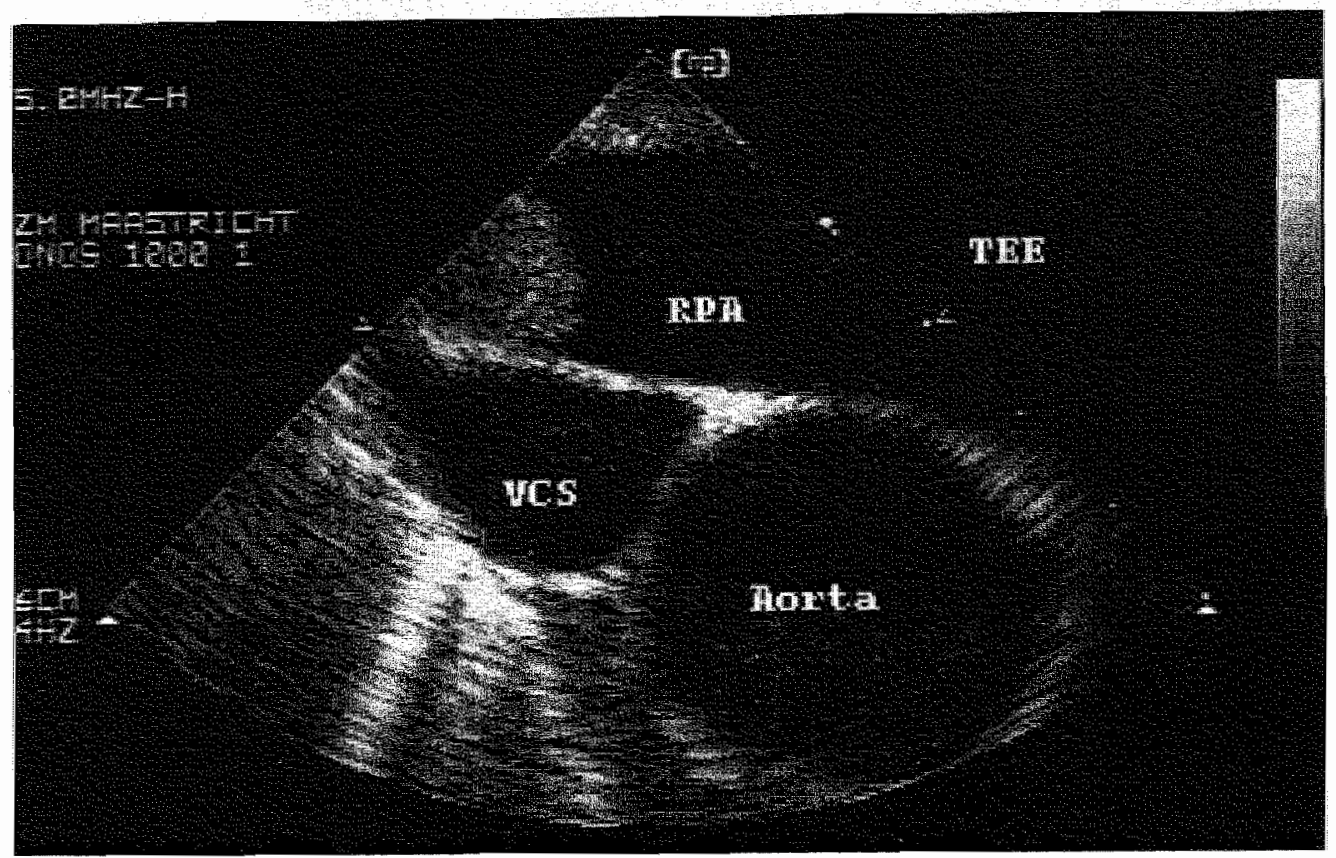

Figure 8: Example of a trans-esophageal echocardiogram (TEE) of a large thrombus lacated in the right pumonary artery (RPA) at the level were the pulmonary artery crosses the vena cava superior (VCS).

probability V/Q-scans have pulmonary embolism. This is also based upon the finding that only $27 \%$ of scans was diagnostic (normal/near-normal or high probability) in the PIOPED study ( 255 of 931 patients) ( $^{48}$. It was also assumed that in $50 \%$ of patients with pulmonary embolism noninvasive tests of the lower extremities would show deep venous thrombosis ${ }^{33}$.

Different strategies have been suggested when pulmonary embolism is suspected. The first strategy could be a V/Q-scan followed by pulmonary angiography. Patients with a nondiagnostic $\mathrm{V} / \mathrm{Q}$-scan would undergo pulmonary angiography directly. The second strategy uses the sequence of $V / Q-s c a n$, a single noninvasive leg test followed by pulmonary angiography. If $\mathrm{V} / \mathrm{Q}$-scan is non-diagnostic and the noninvasive leg test is positive antithrombotic treatment can be given and no angiography is needed. If the leg test is negative pulmonary angiography is the next step. The third strategy is $\mathrm{V} / \mathrm{Q}$-scan, serial noninvasive leg tests and pulmonary angiography. This is similar to the second test with the difference that patients with a low cardiorespiratory reserve will undergo angiography earlier while the other patients will receive serial leg tests to be certain that the first test was adequate. In that study 662 patients entered the study with 194 patients using the first strategy, 195 patients the second and 169 using the third strategy. Using these strategies 25$30 \%$ of suspected patients appeared to have pulmonary embolism. The last method was most cost-effective (calculated on the basis of US dollars and US costs) and proved to be save ${ }^{34}$. 
Others have used the same approach and came to the same conclusion that a combination of a leg test and $\mathrm{V} / \mathrm{Q}$-scan is optimal before deciding on a pulmonary angiogram if tests are non-diagnostic ${ }^{31-33}$.

A potential new strategy was published by Perrier et $\mathrm{al}_{\text {, }}$ using D-dimer levels as an extra step ${ }^{62}$. D-dimer is a degradation product of cross-linked fibrin (ongoing endogenous fibrinolysis) and highly sensitive for venous thromboembolism. Using this approach starting with a V/Q-scan, than clinical probability, followed by D-Dimer and ultrasound only 77 patients of 308 patients in the initial study population needed a pulmonary angiography. Finally $35 \%$ of patients had pulmonary embolism. However the problem with D-Dimer is that sensitivity of the enzyme-linked immunosorbent assay (ELISA) is strongly laboratory and assay dependent. Standardization and calibration of this test are urgently needed ${ }^{63}$. Ddimer, however, is also increased in post-operative patients, in patients with myocardial infarction, sepsis and almost any other systemic illness. D-dimer is therefore best used in patients with suspected pulmonary embolism without a coexisting acute systemic disease.

One of these studies ${ }^{34}$ showed that the cost of one day admission to a non-academic hospital in the US in 1992 was $\$ 575$, a V/Q-scan $\$ 510$, an ultrasound leg test $\$ 300$, a pulmonary angiogram including 2 additional days in hospital $\$ 2553$ and the charges for hospitalization with intravenous heparin followed by warfarin $\$ 6522^{34}$. While these strategies seem reasonable and financially acceptable, the question arises what the diagnostic routing, treatment and cost are of patients with a negative diagnosis of pulmonary embolism, who seek medical attention because of dyspnea and/or chest pain. If a large part of patients arriving at a cardiological department with dyspnea and a differential diagnosis of pumpfailure, pulmonary embolism or pulmonary disease or chest pain because of cardiac ischemia, pericarditis or pulmonary embolism were put into such a scheme the budget for $\mathrm{V} / \mathrm{Q}$-scans and leg tests would be clearly insufficient.

The major clinical problem therefore is:

1. How to evaluate the patient presenting with a differential diagnosis which includes pulmonary embolism as quickly as possible, without only trying to exclude pulmonary embolism?

2. In view of the difficulty of making the correct diagnosis, how to improve the recognition of patients with pulmonary embolism and treat them appropriately?

Surprisingly, in these diagnostic strategies electrocardiography and echocardiography are not included. In recent guidelines for healthcare professionals from the American Heart Association echocardiography is not mentioned at all ${ }^{64}$. Electrocardiography is stated to be normal or nonspecific in general but may be diagnostic in the appropriate setting ${ }^{64}$. Both tests are, however, non-invasive, inexpensive, patient friendly and immediately available on a 24 hours basis. The cardiologist is able to perform and interpret the electrocardiogram and echocardiogram and no other specialist or non cardiologic laboratories are needed. The emphasis of this thesis will therefore be on the value of electrocardiography and echocardiography in making the diagnosis of (acute) right sided pressure overload. It will be shown that these two tests not only allow to diagnose pulmonary embolism but also give insight into other abnormalities leading to similar hemodynamic changes. 


\section{References}

1. Netter FH. Respiratory system. In: Divertie MB, Brass A, ed. The CIBA collection of medical illustrations. Volume 7, 2nd ed, 1980:13-33.

2. Spalteholz-Spanner. Handatlas der anatomie des menschen. Scheltema \& Holkema, Amsterdam. 16th ed. 1970:35-36,233-238.

3. Miller GAH, Sutton GC, Kerr IH, Gibson RV, Honey M. Comparison of streptokinase and heparin in treatment of isolated acute massive pulmonary embolism. Brit Med I 1971;2:681684.

4. Viamonte M. Selective bronchial arteriography in man. Radiology 1964;83:830-839.

5. Nagaishi C. Functional anatomy and histology of the lung. University Park Press, Baltimore, 1972:79-101,110.

6. Chitwood WR, Sabiston DC, Wechsler AS. Surgical treatment of chronic unresolved pulmonary embolism. Clin Chest Med 1984;5:507-536.

7. Sharma GVRK, Mclntyre KM, Sharma S, Sasahara AA. Clinical and hemodynamic correlates in pulmonary embolism. Clin Chest Med 1984;5:421-437.

8. Moser KM, Bloor CM. Pulmonary vascular lesions occurring in patients with chronic major vessel thromboembolic pulmonary hypertension. Chest 1993;103:685-692.

9. Fedullo PF, Auger WR, Channick RN, Moser KM, Jamieson SW. Chronic thromboembolic pulmonary hypertension. Clin Chest Med 1995;16:353-374.

10. Moser KM, Auger WR, Fedullo PF, Jamieson SW. Chronic thromboembolic pulmonary hypertension: Clinical picture and surgical treatment. Eur Respir J 1992;5:334-342.

11. Ryan KL, Fedullo PF, Davis GB, Vasquez TE, Moser KM. Perfusion scan findings understate the sewerity of angiographic and hemodynamic compromise in chronic thromboembolic pulmonary hypertension. Chest 1988;93:1180-1185.

12. Meyer $\mathrm{G}$, Collignon MA, Duinet F, Jeffrey AA, Barritault L, Sors H. Comparison of perfusion lung scanning and angiography in the estimation of vascular obstruction in acute pulmonary embolism. Eur JNucl Med 1990;17:315-319.

13. Lima JAC, Guzman PA, Yin FCP, Brawley RK, Humprey L, Traill TA, Lima SD, Marino P, Weisfeldt ML, Weiss IL. Septal geometry in the unloaded living human heart. Circtilation $1986 ; 74: 463-468$.

14. Naeije R. Pulmonary vascular function. In: Peacock AJ, ed. Pulmonary circulation. Chapman \& Hall. 1th ed. 1996;13-27.

15. Grossman W, Braunwald E. Pulmonary hypertension. In: Braunwald E, ed. Heart disease. A textbook of cardiovascular medicine. WB Saunders. Philadelphia. 4th ed. 1992;790.

16. Davidson WR, Fee EC. Influence of aging on pulmonary hemodynamics in a population free of coronary artery disease. Am J Cardiol 1990;65:1454-1458.

17. Xu JT, Huang YL, Hu DY, Weng XZ. Elevation of arterial plasma endothelin levels and attenuation of pulmonary deterioration induced by thrombolytic therapy in acute pullmonary embolism. Eur Heart I 1996;18:(abstract)P1406.

18. Dschietzig T, Stangl K, Allexiou K, Laule M, Fellix SB, Bauman G. Pulmonary release of endothelin leads to an ETA-mediated coronary constriction in pulmonary embolism. Eur Heart J 1996;18:(abstract)P1409.

19. McIntyre K, Sasahara A. The hemodynamic response to pulmonary embolism in patients without prior cardiopulmonary disease. Am J Cardiol 1971;28:288-294.

20. Bell WR, Simon TL. Current status of pulmonary thromboembolic disease: Pathophysiology, diagnosis, prevention, and treatment. Am Heart J 1982;103:239-262. 
21. Clagett GP, Anderson FA, Levine MN, Salzman EW, Wheeler HB. Prevention of venous thrombosis. Chest 1992;102:3913-407S.

22. Leizorovics $A$. Haugh MC, Chapuis FR, Samana MM, Boissel JP. Low molecular weight heparin in prevention of perioperative thrombosis. Br Med J 1992;305:913-920.

23. Briffa $N$, Large SR. Venous thromboembolism in coronary artery surgery. Heart 1996;75:433.

24. Goldhaber $\mathrm{SZ}$, Hirsch DR, MacDougall RC, Polak JF, Creager MA, Cohn LH. Prevention of venous thrombosis after coronary artery bypass surgery (a randomized trial comparing two mechanical prophylaxis strategies. Am J Cardiol 1995;76:993-996.

25. Grace R, Hunt B. Thromboprophylaxis. Br I Hosp Med 1993;49:720-726.

26. Monreal $M$, Ruiz J, Olazabal A, Arias $A$, Roca J. Deep venous thrombosis and the risk of pulmonary embolism. A systematic study. Chest 1992;102:677-681.

27. Huisman MV, Büller HR, ten Cate JW, van Royen EA, Vreeken J, Kersten M-J, Bakx R Unexpected high prevalance of silent pulmonary embolism in patients with deep venous thrombosis. Chest 1989;95:498-502.

28. Johnson $\mathrm{R}$, Charnley J. Treatment of pulmonary embolism in total hip replacement. Clin Orthop $1977 ; 124: 149-154$

29. Pradoni P, Lensing AWA, Cogo A, Cuppini S, Villalta S, Carta M, Cattelan AM, Polistena P, Bernardi E, Prins MH. The long-term clinical course of acute deep venous thrombosis. Ann Intern Med 1996;125:1-7.

30. Beyth RJ, Cohen AM, Landefeld S. Long-term prognosis of deep venous thrombosis. Arch Intern Med 1995;155:1031-1037.

31. Oudkerk M, van Beek JR, van Putten WJL, Buller HR. Cost-effectiweness analy sis of various strategies in the diagnostic management of pulmonary embolism. Arch Intern Med $1993 ; 153: 947-954$.

32. Dalen JE. When can treatment be witheld in patients with suspected pulmonary embolism? Arch Intern Med 1993;153:1415-1418.

33. Stein PD, Hull RD, Pineo G. Strategy that includes serial noninvasive leg tests for diagnosis of thromboembolic disease in patients with suspected acute pulmonary embolism based on data from PIOPED. Arch Intern Med 1995;155:2101-2104.

34. Hull RD, Feldstein W, Stein PD, Pineo GF. Cost-effectiveness of pulmonary embolism diagnosis. Arch Intern Med 1996;156:68-72.

35. Perrier A, Bounameaux H, Morabia A, de Moerloose P, Slosman D, Didier D, Unger P-F, Junod A. Diagnosis of pulmonary embolism by a decision analysis-based strategy including clinical probability, D-dimer levels, and ultrasonography: A management study. Arch Intern Med 1996;156:531-536.

36. Kakkar VV, Sasahara AA. Diagnosis of venous thrombosis and pulmonary embolism. In: Bloom Al, Thomas DP, ed. Haematosis and thrombosis. 1981:646-647.

37. van den Borne. Consensus-bijeenkomst diepe veneuze thrombose. Amsterdam 1986:34-38.

38. McLachlan MSF, Thomson JG, Taylor DW. Observer variation in the interpretation of lower limbs venograms. Am J Radiol 1979;132:227-230.

39. Anderson DR, Lensing AWA, Wells PS, Levine MN, Weitz JI, Hirsch J. Limitations of impedance plethysmography in the diagnosis of clinically suspect deep venous thrombosis. Ann Intern Med 1993;118:25-30.

40. Ginsberg IS, Wells PS, Hirsch J, Panju AA, Patel MA, McGinnis J, Stevens P, Brill-Edwards $P$. Reevaluation of the sensitivity of impedance plethysmography for the detection of proximal deep vein thrombosis. Arch Intern Med 1994;154:1930-1933.

41. Kearon $C$, Hirsch $J$. Factors influencing the reported sensitivity and specificity of impedance plethysmography for deep vein thrombosis. Thromb Haemost 1994;72:652-658. 
42. Wester JPJ, Holtkamp M, Linnebank ERM, van Ramshorst B, Meuwissen OJATh, de Valois JC, Eikelboom BC, Verzijlbergen JF. Non-invasive detection of deep venous thrombosis: Ultrasonography versus duplex scanning. Eur J Vasc Surg 1994:8:35 7-361.

43. Schindler JM, Kaiser M, Gerber A, Vuilliomenet A, Popovic A, Bertel O. Colour coded duplex sonography in suspected deep vein thrombosis of the leg. Br Med J 1990;301:1369-1370.

44. Wells PS, Lensing AWA, Davidson BL, Prins MH, Hirsch J. Accuracy of ultrasound for the diagnosis of deep venous thrombosis in asymptomatic patients after orthopedic surgery. A metaanalysis. Ann Intern Med 1995;122:47-53.

45. Goodman PC. Pulmonary angiography. Clin Chest Med 1994:5:465-477.

46. Grollmar JH, Gyepes MT, Helmer E. Transfemoral selective bilateral pulmonary angiography with a pulmonary-artery-seeking catheter. Radiology $1970 ; 96: 202-204$.

47. Kearon C, Hirsch J. The diagnosis of pulmonary embolisn. Haemostasis 1995;25:72-87.

48. The PIOPED-inwestigators. Value of the ventilation-perfusion scan in acute pulmonary embolism. Results of the prospective investigation of pulmonary embolism diagnosis (PIOPED). JAMA 1990;263:2753-2759.

49. Walsh PN, Greenspan RH, Simon M. An angiographic severity index for pullmonary embolism. Circulation 4 1973;7(suppl2): 101-108.

50. Simon M, Sharma GVKR, Sasahara AA. An angiographic method for quantitating the severity of pulmonary embolism and the effects of therapy. Int Angiol 1984;3:389-392.

51. Goldhaber SZ, Braunwald E. Pulmonary embolism. In: Braunwald E, ed. Heart disease. A textbook of cardiovascular medicine. WB Saunders. Philadelphia. 4th ed. 1992:1565-1567.

52. Palla A, Peruzzelli S, Donnamaria V, Giutini C. The role of suspicion in the diagnosis of pulmonary embolism. Chest 1995;107:21S-24S.

53. The PISA-PED Investigators. Invasive and noninvasive diagnosis of pulmonary embolism. Preliminary results of the prospective investigative study of acute pulmonary embolism diagnosis. Chest 1995;107:33S-38S.

54. Hull RD, Raskob GE, Pineo GF, Brant RF. The low probabillity scan. A need for change in nomenclature. Arch Intern Med 1995;155:1845-1851.

55. Tardivon AA, Musset D, Maitre S, Bernot F, Dartevelle, Simonneau G, Labrune M. Role of CT in chronic pulmonary embolism: Comparison with pulmonary angiography. J Conuput Assist Tomo 1993;17:345-351.

56. Blum A, Mousseaux E, Deneuville M, Chabot F, Bollaen PE, Claudon M, Danchin N, Regent D. L'imagerie nouvelle dans l'embolie pulmonaire. Arch Mal Coeur Vaiss 1995;88:1735-1743.

57. Kauczor HU, Schwickert HC, Schweden F, Schild HH, Thelen M. Spiral CT of bronchial arteries in chronic thromboembolism. J Comput Assist Tomo 1994;18:855-861.

58. Teigen $\mathrm{CL}$, Maus TP, Sheedy PF II, Stanson AW, Johnson CM, Breen JF, McKusick MA. Pulmonary embolism: Diagnosis with contrast-enhanced electronic beam $\mathrm{CT}$ and comparison with pulmonary angiography. Radiology 1995;194:313-319.

59. Pruszcyk P, Pacho R. Chlebus M, Filipecki S, Zielinski J, Torbicki A. Noninvasive visualization of pulmonary artery thrombi in patients with suspected pulmonary embolism considered for aggressive therapy: Spiral CT versus transoesophageal echocardiography. Eur Heart J 1996;18:(abstract)P2901.

60. King MA, Bergin CJ, Yeung DWC, Belezzouli EE, Olson LK, Ashburn WL, Auger WR, Moser KM. Chronic pulmonary thromboembolism: Detection of regional hypoperfusion with CT. Radiology 1994;191:359-363.

61. van Bruyn H, Bergmann SR, Keyt BA, Sobel BA. Visualization of thrombi in pulmonary arteries with radiolabeled, enzymatically inactivated tissue-type plasminogen activator. Circulation 1995;92:1320-1325. 
62. Perrier $A$, Bounameaux $H$, Morabia A, de Moerloose P, Slosman D, Didier D, Unger P-F, Junod A. Diagnosis of pulmonary embolism by a decision analysis-based strategy including clinical probability, D-dimer levels, and wltrasonography: A management study. Arch Intern Med 1996; 156:531-536.

63. Moser KM. Diagnosing pulmonary embolism. D-Dimer needs rigorous ewaluation. Br Med J $1994,309: 1525-1526$.

64. Hirsch J, Hoak J. Management of deep vein thrombosis and pulmonary embolism. A statement for healthcare professionals. From the council on thrombosis (in consultation with the council on cardiovascular radiology), American Heart Association. Circulation 1996; 93:2212-2245. 


\title{
Chapter 3
}

\section{Fatal pulmonary embolism in the Maastricht area. A retrospective, hospital-based, study.}

\author{
Emile C. Cheriex, Michael G. Havenith ${ }^{a}$
}

Deep venous thrombosis is the main cause for pulmonary embolism. Autopsy studies, however, studying deep venous thrombosis from the planta pedis to the caval vein and the heart are rarely performed

The recognition of pulmonary embolism during autopsy strongly depends on the method used. In routine post-mortem examinations major life threatening thrombi in the central pulmonary vessels are generally not missed and are reported to be present in between 1 and $35 \%$ of post mortem examinations ${ }^{\prime}$. If a careful autopsy is performed, however, smaller (even microscopic) thromboemboli are discovered considerably more frequently. Frieman at al. found evidence of thromboemboli in $64 \%$ of adult cases seen at autopsy ${ }^{2}$. Morell and Dunnill electively searching for emboli in the right lung found emboli in $51.7 \%$ of all autopsies. The left lung of the same patients were searched by "routine pathologists", identifying emboli in only $11.8 \%{ }^{3}$. In an extensive study Havig found gross and microscopic emboli in $69 \%$ of 508 randomized autopsies ${ }^{1}$.

The pre-mortem clinical diagnosis of pulmonary embolism is the most frequently missed clinical diagnosis when reporting the findings from autopsies. Only in around $30 \%$ of the patients dying in hospital pulmonary embolism was diagnosed as the most likely cause of death. If one is trying to get insight in ways to improve the diagnostic accuracy of pulmonary embolism during life one ought to know how often a fatal pulmonary embolism occurred and how often pulmonary emboli contributed to the death of the patient. For that purpose we examined the autopsy records of patients dying between 1986 and 1992 in the University Hospital of Maastricht.

\section{Methods}

The Maastricht area (Maastricht and six smaller surrounding cities: Meerssen, Eijsden, Gronsveld, Margraten, Valkenburg, Gulpen) is geographically well defined (the south and west borders of this region are formed by Belgium). The Academic Hospital is the only hospital in this region with a population of 183.436 inhabitants in 1986 and 189.202 inhabitants in 1992. In 1986, 1671 and in 1992, 1731 persons died in the region (source: ETIL $^{\text {b) }}$. From 1986 to 1992,2398 post-mortem examinations were performed in 5309

\footnotetext{
${ }^{a}$ Department of Pathology. Present address: M.G Havenith, Pathologist. Pathology Laboratory East Metherlands" Enschede. The Netherlands.
}

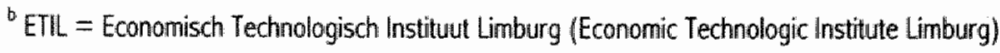


patients dying in hospital (which is about $45 \%$ of all patients dying in the region). The average percentage of autopsies in the different departments was $45 \%$ (table 1 ).

Table 1. Autopsies pefformed per year/depanthent (percentage of autopsies/total amount of death per department).

\begin{tabular}{|l|l|l|l|l|l|l|l|l|}
\hline \multirow{2}{*}{ Department } & \multicolumn{7}{|c|}{ Autopsies performed (\% of total death/department) } & \multirow{2}{*}{ Total } \\
\cline { 2 - 9 } & 1986 & 1987 & 1988 & 1989 & 1990 & 1991 & 1992 & \\
\hline Cardiology & $65(66 \%)$ & $45(47 \%)$ & $63(59 \%)$ & $67(50 \%)$ & $63(47 \%)$ & $65(50 \%)$ & $65(47 \%)$ & 433 \\
\hline Surgery & $49(53 \%)$ & $45(41 \%)$ & $42(43 \%)$ & $43(46 \%)$ & $49(45 \%)$ & $37(46 \%)$ & $39(42 \%)$ & 304 \\
\hline Internal Medicine & $89(52 \%)$ & $76(65 \%)$ & $102(56 \%)$ & $99(50 \%)$ & $74(39 \%)$ & $91(46 \%)$ & $69(33 \%)$ & 600 \\
\hline Pulmonology & $15(20 \%)$ & $33(45 \%)$ & $23(31 \%)$ & $29(33 \%)$ & $29(35 \%)$ & $30(36 \%)$ & $23(29 \%)$ & 182 \\
\hline Neurology & $38(42 \%)$ & $34(29 \%)$ & $36(45 \%)$ & $32(33 \%)$ & $29(32 \%)$ & $35(42 \%)$ & $18(24 \%)$ & 222 \\
\hline Others & 80 & 71 & 85 & 83 & 103 & 109 & 126 & 657 \\
\hline Total & 336 & 304 & 351 & 353 & 347 & 367 & 340 & 2398 \\
\hline
\end{tabular}

Post-mortem diagnoses were centrally stored in a nation-wide registry of pathological departments (PALGA ${ }^{c}$ ). The post-mortem examination reports of patients in whom pulmonary embolism (including tumor- and fat-emboli) was found at autopsy were identified and the following data were retrospectively analyzed:

1. Sex.

2. Age at demise.

3. Medical department delined as last department to which the patient was admitted and eventually died in. Although we attempted to identify which medical specialist was responsible for the final diagnosis at the time of death, it was difficult, in retrospect, to find out whether the diagnosis was made or suggested by the attending or the consulting physician.

4. Presence of cancer or a surgical intervention during the same admission.

5. Role of pulmonary embolism as (possible) cause of death. Category:

A. Pulmonary embolism as primary cause of death. Massive pulmonary embolism was defined as emboli obstructing or occluding the pulmonary bifurcation (saddle thrombus) or one of the main pulmonary arteries (involving more than $50 \%$ of the pulmonary circulation) and as sub-massive when gross pulmonary emboli were present in 22 lobar arteries and pulmonary embolism was found to be the major cause of death.

\footnotetext{
CALGA = Pathologisch Anatomisch Landelijk Geautomatiseerd Archief
} 
B. Other pulmonary disease in combination with pulmonary embolism responsible for death. Pulmonary embolism in one lobar artery or in some segmental arteries and severe pneumonia and/or emphysema causing major pulmonary or systemic failure.

C. Congestive heart failure or other important cardiovascular problems as main cause of death, but pulmonary embolism contributing.

D. Pulmonary embolism as incidental finding

6. Clinical diagnosis in relation to pulmonary embolism.

I. Pulmonary embolism considered to be the cause of death.

II. Pulmonary embolism listed in the differential diagnosis as cause or contributing to death.

III. Pulmonary embolism not suspected.

IV. Pulmonary embolism considered as very unlikely (mis-diagnosed).

7. Presence of echocardiographic evidence for right ventricular overload and time delay between the echocardiographic examination and death (data derived from echocardiographic database. See chapter 4).

\section{Results}

In 105 of $2398(4.4 \%)$ postmortem examinations gross pulmonary embolism was found. The mean age of the patients was $72.8 \pm 12.8$ years. Forty-one patients were men $(39 \%)$ and 64 women $(61 \%)$. In $29(28 \%)$ patients cancer was present. In $15(14 \%)$ patients the death occurred after a surgical intervention during the same admission.

Table 2. Clinical suspicion and autopsy categories:

\begin{tabular}{|l|l|c|c|c|c|}
\hline \multirow{2}{*}{ Autopsy diagnosis } & \multirow{2}{*}{$N$} & \multicolumn{4}{|c|}{ Clinical diagnosis (\% of total per category) } \\
\cline { 3 - 6 } & & 1 & $\|$ & 11 & $N$ \\
\hline Category A & 60 & $12(20 \%)$ & $12(20 \%)$ & $13(22 \%)$ & $23(38 \%)$ \\
\hline Category B & 19 & $1(5 \%)$ & $1(5 \%)$ & $12(63 \%)$ & $5(26 \%)$ \\
\hline Category C & 10 & & $2(20 \%)$ & $5(50 \%)$ & $3(30 \%)$ \\
\hline Category D & 16 & & $1(6 \%)$ & $15(94 \%)$ & \\
\hline Total & 105 & & & & \\
\hline
\end{tabular}

In 60 patients pulmonary embolism was considered to be massive or sub-massive (category A). In 19 patients a combination of pulmonary infectious disease (with or without preexistent pulmonary disease) and pulmonary embolism was found (category $B$ ), and in 10 pulmonary embolism occurred in the setting of severe other cardiovascular problems and could have contributed to death (category C). In 16 patients pulmonary embolism was regarded as an incidental finding (category D). In table 2 the relation is given between the categories of autopsies and the clinical diagnosis. In only $38 \%$ of patients dying of 
pulmonary embolism, the diagnosis was made or considered to be possible. It becomes clear that when the autopsy finding of pulmonary embolism is regarded an incidental finding (category D) the clinical likelihood of making such a diagnosis before death is low $(6 \%)$. Table 3 gives the relation between post mortem diagnosis and the clinical diagnosis of pulmonary embolism in the different clinical departments.

Table 3. Number of patients in the different autopsy categories and (within brackets) the number of patients in whom a chinical diagnosis I or II of pulmonary embolism was made in the different dinical departments.

\begin{tabular}{|l|c|c|c|c|c|}
\hline \multirow{2}{*}{ Department } & \multirow{2}{*}{ Total } & \multicolumn{4}{|c|}{ Autopsy category (number of dinical diagnosis I and II) } \\
\cline { 3 - 6 } & & $A$ & $B$ & $C$ & 0 \\
\hline Cardiology/Thoracic surgery & 18 & $13(7)$ & $2(1)$ & $2(1)$ & $1(0)$ \\
\hline Surgery/Orthopedics/Urology & 20 & $10(6)$ & $3(0)$ & $4(0)$ & $3(0)$ \\
\hline Internal medicane & 31 & $18(6)$ & $6(1)$ & $2(0)$ & $5(0)$ \\
\hline Pulmonology & 13 & $6(1)$ & $4(0)$ & & $3(0)$ \\
\hline Neurology/Psychiatry & 13 & $9(2)$ & $1(0)$ & $1(0)$ & $2(0)$ \\
\hline Others & 10 & $4(1)$ & $3(0)$ & $1(0)$ & $2(1)$ \\
\hline Totals & 105 & $60(23)$ & $19(2)$ & $10(1)$ & $17(1)$ \\
\hline
\end{tabular}

The incidence of deep venous thrombosis could not be determined because dissection of the entire venous system was not routinely performed.

Forty patients were investigated using echocardiography days to months before death. However, only ten of 24 patients from category A listed in the echocardiographic database had their echocardiogram within 4 days before death. In eight patients this echocardiogram showed RV pressure-overload or direct signs of embolism (Figure 1).

In one patient a trans-esophageal echocardiogram revealed a right atrial thrombus and signs of RV pressure overload. In 2 patients the echocardiographic examination was performed during resuscitation; one showing pressure overload of the right ventricle suggestive of pulmonary embolism, the other showed complete cardiac akinesia and was not diagnostic for pulmonary embolism. In the remaining patients from category A no echocardiographic examination was performed within 4 days before death. However, in one patient, showing pulmonary hypertension, pulmonary embolism had already been diagnosed earlier. None of the 16 patients from the other categories had an echocardiogram within 4 days before death. No echocardiogram showed RV pressure overload. 


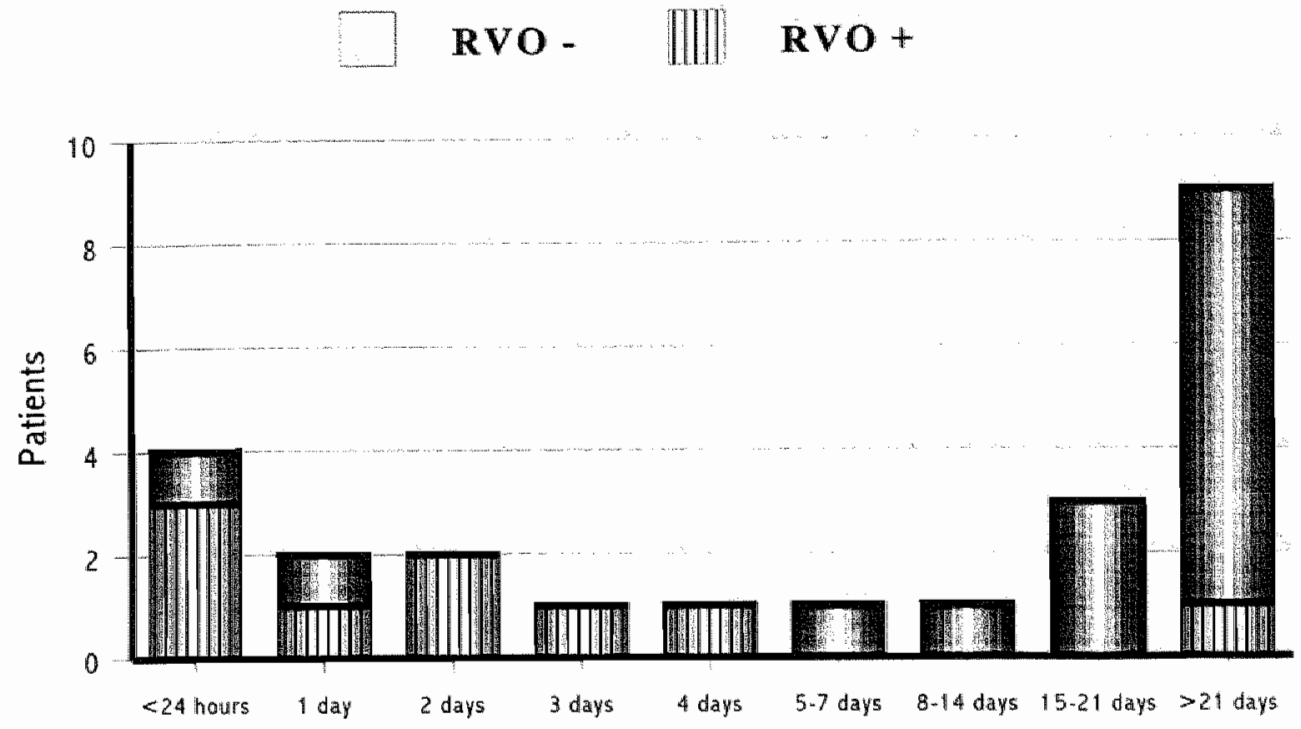

Figure 1: Echocardiographic signs of RV-overload in relation to time of death of the patient.

RVO + = Echocardiographic signs of RV-pressure overload RV - = No echocardiographic signs of RVpressure averload.

\section{Discussion}

Deep vein thrombosis.

Only a few post-mortem studies have been performed looking at the incidence of venous thrombosis. The main reason is probably the fact that extensive dissection is very timeconsuming. Havig did perform such a study in 261 randomized autopsies. In 117 (62\%) death occurred after a chronic underlying disorder (26.1\% malignancy, $11.5 \%$ vascular) and $119(46 \%)$ died because of an acute disorder (acute myocardial infarction/CVA/ accident/post-operative). In 161 cases $(61.7 \%)$ venous thrombi were found. The inferior caval vein had thrombi in $5 \%$ and the iliac vein contained thrombi in $19.3 \%$ of cases. The femoral system showed thrombi in $47.2 \%$, the popliteal vein in $32.9 \%$, the calf-veins in 79.5 $\%$ and the plantar veins in $54 \%$. He divided the thrombi in minor, extensive $(>3 \mathrm{~cm}$ long at a single site or $>1 \mathrm{~cm}$ in multiple locations) and very extensive (most of the venous tree involved). Also, after excluding post mortem clots, thrombi were differentiated into fresh and old ones ( $60 \%$ being fresh with distal thrombi being usiually the oldest). In $40 \%$ the thrombi were minor in size. Extensive thrombi were found in 96 of 161 cases (60\% of the patients with thrombi and $38 \%$ of total study population) ${ }^{\prime}$. These data are in agreement with others showing an incidence of 53-61\% thrombi at autopsy ".5. In the study of Havig no "isolated" thrombi were found in the external iliac vein and in most cases thrombosis abruptly ended at the level of the inguinal ligament'. These studies were performed at a time that heparin 
prophylaxis was not used extensively. This may have affected the total number of thrombi considerably, particularly in the post-operative patient group ( $3.1 \%$ of Havig's study population (8/261)) . Microscopic thrombi, only, were found in 27 additional patients (leading to a total of gross and microscopic thrombi of $72 \%$ in all cases) ${ }^{3}$.

\section{Pulmonary embolism.}

In most studies the following subdivision is made:

$\Leftrightarrow$ Fatal emboli: Thromboemboli occluding at least 2 lobar arteries with no other identifiable cause for death.

$\Rightarrow$ Contributing emboli: An occlusion of at least 1 lobar artery or multiple segmental arteries. In these patients other reasons for death were found in addition to the emboli.

$\Rightarrow$ Incidental emboli: Small or old emboli considered not to have contributed to death.

The occurrence of emboli is probably race dependent. The Asians report the lowest incidence. In a Hong Kong study only 1.1-2.8\% of all autopsies showed pulmonary embolism $^{6}$. In the Caucasian population the incidence of pulmonary embolism at postmortem examination can vary from $2.1-69.3 \%$, depending on definition, method used and thoroughness of the autopsy ${ }^{3}$. In most studies the reported incidence of grossly visible emboli is $10-29.5 \%^{7-11}$. If microscopic emboli and traces of old emboli (e.g. fibrous bands and webs) are included the figure increases to between $50-70 \%{ }^{1-3}$.

In the thorough study of Havig the figure of pulmonary emboli judged to be the cause of death was $18 \%$ and contributing to death in an additional $10 \%$ leading to a total of $28 \%$, which is in agreement with the findings of Barker (24.4\% total mortality) and Lindblad (21$26.1 \%$ of total mortality with $8.9-9.4 \%$ fatal pulmonary embolism) $)^{1,12,13}$. Some studies of patients dying in hospital consist mainly of post-surgical patients or patients with malignancies. A large study of Bergqvist showed gross pulmonary embolism in $23.6 \%$ of 5477 patients coming from surgical departments, $349 / 5477$ were considered fatal $(6.3 \%)$ and $353 / 5477$ contributory $(6.4 \%)^{14}$. In this study more than half of the patients was postoperative and 24 patients had emboli related to central venous lines. The incidence of contributory emboli increased over the study period probably as a result of greater thoroughness in postmortems.

The prevalence of pulmonary embolism in patients having cancer is strongly dependent on cancer type. Patients having ovarian cancer, extrahepatic bile cancer and cancer of the stomach have the highest prevalence $(34.6 \%, 31.7 \%$ and $15.6 \%$ resp.). Palliatively treated cancer of organs within the peritoneal cavity had a significantly higher incidence than all other cancers combined ${ }^{15}$.

Large well performed studies combining deep venous thrombosis and pulmonary embolism are exceptional. Lindblad found $40 \%$ fatal pulmonary emboli without deep venous thrombosis (or remnants of venous thrombosis) ${ }^{13}$. Diebold, reviewing 5039 autopsy cases of two university hospitals, found that $29.8 \%$ patients had pulmonary embolism. In $41.9 \%$ of all cases with pulmonary embolism ( 1500 autopsies $=12.5 \%$ of all autopsies), pulmonary 
Fatal pulmonary embolism in the Maastricht area

embolism was considered to have been fatal. In $10.2 \%$ of cases the source of emboli was in the superior venous tree. Diebold nicely showed the relation between localization of venous thrombosis and fatal and non-fatal pulmonary embolism (table 4)".

Table 4. Adapted from Diebold showing the results of 5039 autopsies in two university hospitals from 1975 1980 and $1987-1988^{\| .}$.

\begin{tabular}{|c|c|c|c|c|c|}
\hline \multicolumn{6}{|c|}{ Pulmonary embolism in 1500 of 5039 autopsies (29.8\%) } \\
\hline \multicolumn{3}{|c|}{ Fatal $n=628(628 / 1500=41.9 \%)$} & \multicolumn{3}{|c|}{ Non-fatal $n-872(872 / 1500=58.1)$} \\
\hline $477 / 62876.0 \%$ & $52 / 6288.3 \%$ & $99 / 62815.8 \%$ & $321 / 87236.8 \%$ & $137 / 87215.7 \%$ & $414 / 87247.5 \%$ \\
\hline $477 / 121339.3 \%$ & $52 / 51210.2 \%$ & $99 / 42023.6 \%$ & $321 / 42076.4 \%$ & $137 / 51226.7 \%$ & $414 / 121334.11 \%$ \\
\hline \multicolumn{4}{|c|}{$\begin{array}{l}\text { Pulmonary embolism } \\
\text { without source } n=420\end{array}$} & & \\
\hline \multicolumn{5}{|c|}{$\begin{array}{l}\text { Granial venous thrombosis } n=512 \\
\qquad(512 / 1725=29.7 \%)\end{array}$} & \\
\hline \multicolumn{6}{|c|}{$\begin{array}{l}\text { Caudal wenous thrombosis }+ \text { combined localization } \\
\qquad n=1213(1213 / 1725=70.3 \%)\end{array}$} \\
\hline $\begin{array}{l}\text { Wenous thrombosis } \\
\text { Wenous thrombosis }\end{array}$ & $\begin{array}{l}725(1725 / 50 \\
\text { dimonary emb }\end{array}$ & $\begin{array}{l}34.2 \%) \\
\text { without sourc }\end{array}$ & 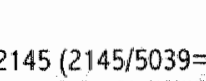 & & \\
\hline
\end{tabular}

Sperry et al. estimated the frequency of death caused by pulmonary embolism in the general population of New Mexico (including all sudden, unexpected and unnatural causes, using data from a statewide forensic pathology program) to be $1.1 \%$ in a non-autopsied and probably under-diagnosed population to $2.4 \%$ in autopsied population ${ }^{16}$. Interestingly the US National Center for Health Statistics (1986) reports the deaths from pulmonary embolism in the general population as 4.4 per 100.000 (data from health certificate records) ${ }^{17}$. The Maastricht area has already more in-hospital deaths due to pulmonary embolism (60 patients of group $A$ in a population of around 185.000 over a seven year follow up period (4.6 per $100.000)$ and 79 group $A$ and $B$ patients (6.1 per 100.000$)$ ) than the US National Center for Health Statistics estimates. Only $45 \%$ of all deaths are, however, in-hospital.

In our study the total incidence of pulmonary embolism at autopsy was low for a in-hospital population (4.4\%). Of all autopsies with pulmonary embolism the percentage of fatal pulmonary embolism ( $57 \%$ ) and pulmonary embolism contributing to death $(28 \%)$ was relatively high, which is probably the consequence of not regularly including "incidental" and smaller emboli to the general database.

\section{Chinical diagnosis}

Multiple reports show that clinicians are under-diagnosing pulmonary embolism as proven by findings from autopsy. In general $40-70 \%$ of fatal pulmonary embolism and pulmonary emboli contributing to death are not diagnosed before death ${ }^{2,18}$. Rubinstein investigated the accuracy of the antemortem diagnosis in 1276 autopsy reports. In only $31.8 \%$ of 44 patients identified with major pulmonary emboli ( $4.4 \%$ of all autopsies) that diagnosis was 
suspected ${ }^{19}$. Madhusudan examined 231 adult autopsies and showed that in 97 of 188 cases the autopsy diagnosis was clinically unexpected. The diagnosis pulmonary embolism was the most missed diagnosis rejative to its actual occurrence $(61.1 \%$ of pulmonary embolic cases were missed) with an Odds ratio of 3.75 . In comparison the Odds ratio for cancer and infections were 0.78 and 1 respectively ${ }^{20}$. Anderson et al. reviewed some studies and concluded that the sensitivity of pre-mortem clinical diagnosis of pulmonary embolism was $34.5 \%$ (specificity $72.5 \%$ ) and the clinical accuracy of a positive diagnosis was $72.5 \%$ (accuracy of negative diagnosis $96.5 \%$ ) ${ }^{21}$. Mercer not only reported $75 \%$ under-diagnosis (clinical diagnosis not made before necropsy) but also $43 \%$ over-diagnosis (patients with clinical diagnosis of pulmonary embolism not found at autopsy) ${ }^{22}$. She concluded that overdiagnosis increased hospital stay considerably.

Also in our hospital the diagnosis of pulmonary embolism was regularly missed. The clinical diagnosis used for our study was the diagnosis listed in the clinical chart of the patient or in the request for the autopsy.

\section{Limitations/conclusions of our study}

In our study the lungs were not extensively examined for the presence of pulmonary emboli, making it a "routine" post-mortem study. The high number of relative large (fatal) emboli suggest that smaller (incidental) emboli are probably not registered. The overall low incidence of pulmonary emboli $(4.4 \%)$ indicate that either not all larger emboli were reported or identified or that many cases of pulmonary embolism were correctly identified and appropriately treated and therefore not coming to autopsy. In only a small number of patients with pulmonary embolism examined at autopsy an echocardiographic study was made shortly before death. Using echocardiography eight of ten patients studied within four days before demise had RV-overload suggesting that more than one single episode of embolism was responsible for the death in at least six of these patients (two were investigated during resuscitation). The fact that these six patients died, despite recognition, suggests that therapy failed. This could have been the result of a new episode of embolism in patients with more chronic forms of pulmonary embolization. 


\section{References}

1. Havig O. Deep vein thrombosis and pulmonary embolism. Acta Chir Scand suppl 1977;478:192.

2. Freiman DG, Suyemoto $\mathrm{J}$, Wessler $\mathrm{S}$. Frequency of pulmonary embolism in man. N Engl J Med $1965 ; 272: 1278-1280$.

3. Morell MT, Dunnill MS. The post-mortem incidence of pulmonary embolism in a hospital population. Brit J Surg 1968;55:3447-352.

4. Neumann R. Ursprungszentren und entwickelungsformen der bein-thrombosen. Virchows Arch Path Anat 1938;301:708-735.

5. Hunter WC, Sneeden VD, Robertson TD, Snydler GAC. Thrombosis of the deep veins of the leg. Its clinical significance as exemplified in 351 autopsies. Arch Intern Med 1941;68:1-17.

6. Chau KY, Yuen ST, Ng THK, Ng WF. An Autopsy study of pulmonary thromboembolism in Hong Kong chinese. Pathology 1991;23:181-184.

7. Zimmernan LM, Miller D, Marshall AN. Surg Gynaec Obstet 1949;88:373-388.

8. Parker BM, Smith JR. Pulmonary embolism and infarction. A review of the consequences of pulmonary arterial obstruction. Am J Med 1958;24:402-427.

9. Dexter L, Dock DS, McGuire LB, Hyland JW, Haynes FW. Pulmonary embolism. Med Clin N Am 1960;44:1251-1268.

10. MeIntyre KM, Sasahara AA, Sharma GVRK. Pulmonary embolism: current concepts. Adv Intern Med 1969;18:199-218.

11. Diebold $\mathrm{J}$, Löhrs U. Venous thrombosis and pulmonary embolism. A study of 5039 autopsies. Path Res Pract 1991;187:260-266.

12. Barker NW, Nygaard KK, Walters W, Priestley JT. A statistical study of post-operative venous thrombosis and pulmonary embolism. Incidence in various type types of operations. Mayo Clin Proc 1940;15:769-773.

13. Lindblad $\mathrm{B}$, Sternby $\mathrm{NH}$, Bergqvist $\mathrm{D}$. Incidence of venous thromboembolism verified by necropsy over 30 years. Brit Med J 1991;302:709-711.

14. Bergqvist D, Lindblad B. A 30-year survey of pulmonary embolism verified at autopsy" an analysis of 1274 surgical patients. Br J Surg 1985;72:105-108.

15. Svendsen $E$, Karwinski B. Prevalence of pulmonary embolism at necropsy in patients with cancer. J Clin Pathol 1989;42:805-809.

16. Sperry KL, Key CR, Anderson RE. Toward a population-based assessment of death due to pulmonary embolism in New Mexico. Hum Pathol 1990;21:159-165.

17. United States Public Health Service: Vital statistics of the United States. Volumes 1950.1986 , Vol 2, montality. National Vital Statistics Division, National Center for Health Statistics, US, GPO, Washington DC.

18. Modan B, Sharon E, Jelin N. Factors contributing to the incorrect diagnosis of pulmonary embolic disease. Chest 1972;62:388-393.

19. Rubinstein I, Murray D, Hoffstein V. Fatal pulmonary emboli in hospitalized patients. An autopsy study. Arch Intern Med 1988;148:1425-1426.

20. Madhusudan GR, Rangwala AF. Diagnostic yield from 231 autopsies in a community hospital. Am J Clin Pathol 1990;93:486-490.

21. Anderson RE, Key CR. The sensitivity and specificity of clinical diagnostics during five decades. JAMA 1989;261:1610-1617.

22. Mercer J, Talbot IC. Clinical diagnosis: a post-mortem assessment of accuracy in the $1980 \mathrm{~s}$. Postgrad Med J 1985;61:713-716. 



\title{
Chapter 4
}

\section{The Maastricht echocardiographic database.}

\author{
Emile C.Cheriex, Rob G.A.Mulleneers, Hubertus P.M.Bleijlevens.
}

Medical doctors see hundreds of patients each year. Every patient is different from the other, although their symptoms may suggest the same specific disease or disease category. The way they present their symptoms can vary from nonspecific to "classic". Despite this wide range of presenting symptoms an experienced doctor can and will make the right decisions in the majority of cases, by combining patient data, knowledge and experience.

In a hospital with increasing possibilities to treat patients and with increasing numbers of patients asking for treatment, optimal patient management is essential. Regulations of "good medical practice" demand adequate provision and documentation of information. Increasing efforts are therefore put in the development and use of electronic patient files or computerbased patients records!. The stand-alone personal computer of the eighties have evolved into extensive local and even wide area networks.

The patient file in general consists of a written history , physical examination and follow-up, documenting diagnostic findings and clinical course. It is likely, that the electronic patient file will eventually enter our daily practice. That requires that all information about the patient including reports of diagnostic tests and therapeutic interventions are entered into the electronic patient file. This needs the cooperation of many persons working in the hospital, not only from the medical and nursing staff of the clinical department in which the patient is admitted but also of other medical specialists who see the patient in consultation or perform diagnostic tests or therapeutic interventions. Registration and reporting has to be performed and authorized at the site of the investigation without delay. The physician in charge during his or her daily review of the patient should "sign" the electronic report (or a print-out) to indicate awareness of the presence of new information. A temporary "classical" portable fille is probably still needed to allow rapid comparison of test results as for example in electrocardiography. Bringing all information from all patients in a database will obviously facilitate clinical research.

At present we have a combination of written information, which is not stored in the electronic patient file, and information, for example from diagnostic tests, which is electronically stored and also printed out and included in the "classical" patient file. Hopefully, when interest and skills to use electronic data collection increases among the hospital personnel the percentage of patient information electronically stored will grow.

\section{Data storage in general}

The use of "databases" is not only of importance for patient management but also essential in obtaining scientific data. This gives rise to approaches with different results: 
A. A "database" containing all available data. If a scientific question arises just consultate the database for the answer. This attitude seems very attractive but cannot be realized in practice: The physicians making the original database have to optimally define the wariables needed for analysis. Physicians in general do not like to think about all the variables that should be included in general databases. In time the database has to be expanded with new variables. The motivation to do so will be dependent on the use and the benefit of the database. In fact when a database is not directly useful for medical management, the quality of the data is dependent on the quality of the investigator or data-manager. Many databases of this kind are data cemeteries!

B. Normally written or dictated reports (e.g. discharge letters) are typed into a directory with free text search capabilities and/or index-words ${ }^{2}$. Thanks to improving softwarepossibillities this method is increasingly used. It is clear that the use of fixed words, diagnosis and/or strings in reports and letters is necessary to avoid missing numbers. The final scientific research will be retrospective.

C. A "database" only containing relevant diagnostic/therapeutic information, but stored in such a way that these data are available for scientific analysis ("storage system"). If a new variable comes to the attention this has to be flexibly implemented in the storage system. To be sure that all data are relevant the storage system has to create a medical report directly. The disadvantage of this type of storage system is that when a certain patient-, disease- or diagnosis-group has been selected for scientific purposes, the other data have to be retrospectively gathered and analyzed. The data-collection is, however, prospective in nature. Although this method is also dependent on quality of the investigator making the report, some quality control in time will come from colleagues using those reports for clinical use and in their research. Storage systems of these kind can be structured (see below) using two approaches. One can use natural language (natural language processing ${ }^{3}$ ) in which data are structured in first-order logic. The core unit is the use of a set of predefined terms and the relationship between these terms in a triplet: term $A$ - relation $B$ - term $C$ (pain-has location-heart) or finding - attribute value. Data can also be stored using a structured data entry with a predefined vocabulary or code".

\section{Specific problems with the collection of medical data}

\section{The characteristic features of medical data collection include:}

1. Nearly infinitive combinations and relations. Patients can have atrial fibrillation, mitral incompetence, myxoma cordis, infarction, hypercholesterolemia of different severity at the same time and can be re-admitted with pericarditis based on a combination of three new factors.

2. A repetitive component is often present. A patient develops an infarction in the inferior wall foll lowed by an anterior wall infarction during the same admission with variables of interest for both infarctions.

3. An undefined (endless) expansion particularly occurs in databases or programs using prescriptions. A patient can have none to multiple medications with different amounts (e.g.; bid, tid) and applications (sc, iv, im). 
4. Lack of uniformity. An ejection fraction can be analyzed using echocardiography, angiography or scintigraphy, each with its own sensitivity and accuracy. Wall motion can also be measured by different methods.

5. Time dependency. Diagnostic routing and treatment are clearly influenced by new developments. Time of admission and severity of the disease will also have its effects on the availability of medical data.

As stated earlier, registration of medical data can be uncoordinated or structured.

In uncoordinated registrations (see database method $\mathrm{B}$ ), the user has to make relations in every patient/problem. For example: "A large $(2.7 \mathrm{~cm}$ in diameter) tumor (myxoma) was present in the LA" or "No (large) tumor was present in the left atrium". Both sentences contain the information: tumor and large. Left atrium and LA is the same, but has to be defined in the search question. Searching for atrium or left atrium will give a large amount of reports. "Myxoma" or "Myxoom" has to specified also.

In structured databases one can choose a fixed systematic approach:

$\begin{array}{ll}\text { Tumor } & 1=\text { yes } \\ & 2=\text { no } \\ \text {-localization } & 1=\text { left atrium } \\ & 2=\text { right atrium } \\ & 3=\text { etc } \\ \text {-size } & 1=\text { small etc. }\end{array}$

-aspect etc.

One can also use a more flexible "mnemonic" code. This "menu interaction" menu's from which a user can select sub-menu's according to the additional data/factors he needs. This works like a tree, starting with a stem and developing branches when needed. The information is stored as a string (using structured data entry or natural language processing) which is flexible in size and structure, but is well defined. When using code this information can be encoded or translated.

\section{The cardiology information system}

In 1986 after two years of collecting data according to method A listed above, we started a echocardiographic storage system with fixed numerical fields for measurements of diameters (of heart chambers and wall thickness) and ejection fraction only and a flexible approach using diagnostic codes for all other measurements, abnormalities and diagnosis in flexible strings (method C). At first we were working with a personal computer with limited memory making storage capabilities limited. After 1989 we modernized the system and started a local area network in 1991. The network now has 80 terminals. From 1989 we reported directly from our database. This method was described in detail after 6.500 patients in $1990^{6}$.

An example of a string containing fixed information is: "06,18/8/1.7>25/13 07,gl-2 30,aa 35 ,". Using a so called "Echo Description Code Language" (EDCL) this can be translated in: "Anterior wall infarction with apical aneurysm and good left ventricular rest-function. 
Mitral stenosis with a maximal gradient of $18 \mathrm{mmHg}$, mean gradient $8 \mathrm{mmHg}$; mitral valve orifice $1.7 \mathrm{~cm}^{2}$ after exercise increasing to a maximal gradient of $25 \mathrm{mmHg}$, mean gradient of 13 mmHg. Grade $1-2$ mitral incompetence.".

After 1990 new modules were developed using the mnemonic programming. The code is available only beyond the screen. The user is guided through the main-menu and the submenu"s. This coding language called CACOLA (CArdiology Coding LAnguage) is used for all modules developed since and can also be shown in an example ": "[CCU>MT:L/a, s:OT72=945;ST+/1,V2-V4;TXT/04"pat..." $] "$. This is the string for: "Myocardial Infarction during stay on Coronary Care Unit. AnteroSeptal site of infarction. Maximal SGOT level of $945 \mathrm{U} / 1$ reached after 72 hours. Remarks by Dr 04:"Pat ........".

At this moment the cardiological information system contains a maincard-module with connections to the hospital information system (for laboratory, pathology and radiology reports) and the following sub-modules: Echocardiographic laboratory, catheterization laboratory, PTCA-procedure, exercise testing, previous history, first heart aid, medication/prescription, notes, medical discharge letters, protocols and management modules.

All modules are specifically developed for registration at the source, actual registration (directly reporting) and authorization of reports.

\section{Echocardiographic laboratories and their supervision}

The diagnostic accuracy of echocardiographic investigations differs between cardiology departments. This is based on two factors; (1) The availability of cardiological supervision, and (2) the knowledge and training of the cardiologist in echocardiography as sub-specialism (echocardiographist). Echocardiographic laboratories vary from those having technicians solely performing the complete investigation to laboratories with continuous cardiological supervision or cardiologists performing the investigations themselves. The cardiologist can be an autodidact or sufficiently trained under the supervision of an echocardiographist. In our laboratory there is constant supervision by experienced echocardiographists. This will influence the prospectively entered data in a specific way. If a patient with shortness of breath is undergoing an echocardiographic investigation he will be investigated from a cardiological standpoint, at possible causes for that shortness of breath. Is there left ventricular dysfunction, is there an important left sided valvular problem? If not; are there signs of right ventricular overload or is there pericardial fluid? In echocardiographic laboratories without this cardiological back-up the echocardiogram can be made without these questions being asked and/or answered. One can expect from an echocardiographist that he is able to measure velocities of a tricuspid valvular regurgitation, needed for the diagnosis of right sided pressure overload, in the patient with dyspnea. Echocardiographic investigations can be used to perform bedside-diagnosis within minutes after admission even in the very sick. 


\section{Available echocardiograms/patients for analysis}

At present, September 1996, there are around 47.000 echocardiograms avallable from approximately 37.500 patients. The mean age of the echodatabase population is $59.1 \pm 16.4$ year. From 1986 to 1996 the workload gradually increased as can be seen in table 1. Mean age of the patient population also increased. Whether this is the result of the increasing age of the patient population cannot be concluded from this table.

The subject of this thesis is pulmonary embolism. During the first three years this diagnosis was not listed prospectively in our database as a specific diagnosis. The coding used in those years was: RV pressure higher than $36 \mathrm{mmHg}$ (as could be derived from a tricuspid regurgitation velocity of $3 \mathrm{~m} / \mathrm{s}$ or higher), mean right atrial pressures higher than $8 \mathrm{mmHg}$ (derived from a diminished respiratory collapse of the inferior vena cava) and abnormal diastolic motion of the inter-ventricular septum. The combination of these three in the absence of diminished LV function and important left sided valvular disease could give the subgroup pulmonary embolism. Atrial septal defect, right ventricular infarction, RV dysplasia, Ebstein's disease, pulmonary stenosis, persistent ductus arteriosus could give the same picture but were already properly coded from the beginning. From 1989 we coded prospectively in our database the diagnosis pulmonary embolism suspected [pe] or to be excluded [pe?].

Table 1: Echocardiographic investigations and number of patients during the period $1987-1995$.

\begin{tabular}{|c|c|c|c|c|}
\hline Year & Patients & Investigations & Investigations/patient & mean age \\
\hline 1987 & 2592 & 3161 & 1.22 & 57.1 \\
\hline 1988 & 2897 & 3643 & 1.26 & 57.4 \\
\hline 1989 & 3266 & 4201 & 1.29 & 58.4 \\
\hline 1990 & 3685 & 4770 & 1.29 & 58.7 \\
\hline 1991 & 3826 & 4720 & 1.23 & 59.6 \\
\hline 1992 & 4020 & 5022 & 1.25 & 59.9 \\
\hline 1993 & 4174 & 5154 & 1.23 & 59.3 \\
\hline 1994 & 4677 & 5969 & 1.28 & 60.3 \\
\hline 1995 & 5086 & 6237 & 1.23 & 60.2 \\
\hline
\end{tabular}

93 patients were listed in the database with this combination until 1993 and were the basis for this thesis (chapter 7). Patients with thrombus in the right atrium and right ventricle were added to this group.

Combining our database with the registry of the hospital and the database from the department of pathology (PALGA ${ }^{d}$ ) would make it theoretically possible to get an impression about the number of patients diagnosed as pulmonary embolism without using an echocardiogram and the amount of treated patients versus the patients dying as a

"PALGA= Pathologisch Anatomisch Landelih Geautomatiseerd Arch"ef (see chapter 3). 
consequence of the embolism. However, at this point in time the amount of patients clinically diagnosed as pulmonary embolism without an echocardiographic investigation or echocardiographically investigated but showing no right wentricular pressure overload remains speculative.

Let us take 1990 for example ([pe]/[pe?]) diagnoses prospectively listed in the database):

\section{Echodatabase}

Twenty-one of the 100 patients we are reporting in chapter 7 were in the echodatabase of 1990. Proven pulmonary embolism was present in 11 cases. Eight of the 11 proven cases were listed in the hospital registry as having had pullmonary embolism as "main diagnosis". The remaining 3 cases were not even listed as having as "sub-diagnosis" pulmonary embolism.

\section{Hospital registry}

20 patients with the diagnosis "pulmonary embolism/pulmonary infarction" (14 as "main diagnosis" and 6 "sub-diagnosis") were registered as having been admitted to the cardiology department. Five of the 14 patients were not diagnosed by echocardiography. Two patients possibly died as a result of pulmonary embolism (no autopsy). One patient was admitted and evaluated during the night because of atypical complaints (no pulmonary embolism), but was diagnosed as pulmonary embolism in the hospital registry.

Three of the six patients with the sub-diagnosis pulmonary embolism in the hospital registry died. In the absence of autopsy data the diagnosis of pulmonary embolism could not be verified. Of the surviving patients, one patient was reported to have multiple pulmonary emboli in the presence of a dilated cardiomyopathy (LVEF $16 \%$ ) and a tricuspid incompetence velocity of $3 \mathrm{~m} / \mathrm{s}$, indicating increased right sided pressures.

In 4 patients ( 2 of 5 with "main diagnosis" and 2 of 6 "sub-diagnosis" pulmonary embolism) pulmonary embolism was diagnosed not using echocardiography.

Three patients in the hospital registry of 1990 had the sub-diagnosis pulmonary embolism and were reported in our chapter 3 about post-mortem examinations (these patients were not admitted to the cardiology department). One actually had a massive pulmonary embolism.

\section{Pathology darabase (PALGA)}

12 patients dying in 1990 had pulmonary emboli at autopsy (no patient from the cardiology department). Three of the four patients with massive or sub-massive embolism were not registered in the hospital database. $2 / 6$ patients with emboli contributing to death were accurately registered as sub-diagnosis pulmonary embolism.

\section{In conclusion}

Probably most massive and sub-massive pulmonary emboli (particularly after 1989) are included in our echodatabase as long as the patient did not die so suddenly that even a resuscitation echocardiographic examination could not be performed. Combining the hospital database with our database did not lead to a substantial increase in number of patients. The 
hospital registry, mainly depending on written statements of residents in the departments, seems not to be very accurate for scientific purposes. After completing this study the reginen of completing the categorically related discharge forms changed. The medical doctor is responsible for making the main diagnosis and sub-diagnoses on discharge.

\section{Final remarks}

During the last years the use of the echocardiogram to diagnose pulmonary embolism has increased. At present 20-30 patients each year will get the echocardiographic diagnosis pulmonary embolism suspected or to be excluded. This is partially due to the fact that specialties other than cardiology are aware that patients with massive pulmonary embolism should undergo thrombolytic therapy and that 24 hours diagnostic and treatment service can be supplied by the department of cardiology. In the academic hospital Maastricht ventilationperfusion scans or perfusion scans can only be performed during regular working hours.

Our storage systems will develop further, probably into complete electronic files. This will hopefully lead to more insight in under- or over-diagnosing of pulmonary embolism. 


\section{References}

1. wan Ginneken AM. The structure of data in medical records. Yearbook of medical informatics. 1995:61-70.

2. Ohtsubo $K$. Shibasaki $K$, Kawamura N, Shimada $H$. A pathology database system for autopsy diagnosis using a free-text method. Med Inform 1994;17:47-52.

3. Campbell KE, Das AK, Musen MA. A logical foundation for representation of clinical data. I Am Med Iriformatics Assoc 1994;1:218-232.

4. Miller $\mathrm{G}$, Britt $\mathrm{H}$. Data collection and changing health care systems. 1. United Kingdom. Med J Awst $1993 ; 159: 471-476$.

5. Turban E. Decision support and expert systems. In: User interface. Macmilian Publishing Company. 1990:645-648.

6. Mulleneers RGA, Cheriex EC, Dassen WRM, Blejilevens BB, Wellens HJJ, Meester GT. Caesars: The CArdiac Echo Storage And Retrieval network System. In: Computers in Cardiology. IEEE Computer Society Press, Chicago. 1990:21 1-214.

7. Mulleneers RGA, Dassen WRM, Bleijlevens HPM, Cheriex EC, Den Dulk K, Wellens HJJ. CACOLA, a flexible coding method for integration of information in cardiology subspecialties. In: Computers in Cardiology. IEEE Computer Society Press, Chicago. 1992:603605 . 


\title{
Chapter 5
}

\section{Cross sectional Doppler echocardiography as the initial technique for the diagnosis of acute pulmonary embolism.}

\author{
Emile C. Cheriex, Narayanswami Sreeram, Ywonne F.J.M. Eussen, Frans A.A. Pleters, \\ Hein J.J. Wellens.
}

(Published in Brit Heart J 1994;72:52-57)

\section{Introduction}

The majority of deaths associated with pulmonary embolism occur because of delays in establishing the diagnosis and in commencing appropriate therapy. Although most emboli originate from deep venous thrombosis in the lower limbs, most episodes of deep vein thrombosis are clinically silent. While investigations such as phlebography or impedance plethysmography may be directed towards ascertaining the presence of deep venous thrombosis, confirmation of a pulmonary embolus depends on performing either a ventilation-perfusion scan or angiography 1,2 . Previous studies have shown however that ventilation-perfusion scans are not always conclusive ${ }^{3-5}$. Pulmonary arterial angiography is the definitive diagnostic test for pulmonary embolus. It is however a high-cost, invasive procedure requiring specialized equipment and personnel. Unless a prior high index of suspicion for pulmonary embolism can be established, a significant proportion of pulmonary angiograms performed to demonstrate emboli may be normal ${ }^{6,7}$. The $\mathrm{M}$-mode and twodimensional echocardiographic features in patients with proven pulmonary embolism have been previously described ${ }^{s}$. With improved imaging techniques, the routine use of Doppler echocardiography and a better understanding of the dynamics of systemic venous return to the right atrium ${ }^{9}$, it is now possible to noninvasively detemine the right ventricular systolic pressure $^{10}$, and the response of the right ventricle to an acute pressure or volume overload". This study reports the use of these techniques in detecting right ventricular overload in a consecutive series of patients, and its diagnostic value in pulmonary embolism.

\section{Patients and methods}

The study population consisted of sixty consecutive patients ( 35 male, 25 female), ranging in age from 44-86 years who were seen at the Academic Hospital Maastricht between November 1987 and December 1992, with the following symptoms: acute onset or progressively worsening dyspnea (49 patients), chest pain ( 8 patients), palpitations ( 1 patient) or acute cardiovascular collapse (11 patients). None of the patients had a previous history of chronic lung disease, and surface electrocardiography during the acute episode did not reveal signs of a recent myocardial infarction. Five patients however had previously documented ischemic heart disease with evidence of regional left ventricular wall motion abnormalities on prior echocardiography, while one patient had a dilated cardiomyopathy without elevated pulmonary arterial pressures. 
Informed consent was obtained from all subjects prior to all investigations or therapeutic measures.

\section{Echocardiography}

Two-dimensional Doppler echocardiography was performed, as the initial diagnostic tool, using a Hewlett Packard $77020 \mathrm{AC}$ or Sonos 1000 ultrasound system with standard imaging transducers. In three patients with visible thrombi in the right atrium or ventricle single plane or biplane trans -esophageal echocardiography $(5 \mathrm{MHz}$ transducer) was additionally performed. The internal diameter of the right ventricle at end-diastole was measured from the two-dimensional echocardiogram in the four-chamber view. The right ventricular dimension was taken as the maximum distance between the endocardium of the right ventricular free wall and the inter-ventricular septum at the level of the tips of the tricuspid valve leaflets, perpendicular to the long axis of the ventricle. The measurement was made at the onset of the $R$ wave of a simultaneously recorded electrocardiogram. This method was adopted as it was not possible to consistently delineate the anterior wall of the right ventricle on parasternal long axis echocardiograms, due to the close proximity of the anterior right ventricular free wall to the transducer, which rendered a large portion of the right ventricular cavity undefinable. The average of three measurements was taken, and measurements were corrected to the nearest $0.5 \mathrm{~mm}$. All measurements were made by a single echocardiographer, either at the time of the initial assessment or from recorded videotape images. The motion of the inter-ventricular septum during the cardiac cycle was assessed in short axis scans, and was considered abnormal if it remained flattened or consistently bulged towards the left ventricle in diastole ${ }^{11}$ (figure 1).

From the subcostal scan position, with right ward angulation the inferior caval vein was imaged in both its long and short axis. By image guided M-mode echocardiography, both the widest diameter of this vessel during expiration and the smallest diameter during forced inspiration were measured. Measurements were taken during diastole before the $P$ wave of the electrocardiogram, in the infra-diaphragmatic portion of the vein just below its junction with the hepatic veins. A collapse index was then derived, defined as the change in diameter during respiration expressed as a percentage of the maximum diameter in expiration ${ }^{2,1 .}$. Studies both in normal subjects and in patients with elevated right atrial pressure have shown that the normal collapse index is $>40 \%$, while a collapse index of $<40 \%$ correlated with a mean right atrial pressure of $>8 \mathrm{~mm} \mathrm{Hg}^{12,13}$.

Figure I (opposite page). Parasternal short axis scan of a patient with acute pumonary embolism. The image in systole shows an enlarged right wentricle (located left superior). The interventricular septum is concave to the left ventricular cavity (localed right inferior). In diastole the septum flattens as result of increased right ventricular diastolic pressure. 


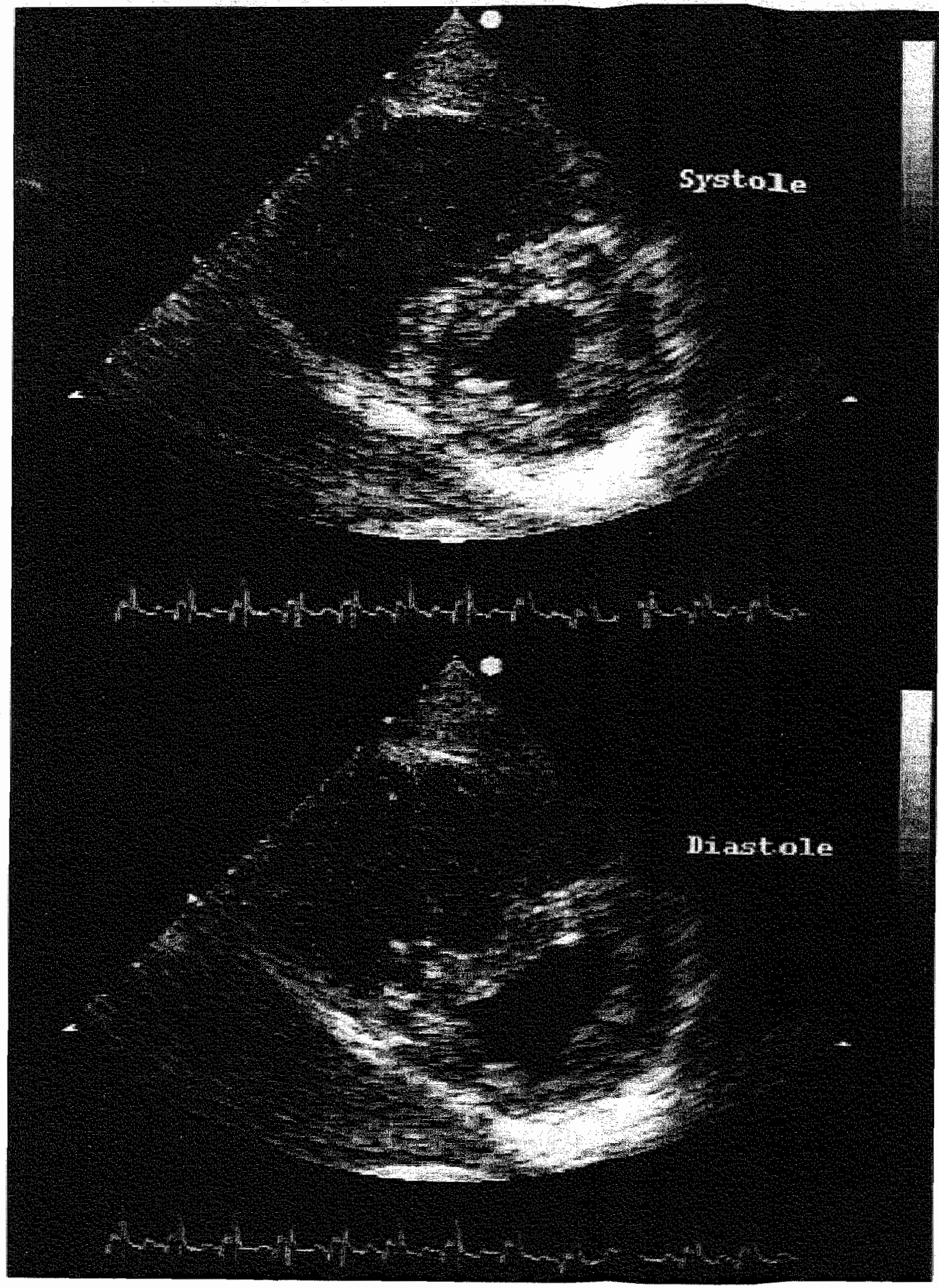


Finally, in all cases two-dimensional image guided continuous wave Doppler echocardiography was performed from the subcostal, apical or parasternal positions, to detect the presence of tricuspid valve regurgitation and to accurately measure the peak systolic velocity of the regurgitant jet. The peak instantaneous trans-valvular systolic gradient was then derived using the modified Bernoulli equation ${ }^{10}$. In selected cases, tricuspid regurgitation was graded from the color Doppler flow image in the apical or parasternal four-chamber view into one of four grades of increasing severity, based on the extension of the regurgitant jet into the right atrium and its density ${ }^{14.15}$.

\section{Corroborative investigations}

\section{A) Ventilation-perfusion scan}

In 36 patients, a standard ventilation-perfusion scan was performed. Perfusion studies were performed with intravenous injection of Techritium $99 \mathrm{~m}\left({ }^{99 \mathrm{~m}} \mathrm{Tc}\right.$ ) labelled macroaggregated albumin, using multiple projections, and ventilation studies using inhaled xenon ${ }^{13}$. Scans were interpreted using accepted criteria and were classified as showing a high, intermediate or low probability for pulmonary embolism ${ }^{16}$, or were classified as normal. Briefly, intermediate and high probability scans showed sub-segmental or segmental perfusion defects with normal ventilation (ventilation-perfusion mismatch), while low probability scans showed perfusion defects with a matching ventilation defect.

\section{B) Pulmonary arterial angiography}

Main or selective branch pulmonary arterial angiography using a non-ionic contrast agent with digital subtraction techniques was performed in 19 patients. Angiograms were considered positive for pulmonary emboli if there were unequivocal filling defects or cutoffs in the pulmonary arteries. The angiographic severity of embolism was graded according to the number of lung segments that showed filling defects and the degree of reduction in blood How ${ }^{1 ?}$.

\section{Results}

\section{Echocardiography}

In acutely ill patients lying in the supine position, the subcostal approach was particularly valuable not only in evaluation of caval vein diameters, but also in assessing right ventricular function and tricuspid valve regurgitation.

\section{Tricuspid valve regurgitation.}

Systolic pressure overload of the right ventricle was evident from the peak velocity of tricuspid regurgitation. This exceeded $3 \mathrm{~m} / \mathrm{sec}$ (calculated peak instantaneous gradient across the tricuspid valve of $36 \mathrm{~mm} \mathrm{Hg}$ ) in 52 patients. In four others, the peak velocities of tricuspid valve regurgitation were $2.7 \mathrm{~m} / \mathrm{sec}$ ( 2 patients), and $2.8 \mathrm{~m} / \mathrm{sec}$ ( 2 patients) respectively, but all had grade 3 ( 3 patients) or grade 4 ( 1 patient) regurgitation by color Doppler flow imaging (Table 1). Only four patients had no evidence of tricuspid valve 
regurgitation, of whom three had asystole and were undergoing resuscitation at the time of echocardiographic examination. Overall therefore, Doppler echocardiography provided a good index of acute pressure overload of the right ventricle in 56 of 57 patients $(99 \%)$ with a spontaneous rhythm.

Collapse index of the inferior caval vein.

The collapse index of the inferior caval vein was $<40 \%$ in 46 patients $(77 \%)$ in the acute stage. This finding was present in all four patients in whom the measured peak velocity of tricuspid regurgitation was $<3 \mathrm{~m} / \mathrm{sec}$ (Table 1 ).

Right rentricular dimensions and function.

In 56 patients $(93 \%$ ) the right ventricular end-diastolic diameter exceeded the upper limit of normal for the adult population ${ }^{818}$, and ranged from 28 to $60 \mathrm{~mm}$ (Table 1). Diastolic dysfunction of the right ventricle was evident in 56 patients $(93 \%)$. This was characterized by diastolic bulging of the inter-ventricular septum towards the left ventricle in the fourchamber view, suggesting a increased diastolic pressure gradient across the ventricular septum $^{19}$.

\section{Intracardiac or vascular thrombi.}

Intracardiac or vascular thrombi were visualized in 9 patients: in the right atrium alone 6 patients), a right atrial thrombus extending into the left atrium via a patent oval foramen ( 1 patient), right atrium and ventricle ( 1 patient), right atrium and pulmonary arteries ( 1 patient). Of three patients with a visible intra-cardiac thrombus in whom trans-esophageal echocardiography was performed, thrombi were detected in both branch pulmonary arteries in one case.

\section{Ventilation-perfusion scan and angiography}

An intermediate (1) or high probability of pulmonary embolus was estimated from the ventilation-perfusion scan in 32 of the 36 patients who underwent the procedure. The remaining four patients had a low probability scan. In two of the four cases confirmation of an embolus was obtained at angiography, and in one case at autopsy. In one patient who died in hospital no autopsy was performed.

Confirmation of an embolus was obtained by pumonary arterial angiography in all 18 cases where this was performed. The angiographic grade of severity ${ }^{17}$ ranged from a score of 10 to 22 (median 15) out of a potential maximum score of 34 , and did not correspond with the right ventricular end-diastolic diameter or the degree of elevation of pulmonary artery pressure as assessed by Doppler echocardiography, presumably as these investigations were performed non-simultaneously, under differing hemodynamic states. 
Chapter 5

Table f: Echocardiographic data and other corroborative investigations in the patients studied

\begin{tabular}{|c|c|c|c|c|c|c|c|}
\hline No & $\begin{array}{l}\text { Tricuspid } \\
\text { reguirgitation } \\
\text { velocily }(\mathrm{m} / \mathrm{s})\end{array}$ & $\begin{array}{l}\text { RNEDD } \\
\text { (mm) }\end{array}$ & PV dystundion & $\mathrm{VCl}<40 \%$ & Thrombus & V/Q $\operatorname{scan}$ & $\begin{array}{l}\text { Angio- } \\
\text { graphy }\end{array}$ \\
\hline 1 & none & 44 & yes & no & RA & yes & no \\
\hline 2 & 4.2 & 42 & yes & yes & $\therefore$ & yes & no \\
\hline $3+$ & 3.4 & 33 & yes & yes & - & no & yes \\
\hline 4 & 4.1 & 35 & yes & yes & - & yes & no \\
\hline 5 & 3.5 & 37 & yes & yes & $=$ & yes & no \\
\hline 6 & 3.5 & 39.5 & yes & yes & - & yes & yes \\
\hline 7 & 3.0 & 40.5 & yes & no & . & yes & no \\
\hline 8 & 4.0 & 37 & yes & yes & - & yes & no \\
\hline 9 & 3.9 & 40 & yes & yes & . & yes (low probability) & no \\
\hline 10 & 3.7 & 39.5 & yes & no & . & no & yes \\
\hline 11 & 4.0 & 45 & yes & yes & - & yes. & no \\
\hline 12 & 3.2 & 34 & yes & yes. & $=$ & yes & no \\
\hline 13 & 2.80 & 31 & yes & yes. & - & no & yes \\
\hline 14 & 3.0 & 46 & yes & yes & - & yes & no \\
\hline 15 & 3.0 & 36 & yes & yes & - & no & yes \\
\hline 16 & 3.8 & 45 & yes & no & - & yes & no \\
\hline 17 & 3.8 & 51 & yes & yes & - & no & yes. \\
\hline 18 & 3.3 & 37.5 & yes & no & - & yes & yes \\
\hline 19 & 2.80 & 29 & yes & yes & - & yes & yes \\
\hline 20 & 4.0 & 36 & yes & yes & - & yes & no \\
\hline 21 & 3.0 & 44.5 & yes & yes & - & no & yes \\
\hline 22 & 4.3 & 35 & yes & yes & - & yes. & yes \\
\hline 23 & 3.2 & 52.5 & yes & yes & . & yes & yes \\
\hline 24 & 3.1 & 60 & yes & yes & - & no & yes \\
\hline 25 & 3.0 & 36.5 & yes & yes & - & ves & no \\
\hline 26 & 3.3 & 33 & yes & yes & - & yes & no \\
\hline 27 & 3.1 & 30 & yes & yes & - & no & yes \\
\hline 28 & 3.2 & 34 & yes & yes & - & yes (low probabilitity) & yes \\
\hline 29 & 3.2 & 36.5 & yes & yes & - & yes (low probability) & yes \\
\hline 30 & 3.8 & 33 & yes & yes & & yes (low probability) & no \\
\hline $31 \star$ & 3.8 & 33.5 & yes & yes & RALA & yes (intermediate) & no \\
\hline 32 & 4.3 & 34.5 & yes & yes & - & yes & no \\
\hline 33 & $3 . \pi$ & 35 & yes. & no & - & yes & no \\
\hline 34 & 3.1 & 31.5 & yes & yes & - & wes & no \\
\hline 35 & 3.0 & 39 & yes & yes & - & yes & no \\
\hline 36 & 3.2 & 30 & yes & no & - & yes & 910 \\
\hline 37 & 3.0 & 53.5 & yes & yes & - & yes & no \\
\hline 38 & 3.2 & 26.5 & yes & no & - & yes & yes \\
\hline 39 & 3.3 & 38.5 & yes & yes & - & yes & no \\
\hline 40 & 3.0 & 43 & yes & yes & $\mathrm{RA}$ & no & yes \\
\hline 41 & 4.0 & 54 & yes & yes & - & yes & yes \\
\hline 42 & 3.7 & 39.5 & yes & yes & - & yes & no \\
\hline 43 & 3.2 & 44 & yes & yes & - & yes & no \\
\hline 44 & 3.5 & 40 & yes & no & - & no & yes \\
\hline 45 & 32 & 44 & yes & yes & - & yes & no \\
\hline 46 & 3.5 & 51 & yes. & yes & & yes. & no \\
\hline
\end{tabular}

$R A=$ right atrium; $R V E D D=$ RV end-diastolic diameter (a normal $R V E D D$ is $<27 \mathrm{~mm}$ ); $V \mathrm{~V}=$ collapse index of inferior vena cava; $V / Q=V / Q$-scan. (1) grade 3 or 4 regurgitation on color flow imaging. * Muttiple emboli at necropsyi + Surgery. 
Doppler echocardiography as initial technique

Table 2. Echocardiographic findings and outcome in patients whout corroboratwe investigations for pulmonary embolus.

\begin{tabular}{|c|c|c|c|c|c|c|c|}
\hline Wo & $\begin{array}{l}\text { Tricuspid } \\
\text { regurgitation } \\
\text { welocity }(\mathrm{m} / \mathrm{s})\end{array}$ & $\begin{array}{l}\text { RVEDD } \\
\text { (mm) }\end{array}$ & $\begin{array}{l}\text { RV } \\
\text { dysfundtion }\end{array}$ & $V O<<40 \%$ & Thrombus & Outcone & Necropsy \\
\hline $\begin{array}{l}47 \\
48 \\
49 \\
50 \\
51 \\
52 \\
53 \\
54 \\
55 \\
56 \\
57 \\
58 \\
59 \\
60\end{array}$ & $\begin{array}{l}2.70 \\
3.3 \\
3.0 \\
3.5 \\
3.0 \\
\text { asystole } \\
3.0 \\
2.70 \\
5.0 \\
\text { asystolle } \\
\text { asystole } \\
3.0 \\
3.2 \\
3.0\end{array}$ & $\begin{array}{l}38 \\
47.5 \\
49.5 \\
28 \\
48 \\
- \\
50 \\
42.5 \\
49 \\
- \\
43.5 \\
34.5 \\
39\end{array}$ & $\begin{array}{l}\text { yes } \\
\text { yes } \\
\text { yes } \\
\text { yes } \\
\text { yes } \\
\text { yes } \\
\text { no } \\
\text { yes } \\
"- \\
\text { yes } \\
\text { yes } \\
\text { yes }\end{array}$ & $\begin{array}{l}\text { yes } \\
\text { yes } \\
\text { yes } \\
\text { no } \\
\text { yes } \\
\text { yes } \\
\text { no } \\
\text { yes } \\
- \\
- \\
\text { yes } \\
\text { yes } \\
\text { yes }\end{array}$ & $\begin{array}{l}\text { no } \\
\text { no } \\
\text { no } \\
\text { no } \\
\text { no } \\
\text { RA } \\
\text { no } \\
\text { no } \\
\text { RA/LPN/RPA } \\
\text { RA } \\
\text { RA } \\
\text { RA } \\
\text { no } \\
\text { RA }\end{array}$ & $\begin{array}{l}\text { died } \\
\text { died } \\
\text { died } \\
\text { died } \\
\text { died } \\
\text { died } \\
\text { died } \\
\text { alive } \\
\text { alive } \\
\text { died } \\
\text { died } \\
\text { died } \\
\text { alive } \\
\text { died }\end{array}$ & $\begin{array}{l}\text { no } \\
\text { no } \\
\text { yes; multiple embiol } \\
\text { no } \\
\text { yes; multiple embol } \\
\text { no } \\
\text { yes; multiple embol } \\
- \\
\text { no } \\
\text { yes; no lung ernboli } \\
\text { no } \\
- \\
\text { yes; multiple embol }\end{array}$ \\
\hline
\end{tabular}

Abbreviations for Table 2: $\angle P A=$ left pulmonary artery; RPA=right pumonary artery. Other abbreviations as for Table t.

\section{Patients without corroborative investigations}

In 14 remaining patients, treatment was undertaken on the basis of the clinical and echocardiographic features alone (Table 2). In six cases, including three patients who had asystole and required cardiopulmonary resuscitation, intra-cardiac thrombi in the right atrium, ventricle or pulmonary arteries were visualized. One of these six patients recovered following surgery or thrombolytic therapy, while five died. Autopsy was performed in two cases and demonstrated multiple lung emboli in one. The second patient, who developed acute cardiorespiratory collapse associated with asystole three days following surgery for an abdominal aortic aneurysm, was noted at echocardiography (performed during a failed attempt at resuscitation) to have a large right atrial thrombus. At autopsy the presence of a right atrial thrombus was confirmed. No emboli were found in the pulmonary arterial tree. However, there was evidence of a fresh, extensive left ventricular infarction and this was concluded to be the cause of death.

Six of the eight patients in whom no thrombi were seen died despite therapy. Autopsy studies were performed in only three cases, and multiple lung emboli were demonstrated in all.

\section{Follow-up echocardiography}

Twenty five patients have undergone at least one echocardiographic examination more than 0.5 months after the initial study (range $0.5-60$ months). Of these, 19 patients ( $76 \%$ ) have shown improvement in their abnormal echocardiographic indices (Table 3). The earliest parameter to normalize was the collapse index of the inferior caval vein (normal in all 19 patients). Reduction of the peak velocity or grade of tricuspid valve regurgitation was the 
next index to show improvement (no regurgitation detected in 5 patients, reduced velocity or grade of regurgitation in 12 patients). Right ventricular end-diastolic dimension and interventricular septal motion became normal in 13 patients; in six others the right ventricular dimensions diminished, but all had persistent abnormalities of septal motion.

Table 3. Follow up echocardiography (patient numbers as tor previous Tables).

\begin{tabular}{|c|c|c|c|c|c|c|}
\hline Mo & $\begin{array}{l}\text { Interval } \\
\text { (monthy) }\end{array}$ & $\begin{array}{l}\text { Tricuspid } \\
\text { regurgitation } \\
\text { velocity (m/s) }\end{array}$ & $\begin{array}{l}\text { RVEDD } \\
(m m)\end{array}$ & $\begin{array}{l}\text { RV } \\
\text { dyshifuntion }\end{array}$ & $\begin{array}{l}\text { VI< } \\
40 \%\end{array}$ & Comment \\
\hline 1 & 0.6 & none & 33.5 & no & no & \\
\hline 4 & 4 & 2.8 & normal & no & no & \\
\hline 6 & 0.3 & 2.3 & normal & no & no & \\
\hline 7 & 9 & none & normali & no & no & \\
\hline 10 & 7 & 2.5 & normal & no & no & \\
\hline$\| 1$ & 36 & 3.3 & 39 & no & no & dilated $\mathrm{RV}$, but improved function \\
\hline 12 & 60 & 2.0 & normal & no & no & \\
\hline 13 & 45 & 2.3 & normal & no & no & diminished grade of TR \\
\hline 14 & 1 & none & normat & no & no & \\
\hline 17 & 13 & 3.6 & 49.5 & yes & yes & no change from first echocardiagram \\
\hline 18 & 17 & none & normal & no & no & \\
\hline 19 & 2.5 & 3.00 & 29 & yes & yes & no change \\
\hline 20 & 0.5 & 3.0 & 33 & yes. & no & partial improvement in RV function \\
\hline 22 & 48 & 3.2 & 31.5 & yes. & na & partial improvement in RV function \\
\hline 25 & 15 & 3.3 & 38 & yes & yes & no change from first echocardiogran \\
\hline 28 & 5 & 3.2 & 34.5 & yes & yes & no change from first echocardiogram \\
\hline 29 & 2 & - none & normal & no & no & \\
\hline 32 & 0.5 & 2.9 & normal & no & no & \\
\hline 35 & 12 & none & mormal & no & no & \\
\hline 36 & 0.5 & 3.0 & 29.5 & yes & no & partial improvement in RV function \\
\hline 39 & 2 & 3.1 & 42 & yes & no & partial improvement \\
\hline 40 & 21 & 3.2 & & yes & yes & $\begin{array}{l}\text { no change from first echocardiogram; } \\
\text { extensive } L V \text { wall motion defects }\end{array}$ \\
\hline 41 & 5 & 2.8 & normal & no & no & \\
\hline 42 & 0.5 & 3.0 & normal & no & no & severe persistent pulmonary hypertension \\
\hline 55 & 26 & 4.6 & 46.5 & yes & yes & \\
\hline
\end{tabular}

Abbreviations: TR=tricuspid regurgitation; "normal" IVVED refers to a right ventricular end-diastofic diameter of $<27 \mathrm{~mm}$. Other abbreviations as for previous Tables.

Six patients showed no change in any of the measured parameters of right ventricular function (follow-up interval 2.5 - 26 months).

\section{Discussion}

The outcome for patients with major emboli depends on the rapidity with which the correct diagnosis is established and appropriate therapeutic measures undertaken. While a number of risk factors for pulmonary embolism have been recognized, the clinical syndromes associated with embolism are varied, and mimic other illnesses. While most emboli originate from thrombi in the venous system of the lower limbs, deep vein thrombosis is often clinically silent. The diagnosis of puimonary embolism has evolved from the use of 
techniques to identify the presence of deep venous thrombosis in the lower limbs to demonstration of areas of the lung fields that are not perfused but are ventilated (ventilationperfusion scan), and finally to directly confirm the presence and extent of vascular occlusion by selective pulmonary arterial angiography.

The ventilation-perfusion scan has an important error rate when compared with angiography. In a correlative study, Marsh et al ${ }^{5}$ demonstrated pulmonary emboli by angiography in $33 \%$ of patients with a low probability scan. Conversely, $55 \%$ of patients with a high probability scan had no emboli. A more recent study of the diagnostic value of ventilation-perfusion scans also confirmed that high probability scans have a low sensitivity for diagnosing pulmonary emboli ${ }^{20}$. Angiography, while very sensitive for embolism is an expensive, invasive investigation that carries a small but definite risk of serious complications. Unless better indices for suspicion of pulmonary embolism are established, pulmonary angiography may be unnecessarily performed in some patients ${ }^{6,7}$.

\section{Echocardiography}

The widespread availability of high resolution two-dimensional echocardiography has allowed the use of this technique for direct visualization of thrombi in the right side of the circulation, and the exclusion of structural cardiac defects or a cardiomyopathy. While the diagnostic hallmark of embolism by echocardiography is the direct visualization of thrombi in the pulmonary arteries, this is possible by surface echocardiography in only a small proportion of patients. Only 9 patients in this series showed evidence of thrombi in the right side of the circulation, and in one case this was probably secondary to an extensive myocardial infarction and ventricular standstill. Trans-esophageal echocardiography has improved the detection of central pulmonary arterial emboli ${ }^{21}$. Peripheral emboli will however be missed, and in patients in an unstable hemodynamic state the procedure may be safely performed only following endotracheal intubation and mechanical ventilation. Acute right ventricular dilatation and dysfunction could however be easilly recognized by measurement of the right ventricular end-diastolic diameter and qualitative assessment of the motion of the inter-ventricular septum in diastole, and served as indirect indices of embolism. In a study of patients with proven emboli Kasper et al ${ }^{\mathbb{N}}$ demonstrated right ventricular and pulmonary arterial dilatation, and leftward shift of the inter-ventricular septum in diastole. Paradoxical septal bulging in diastole occurs as a consequence of both right ventricular dilatation and simultaneous reduction in left ventricular preload due to pulmonary embolism, resulting in a decrease of the left to right ventricular diastolic pressure gradient ${ }^{19}$. Paradoxical bulging of the inter-ventricular septum may be a usefis sign even in patients wi asystole undergoing resuscitation, as in the unloaded non-beating heart the septum normal" Jccupies a central position between the two ventricles ${ }^{22}$. Clinical improvement coinc $s$ with a decrease in the mean systolic pulmonary arterial pressure and restoration of the normal configuration of the inter-ventricular septum ". Using continuous wave Doppler ultrasound, estimation of the right ventricular systolic pressure from the peak velocity of tricuspid regurgitation has been extensively validated ${ }^{10}$. The systolic pulmonary artery pressure may thus be calculated, even without taking into account the mean right atrial pressure ${ }^{23}$. Tricuspid regurgitation was a frequent accompaniment of acute pulmonary embollism, 
occurring in $99 \%$ of patients with effective right ventricular contraction. Cardiac cathentization data suggest that the mean pulmonary arterial pressure correlates with the angiographic severity of embolism ${ }^{24}$. Although the mean pressure can be derived from the Doppler velocity profile, the peak velocity alone served as a sensitive indicator of raised pulmonary arterial pressure. The finding of an elevated right ventricular systolic pressure in combination with dilatation of the right ventricle may also distinguish pulmonary embolism from right ventricular infarction, in which the peak velocity of tricuspid regurgitation may be expected to be low. There appeared to be no relation between the peak systolic pressure and the clinical outcome. Alterations in the peak velocity or grade of tricuspid regurgitation however accompanied improvements in other parameters of right ventricular function.

It has been suggested that in patients with pulmonary embolism, a more specific sign of decreased right ventricular reserve may be an elevation of the filling pressure ${ }^{25}$. Changes in the mean right atrial pressure were studied by calculation of the collapse index of the inferior caval vein. The diameter of the inferior caval vein changes with alterations in central venous pressure or volume. Additional changes occur during the respiratory cycle, reflecting alterations in intra-thoracic pressure and consequently venous return to the lungs. Acute obstruction to the pulmonary circulation, and the concomitant reduction in right ventricular compliance, limits the normal augmentation of venous return with inspiration and may therefore be expected to blunt this variation in caval diameter with respiration. A reduction of the collapse index to $<40 \%$ has been shown to correlate strongly with a mean right atrial pressure of $>8 \mathrm{mmHg}^{12,3}$. At follow-up, this index was the first to normalize. This early normalization may be related in part to dissolution of thrombi following therapy.

An important finding at follow-up was the persistence of right ventricular dysfunction and elevated pulmonary arterial pressures in some patients, suggesting that not all lung emboli resolve despite early and appropriate therapy, and a small proportion of patients develop chronic thromboembolic pulmonary hypertension. Such patients may develop parenchymal scarring resulting in a clinical picture of restrictive lung disease ${ }^{26}$.

In all cases structurat left heart lesions could be excluded. Even in patients with a previous history of ischemic heart disease and impaired regional left ventricular function (5 patients), or cardiomyopathy ( 1 patient), a high probability of acute pulmonary embolism could be established using the combination of echocardiographic parameters described.

\section{Limitations}

In the absence of visible thrombi in the pulmonary circulation, patients with chronic lung disease may demonstrate similar echocardiographic abnormalities of right ventricular function. Although patients with longstanding pulmonary hypertension may have an increased right ventricular free wall thickness ${ }^{27}$, this cannot often be accurately measured by echocardiography. In such cases only the clinical history and duration of symptoms may allow the distinction to be made. Additionally, when patients with known pulmonary disease present with signs or symptoms of pulmonary embolism, echocardiography may not be helpful. Another drawback of the study was that not all survivors had serial follow-up echocardiography. It was not possible from the limited follow-up data to determine the time 
course for resolution of right atrial and pulmonary arterial hypertension, or the restoration of normal right ventricular diameter and function. Finally, autopsy studies could not be obtained in all patients who died in hospital and in whom additional confirmatory tests for pulmonary embolism were not performed.

\section{Conclusions}

Our observations support the use of two-dimensional Doppler echocardiography as an initial investigative tool in patients suspected to have a pulmonary embolus. The described indices can be measured with ease, enabling either appropriate confirmatory investigations to be performed, or, in patients with severe hemodynamic instability, thrombolytic therapy to be undertaken without delay. 


\section{References}

1. McNeil BJ. Ventilation-perfusion studies and the diagnosis of pulmonary embolism: concise communication. INucl Med 1980;21:3 19-323.

2. Cheely $R$, McCartney WH, Perry JR, Delany DJ, Bustad L, Wynia VH, Griggs TR. The role of noninvasive tests versus pulmonary angiography in the diagnosis of pulmonary embolism. Am J Med 1981;70:17-22.

3. Hull RD, Hirsh J, Carter CI, Raskab GE, Gill GJ, Jay RM, Leclerc JR, David M, Coates G. Diagnostic value of ventilation-perfusion lung scanning in patients with suspected pulmonary embolism. Chest 1985;88:819-828.

4. Braun SD, Newman GE, Ford K, Miller GA, Coleman RE, Dunnick NR. Ventilation-perfusion scanning and pulmonary angiography: Correlation in clinical high-probability pulmonary embolism. Am J Roentgenol 1984; 143:977-980.

5. Marsh JD, Glynn M, Torman H.A. Pulmonary angiography. Application in a new spectrum of patients. Am J Med 1983;75:763-770.

6. Robin ED. Overdiagnosis and overtreatment of pulmonary embolism: The emperor may have no clothes. Ann Intern Med 1977;87:775-781.

7. Menzoian JO, Williams LF. Is pulmonary angiography essential for the diagnosis of acute pulmonary embolism? A.m J Surg 1979;137:543-548.

8. Kasper W, Meinertz $T$, Henkel B, Eisner D, Haahn $K$, Hofmann T, Zeiher A, Just $H$. Echocardiographic findings in patients with proven pulmonary embolism. Am Heart I $1986 ; 112: 1284-1290$.

9. Weill $\mathrm{F}$, Maurat $\mathrm{P}$. The sign of the vena cava: echotomographic illustration of right cardiac insufficiency. J Clin Ultrasound 1974;2:27-32.

10. Yock PG, Popp RL. Noninvasive estimation of right ventricular systolic pressure by Doppler ultrasound in patients with tricuspid regurgitation. Circulation 1984;70:657-662.

11. Jardin F, Dubourg $O$, Gueret $P$, Delorme $G$, Bourdarias J-P. Quantitative two-dimensional echocardiography in massive pulmonary embolism: emphasis on ventricular interdependence and leftward septal displacement. J Am Coll Cardiol 1987;10:1201-1206.

12. Cheriex EC, Leunissen KML. Janssen JHA. MoOy JMV, Van Hooff JP. Echography of the inferior vena cava is a simple and reliable tool for the estimation of dry weight in hemodialysis patients. Nephrol Dial Transpi 1989;4:563-568.

13. Moreno FLL, Hagan AD, Holmen JR, Pryor TA, Strickland RD, Castle CH. Evaluation of size and dynamics of the inferior vena cava as an index of right-sided cardiac function. Am $J$ Cardiol 1984;53:579-585.

14. Omoto R. Real-time intracardiac blood flow imaging with color coded two-dimensional Doppler technique: clinical significance of 2-D Doppler. Kokyu to Junkan 1984;32:217-225.

15. Cheriex EC, Lambregts $\mathrm{H}$, Pieters $\mathrm{F}$, Brugada $\mathrm{P}$. Is tricuspid regurgitation underestimated as a clinical problem in valvular heart disease? In: Erbel R, ed. Transesophageal Echocardiography. Berlin: Springer-Verlag, 1989:77-88.

16. Goldhaber SZ, Braunwald E. Pulmonary embolism. In Braunwald E, ed. Heart Disease. Philadelphia: W.B.Saunders Company. 1992:1558-1580.

17. Miller GAH, Sutton GC, Kerr IH, Gibson RV, Honey M. Comparison of streptokinase and heparin in treatment of isolated acute massive pulmonary embolism. Br Med J 1971;2;681-684

18. Feigenbaum H. Echocardiographic measurements and normal values. In: Feigenbaum $H$, ed. Echocardiography. Philadelphia: Lea \& Febiger, 1986:622. 
19. Guzman PA, Maughan WL, Yin FCP, Eaton LW, Brinker JA, Weisfeldt ML, Weiss IL Transseptal pressure gradient with lefward septal displacement during the Mueller maneuve: in man. Br Heart J 1981;46:657-662.

20. The PIOPED Investigators: Value of the ventilation/perfusion scan in acute pulmonary embolism: Results of the prospective investigation of pulmonary embolism diagnosi: (PIOPED). JAMA 1990;263:2753-2759.

21. Wittlich $N_{3}$ Erbel R, Eichler A, Schuster S, Jakob H, Iversen S, Oelert H, Meyer J Detection: of central pulmonary artery thromboemboli by transesophageal echocardiography in patient: with severe pulmonary embolism. I Am Soc Echo 1992;5;515-524.

22. Lima JAC, Guzman PA, Yin FCP, Brawley RK, Humphrey L, Traill TA, Lima SD, Marino P Weisfeld ML, Weiss JL. Septal geometry in the unloaded living human heart. Circulation $1986 ; 74: 463-468$.

23. Berger M, Haimowitz A, Van Tosh A, Berdoff RL, Goldberg E. Quantitative assessment of pulmonary hypertension in patients with tricuspid regurgitation using continuous wave Doppler ultrasound. I Am Coll Cardiol 1985;6:359-365.

24. Miller GAM, Sutton GC. Acute massive pulmonary embolism. Clinical and haemodymamic findings in 23 patients studied by cardiac catheterization and pulmonary angiography. $\mathrm{Br}$ Heart J 1970;342:518-523.

25. McIntyre KM, Sasahara AA. The hemodynamic response to pulmonary embolism in patients without prior cardiopulmonary disease. Am J Cardiol 1971;28:288-294.

26. Morris TA, Ysrael MZ, Olson LK, Auger WR, Fedullo PF, Moser KM. The restrictive spirometric defect in patients with chronic pulmonary thrombo-embolic pulmonary hypertension. Chest 1992;102:1205(abstr).

27. Come PC. Echocardiographic recognition of pulmonary arterial disease and determination of its cause. Am J Med 1988;84:384-394. 



\title{
Chapter 6
}

\section{The value of the 12 lead electrocardiogram at hospital admission in the diagnosis of pulmonary embolism.}

\author{
Narayanswami Sreeram, Emile C. Cheriex, Joep L.R.M. Smeers, Anton P. M. Gorgels, \\ Heint J.J. Wellens.
}

(Published in Am J Cardiol 1994;73:298-303)

\section{Introduction}

The prevalence of electrocardiographic (ECG) changes associated with proven pulmonary embolism has received little attention in recent years ${ }^{1-4}$. As many of the described changes are transient, the value of serial 12 lead ECG's following hospital admission is unknown. Additionally, the frequency of ECG abnormalities associated with acute right ventricular volume or pressure overload, as manifested in the ECG at hospital admission is not well documented. In order to address these questions, the ECG's recorded at hospital admission, and where relevant, serial ECG's following admission were retrospectively evaluated in a consecutive series of patients with proven embolism.

\section{Patients and methods}

In 49 consecutive patients ( 27 male, 22 female; age range $44-86$ years) with proven pulmonary embolism, the 12 lead ECG recorded at hospital admission was retrospectively evaluated by three independent observers in a blinded fashion. The presenting features were acute dyspnea, chest pain, palpitations, or cardiovascular collapse requiring resuscitation. The duration of symptoms was $<3$ hours $(\mathrm{N}=7), 3-24$ hours $(\mathrm{N}=6), 25-72$ hours $(\mathrm{N}=9), 73$ hours -7 days $(\mathrm{N}=3)$, and $>7$ days $(\mathrm{N}=24)$. None of the patients had a previously documented history of chronic lung disease, while five patients had had a previous history of ischemic heart disease, with anterior wall myocardial infarction in two cases. After the recognition of right ventricular pressure or volume overload on echocardiography, pulmonary embolism was confirmed by standard ventilation-perfusion scans $(\mathrm{N}=29)$ or pulmonary arterial angiography $(\mathrm{N}=17)$, within 24 hours of the initial ECG. Confirmation was also obtained at surgery $(\mathrm{N}=3)$ or autopsy $(\mathrm{N}=7$; including six patients in whom autopsy was the only definitive diagnostic test).

None of the investigators was aware of the previous clinical history or hemody namic status of any of the patients. The $49 \mathrm{ECG}$ 's were reported together with 170 other ECG's from patients with various disorders, which had been recorded over a 24 hour period from patients attending the hospital. Additionally, the ECG's of 10 consecutive patients who had been admitted over the preceding 12 months with an acute exacerbation of chronic obstructive pulmonary disease, and in whom a ventilation-perfusion scan for pulmonary embolism was negative, were also blindly evaluated by the same observers. None of the investigators was therefore aware of the number of ECG's which were obtained from patients with proven 
pumonary embolism. A positive ECG diagnosis of pulmonary embolism was accepted if at least two of the three observers reported an individual ECG as being consistent with the diagnosis. For patients in whom at least two observers reported the admission ECG as being non-diagnostic, serial ECG's obtained during the same hospital admission were evaluated by the same obserwers in a non-blinded fashion, to see if this would improve the detection rate for embolism.

Right ventricular pressure and volume overload were assessed by two-dimensional Doppler echocardiography, which was performed as the initial diagnostic investigation following the ECG. The right ventricular end-diastolic diameter was measured at the onset of the $R$ wave of a simultaneously recorded ECG from the four chamber view. The maximum distance between the endocardium of the right ventricular free wall and the inter-ventricular septum, perpendicular to the long axis of the ventricle, was taken. This method was adopted as it was not possible consistently to delineate the anterior wall of the right ventricle in the parasternal long axis echocardiogram. The values from three consecutive cardiac cycles were averaged, and corrected to the nearest $0.5 \mathrm{~mm}$.

Two-dimensional image guided continuous wave Doppler echocardiography was also performed from the subcostal, apical or parasternal positions to detect tricuspid valve regurgitation. From the peak velocity of the regurgitant jet, the peak trans-valvular systolic gradient was calculated using the modified Bernoulli equation ${ }^{5}$. To take into account possible underestimation of the right ventricular systolic pressure by this method, an indirect estimation of the mean right atrial pressure was obtained by calculating the collapse index of the inferior caval vein ${ }^{5}$. From the subcostal scan position, the diameter of the inferior caval vein was measured by $M$-mode imaging, both in peak inspiration and expiration, just before the onset of the $P$ wave of the ECG. Previous studies have shown that a collapse index (change in diameter with respiration expressed as a percentage of the maximum diameter during expuration) of $<40 \%$ correlates well with a mean right atrial pressure of $>8 \mathrm{mmHg}$. In cases where the collapse index was $<40 \%$, an additional $10 \mathrm{~mm}$ was added to the peak right ventricular systolic pressure obtained from the peak velocity of tricuspid regurgitation. For patients with a collapse index in excess of $40 \%$, no correction was made for possibly elevated right atrial pressures.

The presence and degree of ECG abnormalities was correlated with the right ventricular enddiastolic diameter and the calculated right ventricular systolic pressure.

\section{Results}

From the admission ECG, pulmonary embolism as the primary diagnosis was made in 37 patients $(76 \%)$, based on the presence of at least three of the signs described below. This included four of the five patients with associated ischemic heart disease. In the 12 patients in whom the electrocardiographic diagnosis was negative, evaluation of serial ECG's resulted in a positive diagnosis of embolism in three additional cases. Overall, the 12 lead $\mathrm{ECG}$ was therefore suggestive of pulmonary embolism in $40 / 49$ patients (82\%). The abnormal ECG lindings at admission, and their frequency, are described below. 


\section{Electrocardiographic abnormalities}

\section{Right bundle branch block.}

Complete $(\mathrm{N}=7)$ or incomplete $(\mathrm{N}=26)$ right bundle branch block was observed in 33 patients $(69 \%)^{8}$. This was associated with ST segment elevation of $>1 \mathrm{~mm}$ in the same lead $(\mathrm{N}=17)$ and an upright $\mathrm{T}$ wave $(\mathrm{N}=3)$. In six patients, a $Q S$ complex of $>100 \mathrm{~m}$ duration was observed in $\mathrm{V}_{1}$ (figure 1-3).

\section{S wave in leads I and a VI.}

A deep $S$ wave of $>1.5 \mathrm{~mm}$, or an $R: S$ ratio of $<1$ in leads $I$ and a VL was observed in 36 patients $(73 \%)$

\section{Clockwise rotation.}

Clockwise rotation of the heart in the horizontal axis, defined as a shift in the transition zone to $\mathrm{V}_{5}$ or beyond, was recorded in 25 patients $(51 \%)$. Lead $V_{5}$ was chosen as the cutoff, in order to compensate for minor alterations in the positioning of the precordial leads between patients.

\section{4. $Q$ waves in the inferior leads.}

A Q wave was seen in leads III and aVF in 24 patients $(49 \%)$. Significantly, none of the patients had a $Q$ wave in lead II.

\section{Frontal plane QRS axis.}

Right axis deviation, defined as a frontal plane QRS axis of $>90^{\circ}$ occurred in 16 patients (33 $\%)$. An indeterminate axis was present in 15 patients $(31 \%)$. In contrast, left axis deviation of less than $-30^{\circ}$ occurred in only one patient.

6. Low voltage QRS complexes in the limb leads.

A low voltage QRS complex of $<5 \mathrm{~mm}$ in all the limb leads was seen in 10 patients ( $20 \%$ ) (figure 1).

\section{Twave inversion.}

Negative $T$ waves occurred in leads III and aVF (16 patients; $33 \%)$, or in leads $V$, to $V_{4}(13$ patients; $27 \%$. These changes were more commonly observed in patients with a longer clinical history. Thus $12 / 16$ patients with $T$ wave inversion in leads 111 and aVF, and $9 / 13$ patients with $\mathrm{T}$ wave inversion in leads $\mathrm{V}_{1}$ to $\mathrm{V}_{4}$ had had symptoms of over seven days" duration (figure 2).

\section{Atrial arrhythmias.}

Atrial arthythmias were relatively common at admission ( 11 patients; $22 \%$, and included atrial fibrillation ( 9 patients) or frequent atrial premature beats ( 2 patients).

\section{Right atrial hypertrophy.}

Right atrial enlargement or hypertrophy, defined as a $P$ wave in lead $V$, of $>2.5 \mathrm{~mm}$, occurred in only four patients $(8 \%)$. 


\section{Echocardiography.}

The right ventricular end-diastolic diameter was increased $(>27 \mathrm{~mm}$ ) in all 49 patients 9.10. The man diameter was $40.1 \mathrm{~mm}$ (SD \pm 7.14 ), and ranged from 28 to $60 \mathrm{~mm}$. Tricuspid wave regurgtation was detectable in all cases at admission. The right ventricular systolic pressure, calculated from the peak velocity of tricuspid regurgitation and the collapse index of the inferior caval vein, was elevated in all cases, and ranged from 33 to $84 \mathrm{mmHg}$ (mean $54.9+12.7 \mathrm{~mm} \mathrm{Hg})$

\section{Statistical methods.}

All echocardiographic vallues are expressed as mean \pm SD. Comparisons between groups were made using an unpaired Student's t test, and a value of $<0.05$ was accepted as significant.

\section{Electrocardiographic versus echocardiographic findings.}

There was no significant difference in the right ventricular end-diastolic diameter between patients with abnormal electrocardiographic signs and those with normal ECG's $(41.1 \pm 7.2$ $\mathrm{mm}$ versus $36.8 \pm 6.3 \mathrm{~mm} ; \mathrm{p}>0.05)$. Similarly, there was no significant difference in the peak systolic pressure of the right ventricle between patients with and without $\mathrm{ECG}$ abnormalities $(55.0 \pm 13.3 \mathrm{mmHg}$ versus $53.8 \pm 9.8 \mathrm{mmHg} ; \mathrm{p}>0.05)$.

Patients with abnormal ECG's at admission $(\mathrm{N}=37)$ were further subdivided into three groups based on the number of the described abnormalities that were observed, as follows: (A) 7 or more abnormal signs $(N=7)$; (B) 5-6 abnormal signs ( $N=22$ ); (C) 3-4 abnormal signs $(\mathrm{N}=8)$. Comparisons between each of these subgroups, or between individual subgroups and the 12 patients with normal ECG's revealed no significant differences either in the right ventricular end-diastolic diameter or peak right ventricular systolic pressure (Table I).

Table t: Relation between electrocandiographic (ECG) changes and echocardiographic measurements of right ventricular end diastolic diameter and peak systolic pressure.

\begin{tabular}{|l|c|c|c|}
\hline ECG changes & No & RVEDO mm & RV peak systolic pressure mmHg \\
\hline $7+$ abnormalities & 7 & $38.8( \pm 3.7)$ & $57.3( \pm 15.3)$ \\
\hline $5-6$ abnormalities & 22 & $41.1( \pm 8.1)$ & $55.5( \pm 12.6)$ \\
\hline $3-4$ abnormalities & 8 & $43.0( \pm 6.9)$ & $56.1( \pm 14.8)$ \\
\hline Normal ECG & 12 & $36.8( \pm 6.3)$ & $53.8( \pm 9.8)$ \\
\hline
\end{tabular}

No significant differences were obsened for either RVEDD or peak RV systolic pressure between any of the groups. Abbreviations: $A V=r i g h t$ ventricle; RVEDD=right ventricular end-diastolic diameter. Values were expressed as mean ( \pm SD) 
The 12 lead electrocardiogram at hospital admission
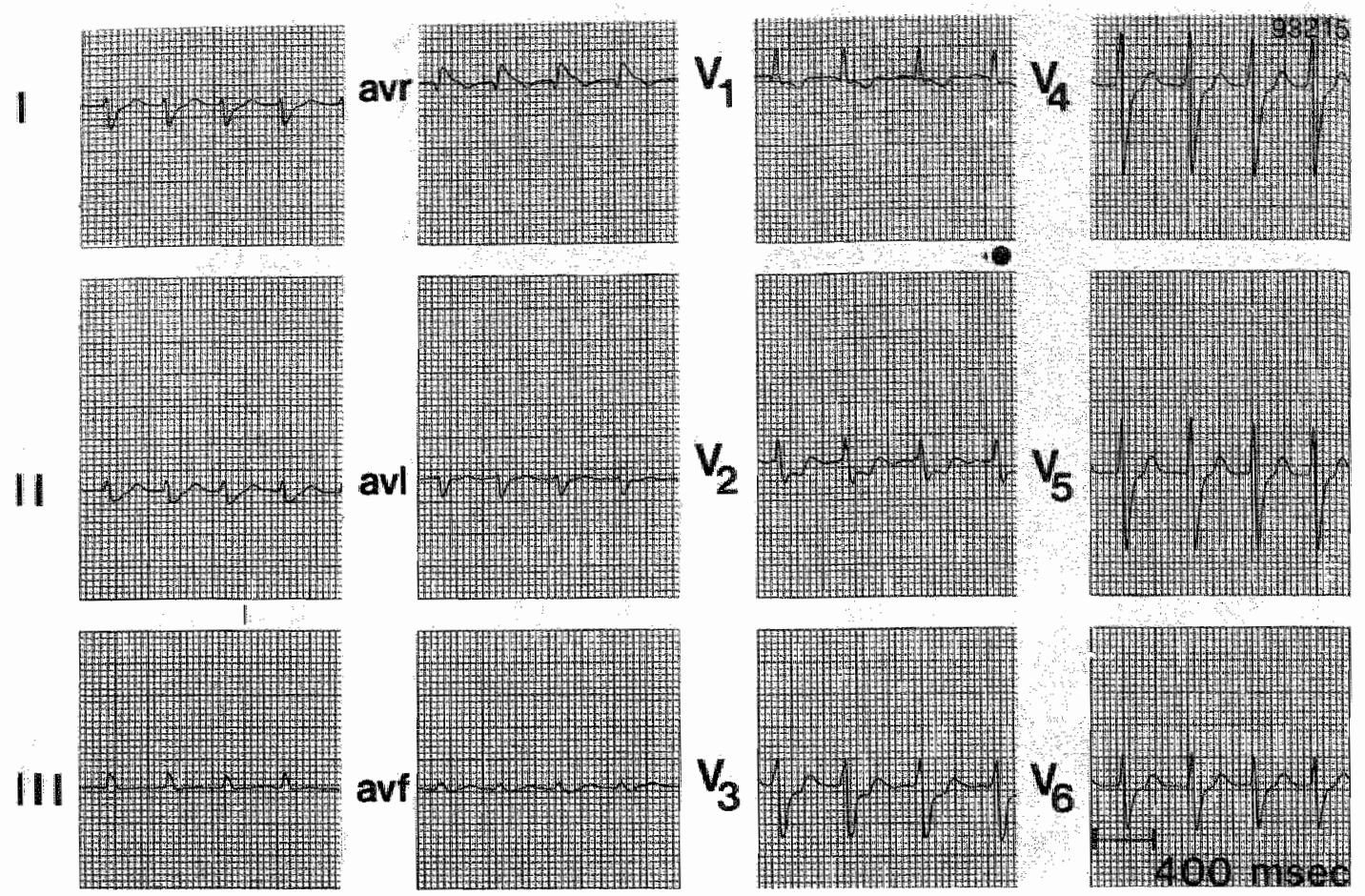

Figure 1: Electrocardiogram of a patient with massive pulmonary embolism showing: (1) atrial fibrillation, (2) low-voltage in the limb leads, (3) right axis deviation, (4) leftward shift of the transition zone, and (5) right sided conduction delay.

\section{Electrocardiograms in patients with chronic lung disease, and without embolism.}

Using the criteria for diagnosis of pulmonary embolism described above, and based on the occurrence of at least three of the listed abnormalities, a positive diagnosis of embolism was considered in $8 / 10$ patients. Apart from these cases, there were only one false positive diagnosis of embolism by two of the three observers among the other 170 ECG's reported.

\section{Discussion}

\section{Historical background}

The initial description of electrocardiographic abnormalities associated with pulmonary embolism by McGinn and White consisted of the presence of a Q wave in lead III with late inversion of the $\mathrm{T}$ wave, and an $\mathrm{S}$ wave in lead I (SIQ3T3) in seven patients. Transient right bundle branch block, clockwise rotation with a shift of the transitional zone to the left, and $T$ wave inversion in the precordial leads facing the right ventricle were observed in rapid succession as being associated with acute cor pulmonale ${ }^{11-13}$. With the increased accuracy of diagnosis of pulmonary embolism by invasive means (ventilation-perfusion scan or 


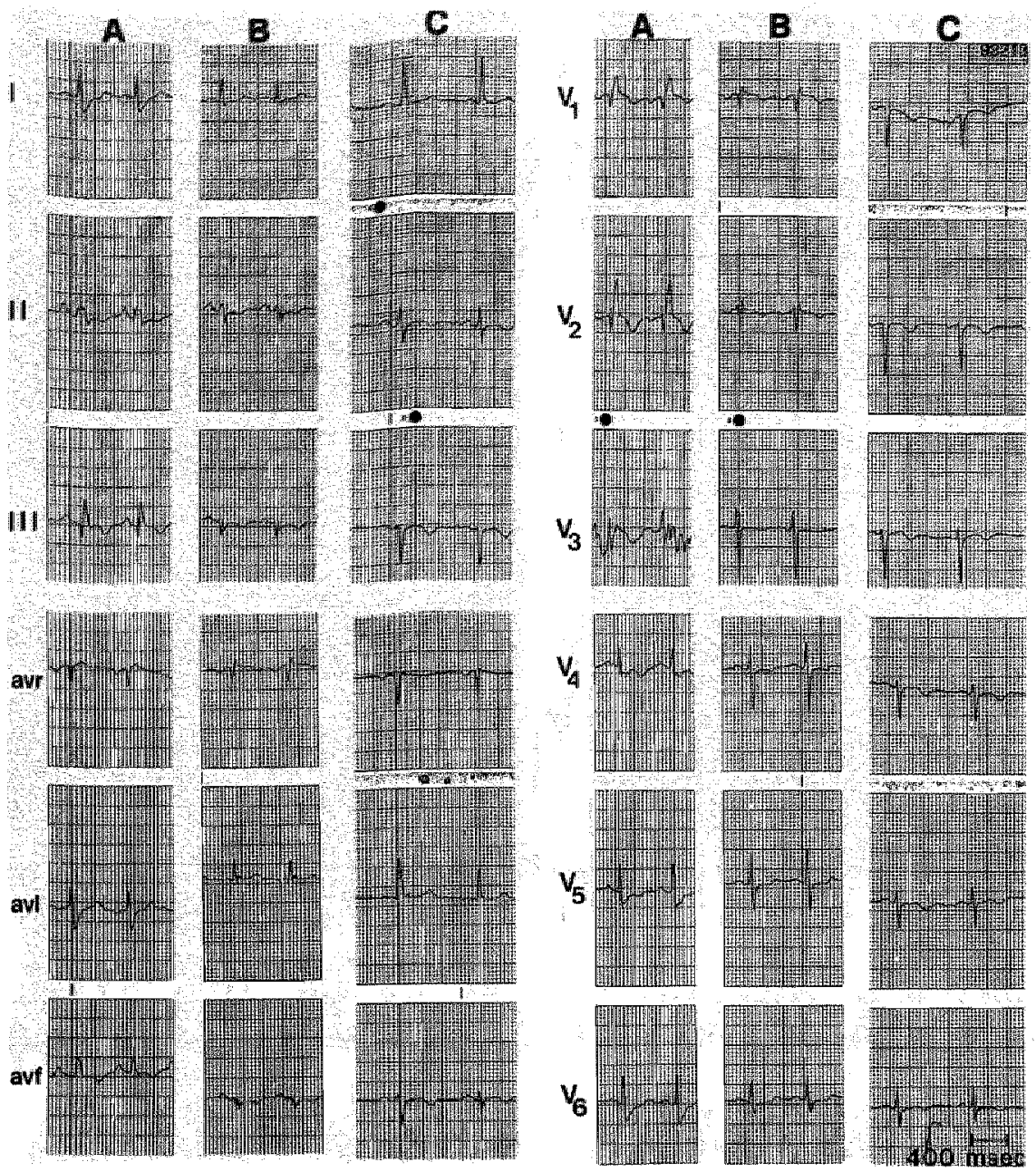

Figure 2: Electrocardiogram from a patient treated with thrombolytic therapy. A shows the electrocardiogram during the acute phase with sinus tachycardia, right atrial dilatation, $5 \mathrm{in}, \mathrm{Q}$ in $/ 1 / \mathrm{l}$ and complete right bundle branch block. The electrocardiogram $B$ was recorded 24 hours later and shows a decrease in $P_{\text {-wave woltage, }}$ rotation of frontal plane axis back to a horizontal position, and incomplete right bundle branch block. C shows the electrocardiogram after 10 days, with development of negative $T$ waves up to $V_{6^{*}}$ The right bundle branch block has resolved.

pulmonary arterial angiography) the importance of the ECG as a diagnostic tool for pulmonary embolism diminished. It was also evident that preexisting cardiopulmonary disease could mimic several of the described abnormalities associated with embolism, thereby reducing the specificity of the ECG.

There are few large scale studies of the prevalence of ECG changes associated with pulmonary embolism in patients without prior cardiopulmonary disease ${ }^{2-4}$. In a study of 20 such patients by McIntyre et al, only one patient was thought to have the diagnostic ECG 
changes of right ventricular strain, while three others had nonspecific changes in the ECG which were suggestive of the diagnosis ${ }^{3}$. A further study by Stein et all. of 90 participants in the Urokinase Pulmonary Embolism Trial without preexisting cardiac or pulmonary disorders suggested that while ECG abnormalities were common in patients with angiographically proven emboli, the commonest abnormalities were those of the RST segment and the T wave (41. \% and $42 \%$ respectively $)^{4}$.

There was also no significant difference in the incidence of these abnormalities between patients with massive versus sub-massive embolism. The presence of ECG abnormalities appeared to be related to the severity of embolization, and also to the degree of elevation of the mean pulmonary arterial pressure and the right ventricular end-diastolic pressure. However, it was not related to the partial pressure of oxygen in the systemic arterial blood, to right ventricular work, or to the total pulmonary resistance.

\section{The present study}

In the present study, acute abnormalities were observed more commonly in the QRS complex. Additionally, with the occurrence of at least three of the described abnormalities, a diagnosis of pulmonary embolism could be considered in $76 \%$ of patients based on the admission ECG alone. One reason for the high prevalence of ECG abnormalities in this series may have been the presence of a high peak right ventricular systolic pressure in all 49 patients. In this respect, the study group differs from those reported in the literature, where usually a wide variation in peak pulmonary arterial pressure was found. The presence of ECG abnormalities was however not related to patient's hemodynamic status, and the clinical presentation ranged from dyspnea of over seven days' duration in hemodynamically stable patients to acute cardiovascular collapse. T wave inversion was more commonly observed
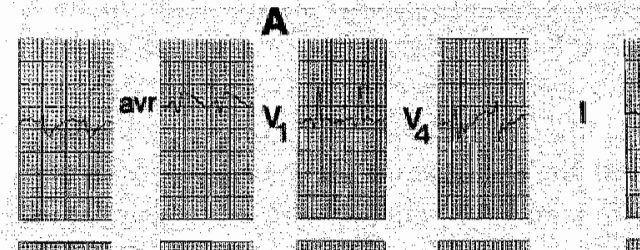

B
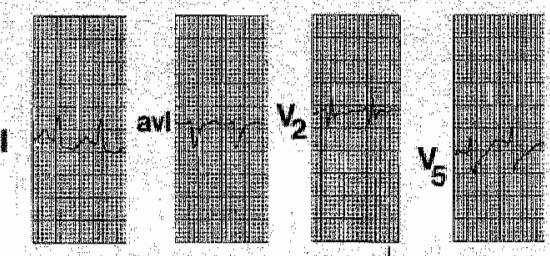

111
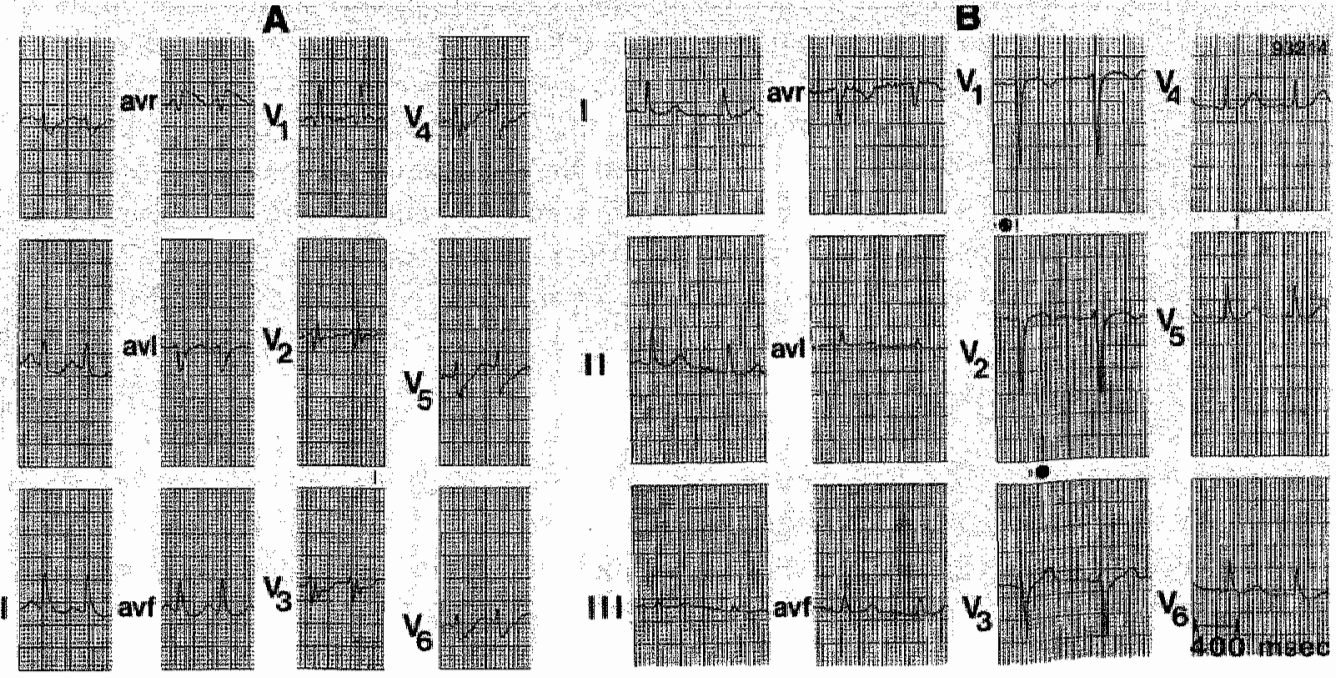

Figure 3: Electrocardiogram in pulmonary embolism. A demonstrates sinus tachycardia, right axis deviation and right bundle branch block. $B$ shows the electrocardiogram after successful treatment, with return of the axis to normal in frontal and horizontal planes. 
un patients with a longer clinical history, suggesting that these may represent the subacute stage of embolism. Additional ECG features included low voltage QRS complexes in the limb leads, a feature which has only been described in one previous report ${ }^{4}$. In contrast to previous reports, a rightward QRS axis was commonly observed, and left axis deviation occurred in only one patient with proven embolus ${ }^{4.14}$. A new finding was the occurrence of an indeterminate frontal plane axis, presumably related to right ventricular dilatation. Atrial arrhythmias were common, in contrast to previous reports which suggest that such arthythmias occur more commonly in association with coexisting ischemic heart disease ${ }^{15}$. Acute changes in right atrial pressure or size accompanying embolization were however poorly reflected by the ECG, and ECG criteria for right atrial enlargement were uncommon.

\section{Association between ECG and echocardiographic measurements}

There was a poor association between echocardiographic parameters of acute right ventricular volume or pressure overload, and the presence or magnitude of ECG abnormalities. The ability of the right ventricle to adapt to acute changes in afterload is not well understood. In experimental studies, visible right ventricular dilatation preceded the changes observed in the ECG ${ }^{16}$, and it may well be that the echocardiogram is a more sensitive indicator of acute changes in right ventricular size and pressure.

\section{Patients with preexisting lung disease or ischemic heart disease}

As expected, the poor specificity of the ECG in patients with preexisting lung disease was clearly demonstrated. The differentiation of acute embolism from myocardial infarction may also be difficult. The presence of right bundle branch block with ST segment elevation or a positive $\mathrm{T}$ wave in lead $\mathrm{V}$, may be an expression of either anteroseptal infarction complicated by right bundle branch block, or a reciprocal expression in patients with a true posterior infarction ${ }^{17,18}$. Clockwise rotation may result in a QS complex in lead $\mathrm{V}_{1}$ (recorded in six patients in this series), reflecting an intra-cavitary complex recorded over a dilated right atrium, which may be mistaken for an anteroseptal infarction ". Serial ECG's may be useful in the differentiation, in such cases. On the other hand, while $Q$ waves were commonly observed in leads III and aVF, they did not occur in lead II in patients with embolism. In the four patients with ischemic heart disease in this series (and previous infarction in two cases), the ECG appeared to be a satisfactory technique for the differentiation of embolus from a further ischemic insult.

\section{Role of serial ECG's}

Finally, the use of serial ECG's in patients with an initially negative ECG did not appear to significantly improve the diagnostic ability of the electrocardiogram ( 3 of 12 patients). This may be related in part to the widely varying duration of reported symptoms in the group of patients studied. 


\section{Conclusion}

Despite echocardiographic evidence of acute right ventricular pressure and volume overload, $26 \%$ of ECG's from patients with proven emboli are normal at admission to hospital, and $18 \%$ remain normal over the duration of hospital stay. An elevated right ventricular enddiastolic diameter and peak systolic pressure appear to have a variable electrocardiographic expression, both in terms of the presence of, and the number of ECG abnormalities. Given sufficient attention to the described criteria, the standard 12 lead ECG at admission to hospital appears to demonstrate abnormalities consistent with a diagnosis of pulmonary embolism in the majority of patients without previously documented chronic lung disease. 


\section{References}

1. McGinn S, White PD. Acute cor pulmonale resulting from pulmonary embolism. JAMA $1935 ; 104: 1473-1480$.

2. Cutforth RH, Oram S. The electrocardiogram in pulmonary embolism. Br Heart J 1958;20:4154.

3. Mclntyre KM, Sasahara AA, Littman D. Relation of the electrocardiogram to hemodynamic alterations in pulmonary embolism. Am J Cardiol 1972;30:205-210.

4. Stein PD, Dalen JE, McIntyre KM, Sasahara A, Wenger NK, Willis PW. The electrocardiogram in acute pulmonary embolism. Prog Cardiovasc Dis 1.975;17:247-257.

5. Yock PG, Popp RL. Noninvasive determination of right ventricular systolic pressure by Doppler ultrasound in patients with tricuspid regurgitation. Circulation 1984;70:657-662.

6. Moreno FLL, Hagan AD, Holmen JR, Pryor TA, Strickland RD, Castle CH. Evaluation of size and dynamics of the inferior vena cava as an index of right-sided cardiac function. Am J Cardiol $1984 ; 53: 579-585$.

7. Cheriex EC, Leunissen KML, Janssen JHA, Mooy JMV, Van Hooff JP. Echography of the inferior vena cava is a simple and reliable tool for the estimation of dry weight in hemodialysis patients. Nephrol Dial Transpl 1989;4:563-568.

8. Willems $\mathrm{JL}$, Robles de Medina E, Bernard R, Coumel P, Fisch C, Krikler D, Mazur NA, Meijler FL, Mogensen L, Moret P, Pisa Z, Rautaharju PM, Surawicz B, Watanabe Y, Wellens HJJ. Criteria for intraventricular conduction disturbances and pre-excitation. J Am Coll Cardiol $1985 ; 5: 1261-1275$.

9. Kasper W, Meinertz T, Henkel B et al. Echocardiographic findings in patients with proven pulmonary embolism. Am Heart J 1986;1 12:1284-1290.

10. Feigenbaum $H$. Echocardiographic measurements and normal values. In: Feigenbaum $H$, ed. Echocardiography. Philadelphia: Lea and Febiger, 1986:622.

11. Durant TM, Ginsberg IW, Roesler $H$. Transient bundle branch block and other electrocardiographic changes in pulmonary embolism. Am Heart J 1939;17:423-430.

12. Wood P. Pulmonary embolism: diagnosis by chest lead electrocardiography. Br Heart J $1941 ; 3: 21-29$.

13. Wilson FN, Rosenbaum FF, Johnston FD. Interpretation of the ventricular complex of the electrocardiogram. Adv Intern Med 1947;2:1-63.

14. Lynch RE, Stein PD, Bruce TA. Leftward shift of frontal plane QRS axis as a frequent manifestation of acute pulmonary embolism. Chest 1972;61:443-446.

15. Dalen JE. Diagnosis of acute pulmonary embolism. In: Dalen JE, ed. Pulmonary embolism. New York: Medcom, 1,972:28-39.

16. Lowe WS, Brugler GW, Winslow N. Electrocardiographic studies in clinical and experimental pulmonary embolization. Ann Intern Med 1938;11:2109-2123.

17. Wellens HJJ. ECG recognition of acute pulmonary embolism. In: Wellens HJJ, Conover MB, eds. The ECG in emergency decision making. Philadelphia: WB Saunders Company, 1992:129138.

18. Brugada P, Gorgels AP, Wellens HJJ. The electrocardiogram in pulmonary embolism. In: Wellens HJJ, Kulbertus HE, eds. What's new in electrocardiography. The Hague: Martinus Nijhoff, 1981:366-380. 


\title{
Chapter 7
}

\section{When is echocardiographically detected right ventricular pressure overload suggestive for pulmonary embolism?}

\author{
Emile C. Cheriex, Yvonne F.J.M. Eussen, Andrea Palmans-Meulemans, \\ Willem R.M. Dassen, Hein J.J. Wellens.
}

\section{Introduction}

The diagnosis and management of pulmonary embolism is a recurrent topic in the medical literature. Interestingly the different medical specialties look differently at this problem. Depending upon the circumstances the patient is seen by the general practitioner, the internist, lung specialist, cardiologist, gynaecologist and surgeon, who perform different diagnostic tests to document their suspicion of pulmonary embolism. In general the internist and lung specialist favor the use of the ventilation perfusion scan in combination with ultrasound for detection of deep venous thrombosis, the cardiologist starts with the electrocardiogram and in some centers, the echocardiogram followed by more direct visualization of the emboli. The surgeon probably favors phlebography or ultrasound of the leg-veins. Different specialties not only use different diagnostic tools, but require different other specialists to identify the cause of pulmonary embolism and to select the most appropriate treatment.

Because of the presenting complaints many patients with pulmonary embolism are seen by the cardiologist. Cardiology typically has developed into a specialty trained to make diagnosis without delay by using tests they can perform themselves. The cardiologist is used to work with ECG's, echocardiography, angiography and thrombolysis 24-hours a day and can monitor the effect of treatment in a well trained environment (CCU). In a disease where delay in treatment can play a catastrophic role, optimal management of pulmonary embolism can therefore be offered by the cardiological department.

In two recent publications we addressed the role of electrocardiography and echocardiography as initial diagnostic tools in patients with pulmonary embolism ${ }^{1.2}$. Both publications dealt with the subgroup of patients with echocardiographically proven right sided pressure overload not related to a left sided cardiac cause. A problem in making the correct diagnosis is the exclusion of right sided pressure elevation by preexistent pulmonary vascular disease. To evaluate the accuracy of the echocardiogram to make the correct diagnosis we therefore retrospectively analyzed the echocardiographic findings in all patients with right sided pressure overload in the absence of a left sided cardiac cause. 


\section{Methods}

\section{Patient selection}

Since September 1986 all echocardiographic reports are stored in a database ${ }^{3}$. At the end of $1992,16.465$ patients and a total of 26.465 investigations, accumulated in this database, were available for analysis. When, after 1986, new insights appeared on the value of certain echocardiographic findings they were scored prospectively in the database. From 1990 we used the diagnosis "pulmonary embolism suspected" or "pulmonary embolism to be excluded (inappropriate high pressure at the right heart)". Before 1990 we only scored right ventricular pressures above $36 \mathrm{mmHg}$ as a separate code. Patients with the combination of this last code and RV dilatation, abnormal septal motion and no left sided explanation for these right sided abnormalities were retrospectively encoded as "pulmonary embolism suspected". All patients with an other cause for right sided dilation were excluded like right ventricular infarction, right ventricular volume overload (atrial septal defect of any size/type, patent ductus arteriosus), pulmonary stenosis, right ventricular dysplasia and congenital abnormalities as Ebstein's disease. Also echocardiograms with elevated right sided pressures in patients with LV dysfunction diagnosed only on the basis of a high E/A ratio in the pulsed Doppler tracings of the mitral-inflow (supposed to indicate elevated LV end-diastolic pressures) were not included. Lung vein flow was not studied and reported.

\section{Echocardiographic examination and subgroup selection}

All echocardiograms were analyzed according to the recommendations of the American Society of Echocardiography ${ }^{4,5}$. In evaluating right sided pressures the measurement of the velocity of the tricuspid regurgitation (TR) is essential. We chose not to perform any angle correction in our measurements to prevent possible overestimation of pressure drops. In our laboratory the chest is carefully screened for maximal acoustic windows and maximal velocities. The subcostal approach is often very helpful in finding TR. More detailed information concerning our echocardiographic evaluation in patient with pulmonary embolism is described elsewhere ${ }^{2}$.

The echocardiograms in this study were subdivided in 4 groups:

I. Echocardiograms with RV-dilatation and a tricuspid incompetence velocity of more or equal to $2.7 \mathrm{~m} / \mathrm{s}$, indicating a pressure drop between RV and RA of equall or more than $30 \mathrm{mmHg}$ in the absence of any left sided reason for pressure elevation (LVdysfunction or valvular dysfunction). In this subgroup the behavior of the inferior caval vein was used as an index of elevated mean right atrial pressure. An inferior caval vein (IVC) collapse of less than or equal to $40 \%$ was considered as a mean right atrial pressure (MRAP) of more than or equal to $8 \mathrm{mmHg}^{6}$. For practical purposes 10 mmHg was added to the pressure difference between RV and RA as was calculated using tricuspid regurgitation (TR) velocity measured with continuous Doppler. Patients having a thrombus in RA/RV were included in this group, only if TR velocity was $2.7 \mathrm{~m} / \mathrm{s}$ or more.

II. Echocardiograms with TR velocity of equal to or more than $2.7 \mathrm{~m} / \mathrm{s}$ with an appropriately collapsing IVC, indicating normal MRAP. In these cases no $\mathrm{mmHg}$ 
were added to the calculated RV-RA pressure drop.

III. Patients were the amount of LV dysfunction or valvular regurgitation of the left sided heart valves was not supposed to be the reason for the elevated right sided pressures. In some cases a statement was made "cannot exclude a pulmonary component or pulmonary embolism as cause for this inappropriately high right sided pressure". "The echocardiograms with these statements were not excluded from our study, because we were interested in the clinical follow up.

IV. Patients showing $\mathbb{R A} / \mathrm{RV}$ thrombus without proof for elevated right sided pressures. These patients usually were patients without cardiac output, during resuscitation, or patients with a floating thrombus with a TR with velocities less than $2.7 \mathrm{~m} / \mathrm{s}$.

\section{Clinical data}

For practical purposes we decided to evaluate only patients already admitted to hospital or patients admitted after the echocardiographic investigation. A total of 100 patients could be analyzed. Only the first echocardiographic examination with signs of right sided pressure overload was used for the study.

The hospital file was reviewed for:

1. Historical data (previous history, intoxications, current thistory)

2. Findings on physical examination.

3. Electrocardiographic findings. By reviewing all ECG's during the total hospital stay we tried to get insight in the sequential changes on the electrocardiograms. If a patient died before a follow up ECG was recorded, we also used (when available) an earlier electrocardiogram, which could be expected to be representative for the situation before the complaints that prompted the echocardiographic examination. The electrocardiographic abnormalities specifically analyzed are described elsewhere!. In short: A scoring system was used giving points to (1) an (in)complete RBBB with or without ST-segment elevation in $\mathrm{V}_{\text {, }}$ or aVR (which was scored as an additional point). (2) $\mathrm{S}$ in I and aVL of $\geq 1.5 \mathrm{~mm}$. (3) $\mathrm{Q}$ in III and aVF without a $\mathrm{Q}$ in II. (4) R/S $<1$ to lead $V_{5}$. (5) Right axis deviation. (6) A low voltage electrocardiogram in the limb leads and (7) the presence of negative T-waves in the precordial leads (particularly in $\mathrm{V}_{1}$ to $\left.\mathrm{V}_{3-4}\right)$. (8) A P-pulmonale was scored as last point. Atrial arrhythmias were not included in the scoring system.

In addition ECG's were placed in either a group showing serial changes (which we regard as a sign of a temporary right sided pressure elevation) and a group not showing changes in sequential electrocardiograms (an argument for a more chronic form of right sided pressure elevationy.

4. Laboratory values, particularly blood gas analysis. The blood gas analysis was done on admission without oxygen supply, after oxygen supply and, when possible, after discontinuation of oxygen. Arterial $\mathrm{CO}_{2}$ and $\mathrm{O}_{2}$ pressures are expressed in $\mathrm{KPa}(760$ mmHg $=1$ atmosphere $=100 \mathrm{kPa}, 1 \mathrm{kPa}=7.6 \mathrm{mmHg}, 1.32 \mathrm{kPa}=10 \mathrm{mmHg})$. Alveolar-Arterial oxygen gradient ( $A$-a gradient) was calculated (in $\mathrm{mmHg}$ ) : 150 $\left(1.25 \times \mathrm{pCO}_{2}\right)-\mathrm{pO}_{2}$.

5. The procedure or investigation responsible for the clinical "working" diagnosis. 
6. The procedures/investigations used to confirm or exclude the diagnosis "pulmonary embolism".

All the files were thereafter judged by two independent investigators to come to a "final diagnosis" and to determine whether the diagnosis was recognized by the attending physicians during hospital admission.

This final diagnosis was scored as follows:

A. Pulmonary embolism recognized clinically:

- Patient died before adequate treatment could be started.

- Patient hemodynamically unstable and surgically treated.

- Medical treatment with thrombolytics followed by heparin (7-14 days) with a (usually temporary) filter in the inferior caval vein.

- Treatment with thrombolytics followed by heparin (7-14 days).

- Treatment with heparin (7-14 days) and a temporary filter.

- Treatment with heparin alone (7-14 days).

B. Clinically not treated as pulmonary embolism, but as having a cor pulmonale on the basis of COPD, pneumonia, silicosis or emphysema:

- The diagnosis pulmonary embolism cannot be excluded and is retrospectively still possible.

- Small additional pulmonary embolism not excluded.

- COPD most likely reason for right sided pressure elevation.

C. Pumpfailure or COPD not supposed to be the reason for the markedly elevated right sided pressure in the presence of slight left ventricular dysfunction and/or left sided valvular dysfunction.

D. Pulmonary hypertension (idiopathic, HIV, interstitial fibrosis). Not primarily COPD and or emphysema.

E. Rest-group. Patients difficult to classify (for instance: resuscitation with floating thrombus in patient without any output or RV dilatation or patients in whom no attention was given to the echo-report).

If a patient was hemodynamically stable enough to undergo $V / Q$-scanning or angiography for diagnosis only a high probability $\mathrm{V} / \mathrm{Q}$-scan or a positive angiogram was accepted for a definitive diagnosis pulmonary embolism. Surgery and post-mortem examinations were also regarded as absolute proof.

\section{Statistical analysis}

The unpaired t-test was used to identify the significant differences between the subgroups. Analyzing the diagnostic accuracy of the $\mathrm{pCO}_{2}$, in combination with echocardiographically detected right ventricular pressure overload, for the presence of pulmonary embolism, sensitivity, specificity, positive and negative predictive accuracy were calculated for each step of $0.5 \mathrm{kPa}$ and presented graphically. 


\section{Results}

\section{Patient population}

50 male and 50 female patients were included in the study. The mean age was $71 \pm 10$ years (range 20-104 years). During admission or shortly after discharge 27 patients died (27\%). Five patients were only seen during a resuscitation attempt. Four of these patients died and one was successfully surgically treated. Ten patients had overt malignancy and ten patients were seen in the post-operative period.

Table 1: Classification of the study population as to echocardiographic parameters.

\begin{tabular}{|c|c|c|}
\hline \multicolumn{3}{|c|}{ Echocardiographic RV -pressure overload / suspicion of Pulmonary Embolism } \\
\hline Group 1 & $\begin{array}{l}\text { RV-dilatation No left sided explanation for RV-RA pressure difference exceeding } 30 \mathrm{~mm} H \mathrm{Hg} \\
\text { (TR } 22.7 \mathrm{~m} / \mathrm{s} \text { ). Inferior caval vein collapse } \leq 40 \% \\
\Rightarrow \text { with RA/RV thrombus (TTE) } \\
\Rightarrow \text { with RAVRV thrombus (TEE) } \\
\Rightarrow \text { during resuscitation attempt (no thrombus) } \\
\Rightarrow \text { TR severe and velocity dubious ( } 52.7 \mathrm{~m} / \mathrm{s} \text { ) but } / N C \text { mot collapsing (RVI?) } \\
\text { Total }\end{array}$ & $\begin{array}{l}56 \\
4 \\
2 \\
3 \\
1 \\
66\end{array}$ \\
\hline Group II & $\begin{array}{l}\text { RV-dilatation. No left sided explanation for RV-RA pressure difference exceeding } 30 \\
\mathrm{mmHg}(\mathrm{TR} \geq 2.7 \mathrm{~m} / \mathrm{s}) \text {. Inferior caval wein collapse }>40 \%\end{array}$ & 22 \\
\hline Group III & $\begin{array}{l}\text { Inappropriate RV-pressures in the presence of some LW-dysfiunction and/or left sided } \\
\text { valuular dysfunction. }\end{array}$ & 9 \\
\hline Group IV & $\begin{array}{l}\text { RA/LV thrombus without signis of pressure elevation or ." } \\
\Rightarrow \text { during resuscitation attempt } \quad \text { (TTE) } \\
\Rightarrow \text { during resuscitation attempt } \quad \text { (TEE) }\end{array}$ & $\begin{array}{l}1 \\
1 \\
1\end{array}$ \\
\hline & Total & 3 \\
\hline \multicolumn{2}{|c|}{ Total number of echocardiographic investigations } & 100 \\
\hline
\end{tabular}

Abbreviations: TE=Trans-Thoracic Echocardiogram, TEE=Trans-Esophageal Echocardiogram.

\section{Echocardiographic classification}

As described in the method section, the echocardiograms were divided in 4 subgroups. These subgroups are listed in table 1. In total 66 patients did not have a collapsing caval vein, indicating an elevated MRAP. A normal MRAP was present in 22 patients. In nine patients 
(six of group I and all group IV patients) a thrombus was detected in the right ventricle, right atrium or (one) in the pulmonary artery. In one patient the thrombus present in the right atrium protruded into the lef atrium through a patent foramen ovale (figure 1 ).

\section{Clinical data}

Although a careful search was undertaken to get all clinical data, complete information was not available in nine patients. Because our questions were related to our echocardiographic database we chose not to remove these nine patients from our study. Their findings will be shown separately.

Clinical findings are listed in table 2. The relation between the clinical subgroups and the echocardiographic subgroups are given in table 3.

Table 2: Clinical findings in the 100 patients (see text).

\begin{tabular}{|c|c|c|}
\hline \multicolumn{3}{|l|}{ Ginical findings in total population ( 100 patients) } \\
\hline Group A: Proven pulmonary embollism (50 patients) & $\begin{array}{l}\text { Died before treatment } \\
\text { Emergency Surgery } \\
\text { Thrombolysis + Filter } \\
\text { Thrombolysis } \\
\text { Heparin + Filter } \\
\text { Heparin }\end{array}$ & $\begin{array}{l}3 \\
4 \\
3 \\
11 \\
2 \\
27\end{array}$ \\
\hline Group B: Cor pulmonale not caused by pulmonary embolism (24 patients) & $\begin{array}{l}P E(?)+C O P D \\
C O P D+P E(?) \\
C O P D\end{array}$ & $\begin{array}{l}6 \\
6 \\
12\end{array}$ \\
\hline $\begin{array}{l}\text { Group C: No pulmonary/cardiac explanation for elevation of right sided pressures } \\
\text { in patients with minor left sided disease }\end{array}$ & & 6 \\
\hline Group D: Pulmonary Hypertension (AIDS, Idiopathic, Interstitial fibrosis) & & 5 \\
\hline Group E: Unexpected findings/difficult to classify & & 6 \\
\hline Insufficient dinical data & & 9 \\
\hline Total & & 100 \\
\hline
\end{tabular}

The positive diagnosis pulmonary embolism was made using scintigraphy (ventilationperfusion scanining (V/Q)) and/or selective pulmonary angiography. In five patients digital subtraction imaging was used.

\section{Findings on V/Q-scan and pulmonary angiography}

Group $A$ : In the 50 patients with the diagnosis pulmonary embolism a high probability V/Qscan was present in $27 / 32$ patients. Of the remaining 5 patients 1 had an intermediate and 4 a low probability scan. Angiography, including digital subtraction imaging, was positive for pulmonary embolism in $18 / 19$ cases. The digital subtraction images were conclusive in $4 / 5$ 
patients. The patient with a dubious digital image had a high probability $\mathrm{V}$ Q-scan and was accepted as having had pulmonary embolism. Three of 4 cases with low probability $\mathrm{V} / \mathrm{Q}$ scanning were additionally proven to have pulmonary embolism by angiography or postmortem examination (1). The fourth patient had a positive test for deep venous thrombosis.

Table 3." Relation between the dinical (table 2) and echocardiographic diagnosis (table 1).

\begin{tabular}{|c|c|c|c|c|}
\hline \multicolumn{5}{|c|}{ Relation between clinical and echocardliographic diagnosis } \\
\hline Clinical group & Echo group 1 & Echo group II & Echo group Ill & Echo group IN \\
\hline A. Proven pulmonary embolism & $39 / 50(78 \%)$ & $11 / 50(22 \%)$ & & \\
\hline B. Cor pulmonale (COPD) & $15 / 24(62.5 \%)$ & $7 / 24(29 \%)$ & $2 / 24(8.5 \%)$ & \\
\hline C. Some left sided disease & $1 / 6(17 \%)^{*}$ & & $5 / 6(8390)$ & \\
\hline D. Pulmonary Hypertension & $4 / 5(80 \%)$ & $1 / 5(20 \%)$ & & \\
\hline E. Oinically difficult to classify & $3 / 6(50 \%)$ & $1 / 6(17 \%)$ & & $2 / 6(33 \%)$ \\
\hline No dinical data & $4 / 9(45 \%)$ & $219(22 \%)$ & $2 / 9(22 \%)$ & $1 / 9(11 \%)$ \\
\hline
\end{tabular}

* This was a patient with keft inferior and right ventricular wall infarction 6 years earlier.

In 6 cases we did not perform any other investigations than the echocardiogram. Three patients died before further diagnostic tests could be performed. These patients had thrombi in the right heart and signs of pulmonary hypertension. Autopsy proved the presence of emboli in one patient. An other patient succumbed on the way to the operation theater. Postmortem investigations were not performed in two patients.

Of the three patients who did not die acutely one underwent emergency surgery and had also a deep venous thrombosis and was described as a case report elsewhere ". Two other patients (both having thrombi and pulmonary pressure elevation) were treated with thrombolytics or heparin but died early. Additional investigations were not thought to be necessary in one (end-stage ovarium carcinoma) and were not performed in the other (died 3 days after the acute episode from cerebral hemorrhage while on thrombolytic therapy).

In 27 patients investigations were performed to exclude the presence of deep venous thrombosis. In $48 \%$ deep venous thrombosis could not be detected. This investigation, however, was never used as first line diagnostic tool.

Group $B$ : In the patients in whom a diagnosis was made of cor pulmonale on the basis of chronic pulmonary disease (24 patients) the $\mathrm{V} / \mathrm{Q}-\mathrm{scan}$ in only one patient showed a high probability for pulmonary embolism. This diagnosis was not accepted by the lung specialist on clinical grounds and treatment was not installed. Angiography was not performed, because of severe contra-indications to anti-coagulation. The other ten V/Q-scans showed low probability $(8 / 10)$ or were normal $(2 / 10)$. Digital subtraction imaging was performed in 


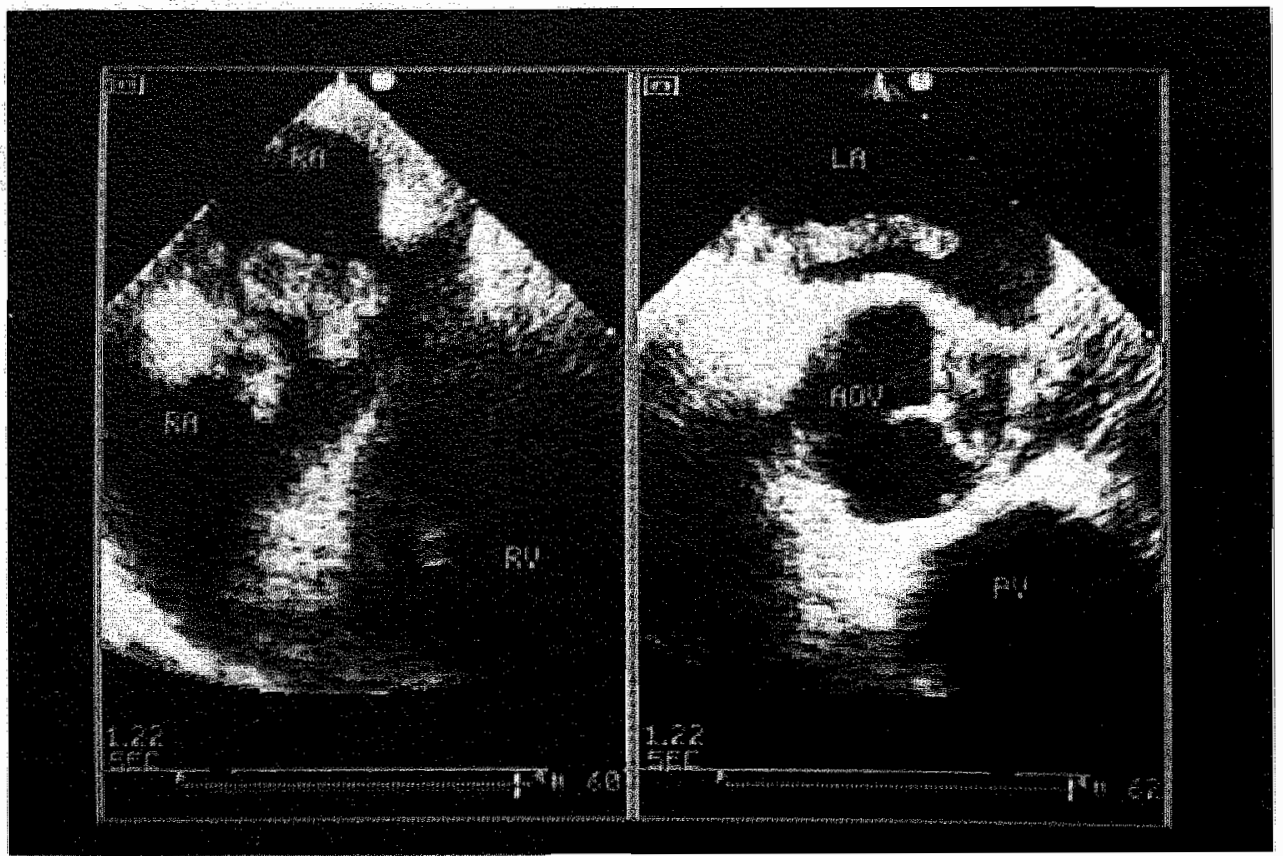

Figure 1: Trans Esophageal Echocardiogram. The left panel shows a large thrombus in the right atrium (RA) held in place by the protrusion of a part of the thrombus through the patent foramen ovale into the left atrium (LA) (right panel). AOV = Aortic valve, RV = Right ventricle $P V=$ Pusmonary valve.

two patients and was negative. Deep venous thrombosis was detected in two of the three patients in whom this investigation was performed, without changing the diagnosis.

The number of additional investigations after the RV-overload-echocardiogram show that in the majority of cases the attending physician was not willing to accept embolization in addition to COPD as a real possibility. Reviewing the cases we tend to agree with that decision in $18 / 24$ patients in this subgroup. Although the other six had clearly pulmonary disease, pulmonary embolism was not definitively excluded.

Group $C$ : In four of the six cases in whom right sided pressures were inappropriately high for left sided disease $V / Q$-scans were performed (one high probability and three low probability). In one other patient the echocardiographic diagnosis was not accepted by the department of internal medicine. This patient was known with an inferior wall infarction and tight ventricular involvement 6 years before this admission. Pressures now were higher than before. No additional investigations were performed. None of these six patients received additional antithrombotic treatment.

Group D: Of the five patients falling in this group one had (fenfluramide induced) primary pulmonary hypertension ${ }^{8}$. One patient had a HIV infection as cause for his pulmonary hypertension. The other three patients suffered from chronic pulmonary hypertiension. Angiography in the past did not show major thrombi (although chronic micro-embolization was suggested in two). 
Growp E: This group is heterogenous. In two cases thrombi were present in the right heart. One having a RA-thrombus during resuscitation because of cardiac standstill was found to have an occlusion of the mainstem of the left coronary artery (figure 2). The thrombus was still present during postmortem examination but had not resulted in any pulmonary embolization.

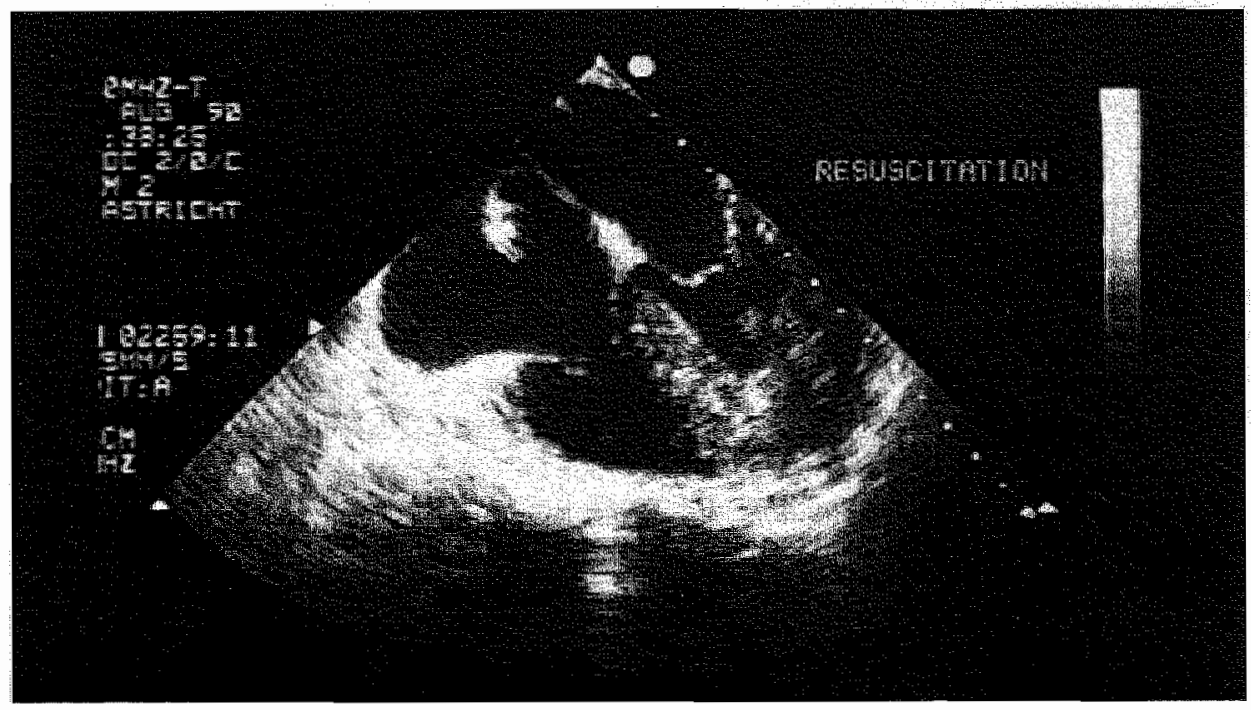

Figure 2: Echocardiogram (TEE) performed during resuscitation showing a floating thrombus in the right atrium.

The other patient showed during resuscitation a right heart thrombus. A V/Q-scan had already shown a high probability for emboli 10 days before but the patient was treated for a pneumonia. After the resuscitation no prolonged heparinization was given and patient died after a hemicolectomy for carcinoma. No postmortem examination was performed. One patient with a rectumcarcinoma and metastasis was admitted with dyspnea ( $\mathrm{pH} 7.48, \mathrm{pCO}_{2}$ $3.4 \mathrm{kPa}$ and $\mathrm{pO}_{2} 6.5 \mathrm{kPa}$ ) but this was not recognized as pulmonary embolism and treated for pumplailure. The consulting cardiologist asked for an echocardiographic examination, which revealed findings suggestive of embolism. The patient was, however, discharged with a normal blood gas analysis without additional investigations and anticoagulant therapy. Three weeks later the patient was readmitted with dy spnea and died. Postmortem diagnosis revealed a bronchopneumonia and multiple pulmonary emboli. An other patient with a pancreatic carcinoma did show pulmonary hypertension without any response to treatment (no postmortem examination). One patient was treated for cholangitis. This was followed by respiratory failure and transient RV-pressure overload, not leading to a change in treatment. Three days later she died in shock. Postmortem examination did not show gross pulmonary emboli. The last patient with pulmonary hypertension had a high probability V/Q-scan and a negative sub-optimal digital subtraction angiography. She was treated as having idiopathic pulmonary hypertension, with oral anticoagulation. 


\section{Establishing the diagnosis pulmonary embolism}

It is easy to describe the diagnostic tools used to proof the presence of pulmonary emboli, however, the correct diagnosis in a patient suspected to have a pulmonary embolism is not always simple. In $35 / 50$ patients with proven pulmonary embolism clinical suspicion and abnormalities found on the electrocardiogram were reason to make an echocardiogram to proof the presence of RV-pressure overload. In the remaining 15/50 the initial diagnosis was different (e.g. pumpfailure or unstable angina) and the echocardiogram changed the diagnostic route and treatment considerably.

We scored the electrocardiographic abnormalities in the total patient population in whom an electrocardiogram was available at the time of maximal complaints ( 80 patients). We divided. the electrocardiograms in two categories: One category patients with serial changes on the electrocardiogram, the other with fixed abnormalities (more suggestive of a chronic form of pressure overload). The results are shown in table 4 . It is clear from these results that the combination of typical ECG abnormalities (more than or equal to four points) is present in $29 / 47$ patients $(62 \%$ ) with proven pulmonary embolism. In $66 \%$ (31/47) of cases changes were observed in comparison with recent previous ECG's or changes towards normalization recorded during follow up. It is clear, however, that also $31 \%(6 / 19)$ of our COPD group showed serial changes probably as a result of improvement in hemodynamics.

Table 4: Relation between the clinical subgroups and the electrocardiographic abnormalities. A distinction is made between ECG with and without serial changes (serial changes are not scored in the score of each of the ECG's).

\begin{tabular}{|c|c|c|c|c|c|}
\hline \multicolumn{6}{|c|}{ Relation belween presence of pulmonary embolism and electrocardiographic signs of RV-overload } \\
\hline \multirow[t]{2}{*}{ Cinical groups } & \multicolumn{2}{|c|}{$\begin{array}{c}\text { Serial electrocardiographic } \\
\text { changes }\end{array}$} & \multicolumn{3}{|c|}{ No changes in the electrocardiogram } \\
\hline & $\geq 4$ points & $<4$ points & 4 points & $<4$ points & $\begin{array}{c}\text { no } \\
\text { abnormalities }\end{array}$ \\
\hline A. Proven pulmonary embalism & $23 / 47 \quad 49 \%$ & $8 / 47 \quad 17 \%$ & $6 / 47 \quad 13 \%$ & $6 / 47 \quad 13 \%$ & $4 / 478 \%$ \\
\hline B. COPD group & $5 / 1926 \%$ & $1 / 195 \%$ & $7 / 19 \quad 37 \%$ & $4 / 1921 \%$ & $2 / 19 \quad 11 \%$ \\
\hline D. LV dystundion & $2 / 5 \quad 40 \%$ & & & $\| / 5 \quad 20 \%$ & $2 / 5 \quad 40 \%$ \\
\hline E. Pulmonary hypertension: & & & $2 / 450 \%$ & $2 / 450 \%$ & \\
\hline D. Classification difficult & $2 / 5 \quad 40 \%$ & $1 / 520 \%$ & $1 / 5 \quad 20 \%$ & $1 / 5 \quad 20 \%$ & \\
\hline Total & $32 / 80 \quad 40 \%$ & $10 / 80 \quad 12 \%$ & $16 / 80 \quad 20 \%$ & $14 / 80 \quad 18 \%$ & $8 / 80 \quad 10 \%$ \\
\hline
\end{tabular}

\section{Laboratory findings in the clinical subgroups}

Blood gas analysis showed clear differences between the subgroup "pulmonary cause for cor pulmonale" and "proven pulmonary embolism". The $\mathrm{pCO}_{2}$ in the patient group with proven 
pulmonary emboli was markedly lower than in the other group. Only patients with respiratory failure in the setting of pulmonary embolism and an overall very poor hemodynamic state did show an elevated $\mathrm{pCO}_{2}$. The data, presented in table 5 , clearly show that respiratory compensatory capacity is preserved in patients without important COPD and is impaired in the other group. The stable patients in whom blood gas analysis was performed before discontinuation of oxygen are probably representing a subgroup with less rapid improvement. The differences in $\mathrm{pCO}_{2}$, measured acute, with $\mathrm{O}_{2}$ and in the stable situation, are statistically significant between the two groups. The sensitivity, specificity, positive and negative predictive accuracy of the combination of echocardiographically detected right ventricular pressure overload and a certain $\mathrm{pCO}_{2}$ value, showed that the optimal $\mathrm{pCO}_{2}$ levels for the diagnosis pulmonary embolism were $\leq 4.5 \mathrm{kPa}$ (figure 3 ).

Calculation of the A-a gradient (alveolar-arterial oxygen gradient) showed values of 52.3 $\pm 20.6(n=45)$ in the pulmonary embolism group and $26.9 \pm 30.7(n=19)$ in the COPD group $(p=<0.001)$. Patients with pulmonary embolism showed in $9 \%$ normal A-a gradients (normal value $\leq 20$ ). The COPD group had normal A-a gradients in $37 \%$ of cases. No significant differences between the two groups in all other blood gas analysis data were found.

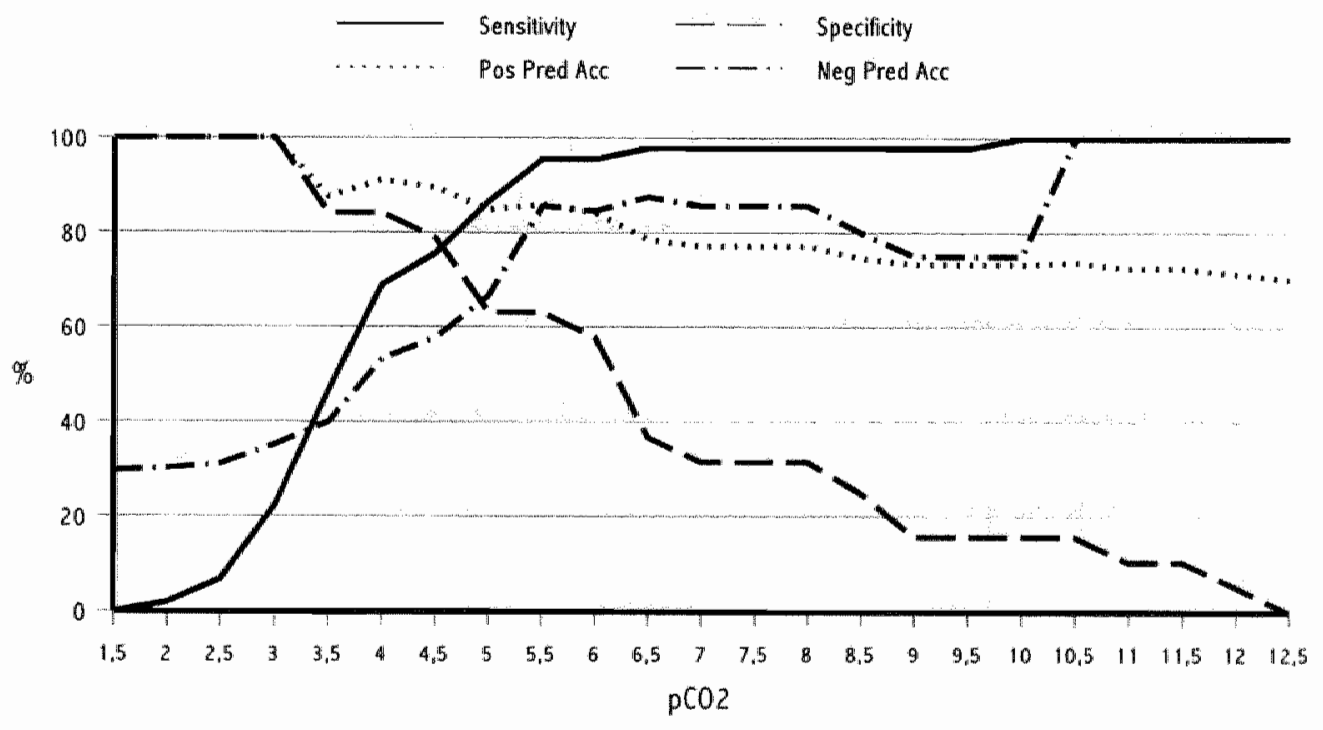

Figure 3: This graph depicts the sensitivity, specificity, positive and negative predictive accuracy to detect pulmonary embolism based on a certain $\mathrm{CO}_{2}$ value, obtained at admission, in patients with right ventricular pressure overioad. For each value at the horizontal axis the test is considered positive if the $\mathrm{pCO}_{2}$ is smaller than or equa/ to this threshold. The graph illustrates that a $\mathrm{pCO}_{2}$ value of $4.5-5 \mathrm{kPa}$ would form an optimat threshold to separate patients with pulmonary embolism and patients with exacerbation of chronic pulmonary disease. 


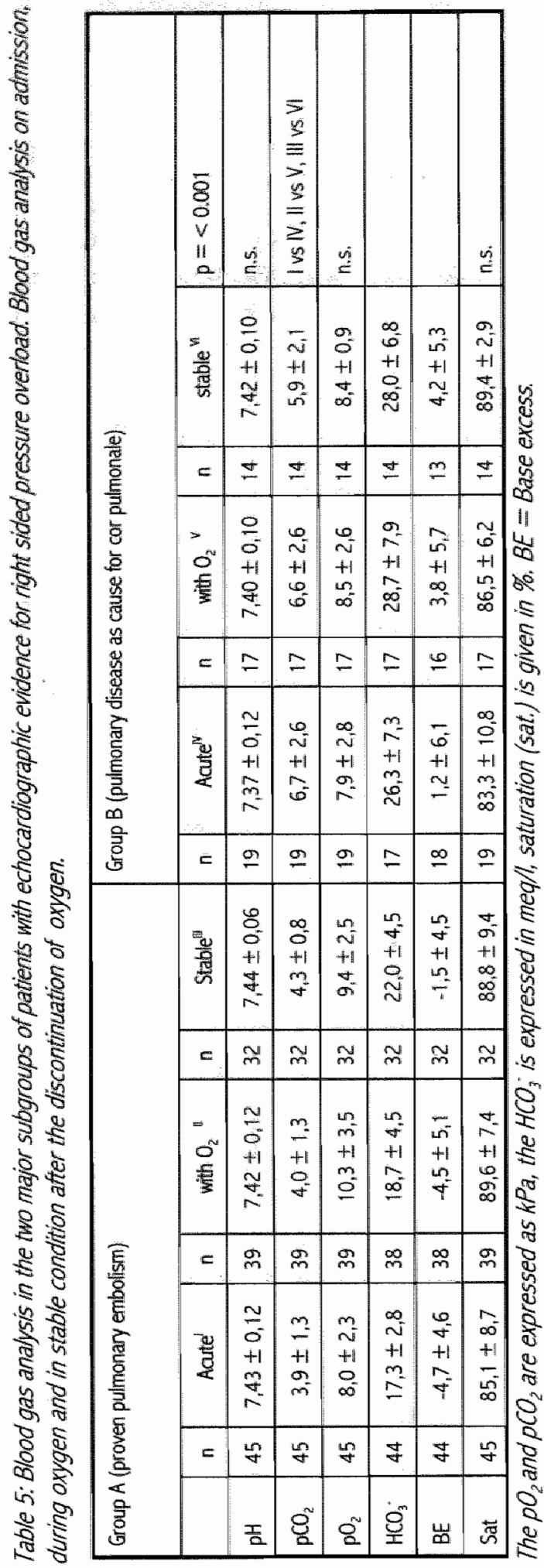




\section{Discussion}

\section{Patient selection and subgroup selection}

This study primarily addresses the role of echocardiography to recognize patients with a possible pulmonary embolism based on the finding of RV-pressure overload. A certain bias will be present here. A patient with suspected pulmonary embolism will be studied in more detail as to RV-function. We are, however, convinced that echocardiography made the diagnosis in at least $30 \%$ of our patient population. In a substantial number of the other patients the diagnosis embolism was mentioned in the differential diagnosis and the use of echocardiography as a first line diagnostic tool altered the ranking of diagnosis. Our report system is on-line and after being authorized accessible to all other terminals in our department. This means that in this study we have been using the original diagnosis made by the attending echocardiographist at the time of investigation. If the picture of RVoverload was missed during the examination this echocardiogram could not be retrospectively incorporated in the study.

We decided to classify every echocardiogram on basic echo-parameters as TR-velocity and signs of high MRAP. In our experience in the presence of RV overload a wide and noncollapsing inferior caval vein is more a sign of acute embolism and a well collapsing IVC a sign of a more chronic pressure overload. If the IVC did not collapse MRAP was considered to be more than $15 \mathrm{mmHg}$. In those cases right ventricular pressures can be elevated with TR velocities of less than $2.7 \mathrm{~m} / \mathrm{s}$ (but distinction between right ventricular infarction and pulmonary embolism is more difficult). A nice overview of RVhemodynamics in pulmonary diseases is given by Schulman and Matthey ${ }^{10}$. McIntyre and Sasahara studied the effects of acute embolism in 20 previously healthy patients ". An increase of mean pulmonary artery pressures was found after obstruction of $25 \%$ of the pulmonary vascullar bed. Mean pressures never exceeded $40 \mathrm{mmHg}$. Right atrial pressures increased in all patients with obstruction of more than $35 \%$ of the pulmonary vascular bed. Thus acute pressure elevation will first lead to an increase in pulmonary pressures followed by an increase in filling pressures. The initial response to an acute increase in afterload is dilatation and the secondary response is hypertrophy. By enlarging the RV and increasing the preload, cardiac output is maintained as long as possible. In dogs with acute pulmonary hypertension cardiac output can be maintained up to pressures of $60 \mathrm{mmHg}$ (partial occlusion of the pulmonary artery) ${ }^{12}$. A mean arterial pressure of $40 \mathrm{mmHg}$ in man and $60 \mathrm{mmHg}$ in dogs will lead to systolic pressures of at least $60-70 \mathrm{mmHg}$. A TR-velocity of more than 3.7 $\mathrm{m} / \mathrm{sec}$ is not unusual (a pressure difference between RV en RA of more than $55 \mathrm{mmHg}$ ). High TR-velocities are not in disagreement with acute embolism.

In patients with slowly progressive forms of pulmonary hypertension (COPD with arterial hypoxemia) hypertrophy is present without marked dilatation. Dilatation develops when de right ventricle starts to fail. This is the reason that in stable COPD patients TR is not always detectable and measurements of pulmonary artery flow are necessary to get information about pulmonary artery pressures. Absence of IVC collapse can be found after the start of RV-dysfunction. Our suggestions are partially in disagreement with Kasper et al. ${ }^{13}$. They 
defined subacute pulmonary embolism apart from other parameters on the basis of a not collapsing IVC. In our study we made the sub-selection on the basis of IVC collapse because we were convinced that in patients with pulmonary hypertension of longer duration, filling pressures are lower because of adaptation of the ventricle. Also patients might receive diuretics in the course of their disease, decreasing MRAP. Our findings indicate that an absent IVC collapse indicating a high MRAP is present in $78 \%$ of patients with proven acute pulmonary embolism, but also in $62.5 \%$ of patients with severe COPD, probably indicating RV-dysfunction caused by exacerbation of COPD. Wall motion abnormalities of the right ventricle ${ }^{13-16}$ were not studied in our patient population. We believe that, except for increased oxygen demand of the right ventricle, loading conditions playing a role in producing a noncollapsing IVC also cause hypokinesis of the RV free wall but did not study this specifically.

It is unclear how many patients with pulmonary embolism will not show signs of pressure overload. As stated earlier increase in mean pulmonary pressures can be expected when 25 $\%$ of the pulmonary vascular bed is obstructed. Whether this means that with lesser obstruction one will not have systolic pressure elevation is unclear. Also the additional vasoconstrictive effects of serotonin and tromboxane $A_{2}$ release on acute (temporary) changes in pressures are unclear. Theoretically smaller thrombi could be missed using RVoverload as diagnostic criterium. The question is whether the smaller ones are seen by the lung specialist and the larger ones are primarily coming to the cardiologist because of the more acute hemodynamic consequences.

The subgroup "inappropriate RV-pressures in the presence of some LV-dysfunction and or valvular dysfunction" (group III) is a difficult one. Using Color Doppler, mitral flow parameters, lung-vein-flow characteristics and even transesophageal approaches an experienced investigator (with adequate echocardiographic equipment) can rule out LVdysfunction or valvular dysfunction as important cause in the majority of cases. It would be interesting to enlarge this subgroup and study the mechanisms causing pulmonary pressure elevation in that population more carefully. This study only shows no signs of acute gross embolic events in at least $78 \%$ of this subgroup.

The last subgroup is clear. If a right heart thrombus is present without pressure elevation the thrombus is, or parts of the thrombus are, not yet in the pulmonary circulation or there was no relation with the event that initiated the echocardiographic examination. In case of resuscitation there are also two possibilities. The thrombus was not responsible for circulatory collapse leading to the resuscitation attempt (and was an accidental finding) or the thrombus was the causal factor for the resuscitation.

The study of Kinney et al. shows that the probability of survival of patients with right sided heart thrombi is low if patients are not treated, particularly if there are already signs of pulmonary embolism ${ }^{17}$. Recently Casazza showed that in $15 \%$ of patients with pulmonary embolism a thrombus in the right heart can be detected ${ }^{18}$. It is clear that in a patient who is being resuscitated and in whom a right sided heart thrombus is found pulmonary embolism is likely to be the cause for the circulatory collapse. In one of our patients, however, the thrombus present on echocardiogram and post-mortem examination was not the cause for the death of the patient (figure 2). 
A comparison between the reported results of our previous echocardiographic study of 60 patients ${ }^{2}$ with the total population of 100 patients in this study shows some differences; proven pulmonary embolism is present in 50 patients in both studies. One patient is added to the first study with a thrombus during a resuscitation attempt. He died but we could not obtain any other clinical data. Also 3 patients in the COPD group ( 2 with positive deep venous thrombosis investigations and 1 with a high probability scan, all without treatment) and 5 patients of group $\mathrm{E}$ (including the mainstem problem) are also incorporated. The last patient completing the total of 60 is a patient from group $\mathrm{C}$ with a high probability scan without treatment for pulmonary embolism.

\section{Treatment}

Treatment of pulmonary embolism is not the primary issue of this article. As stated in our previous article echocardiography can be of help in the acute evaluation of very unstable patients ${ }^{2}$. In those patients thrombolytic drug intervention or surgery can be initiated after completing the echocardiographic examination and establishing the RV-pressure overload ${ }^{2}$. "Those who demand absolute proof before the diagnosis of pulmonary embolism is accepted and treatment instituted, may only too often have been provided with the only absolute proof, namely the autopsy" (Isreal and Goldstein) ${ }^{19}$. Table 2 indicated the treatments given to our patients. If patients are treated with thrombolytics, particularly after angiography, the effect of treatment is documented by monitoring pulmonary artery pressures. Prognosis of a patient with thromboembolic disease is dependent on three factors: Does the patient survive the initial event, will he develop a recurrence and can we prevent that (also in the future) and how are the pulmonary artery pressures after treatment. When the pulmonary vascular bed is still partially occluded after treatment (previous older emboli, micro-thromboemboli, partially recanalized thrombi) persistent pulmonary hypertension will be present after discharge. Even if resting values are near normal, exercise could lead to inadequate rise in pressure ${ }^{20}$. Mortality is very high in patients having mean pulmonary pressures exceeding $30 \mathrm{mmHg}$ more than 2 months after the initial event ${ }^{20}$. Echocardiography is an adequate noninvasive tool to document a decrease in pulmonary artery pressure. In our previous study we reported the follow-up of 25 patients $^{2}$. In $76 \%$ patients IVC-collapse returned to normal. In $48 \%$ TR-velocity decreased (but did reach normal values only in 10 patients). In $52 \% \mathrm{RV}$ dimensions decreased. In $24 \%$ no change occurred at all. It is clear that evaluations like this are essential when reporting the long term outcome after pulmonary embolism.

\section{The electrocardiogram and pulmonary embolism}

One of our previous studies showed that in patients with RV-pressure overload due to pulmonary embolism ECG changes can be observed in $76 \%$ of cases '. This study indicates the value of looking at serial ECG changes as sign of temporary RV pressure overload. This also allows to monitor effects of treatment. If the ECG changes back to normal after thrombolytics it is highly diagnostic for a temporary RV-pressure overload. 


\section{Blood gas analysis}

In our patient population with pulmonary embolism and documented TR velocities $\geq 2.7 \mathrm{~m} / \mathrm{s}$, only two patients $(4 \%)$ had a pCO of more than $5.5 \mathrm{kPa}(42 \mathrm{mmHg})$ and eleven $(24 \%)$ a $\mathrm{pCO}_{2}$ of more than $4.5 \mathrm{kPa}(34 \mathrm{mmHg}$ ). In contrast to these values $76 \%$ of our COPD group showed a $\mathrm{pCO}_{2}$ of more than $4.5 \mathrm{kPa}$ at the initial blood gas analysis. In patients with pulmonary embolism the $\mathrm{pCO}_{2}$ is usually low, particularly if patients are still in a hemodynamically reasonable condition (and able to develop a TR-velocity of $\geq 2.7 \mathrm{~m} / \mathrm{s}$ ) and not having pre-existent pulmonary disease. We realize, however, that there are reports on patients showing hypercapnia in the presence of pulmonary embolism. The majority of these patients had severe obstruction of at least $50 \%$ of the pulmonary circulation and no prior cardiopulmonary disease ${ }^{21}$. A decrease in $\mathrm{pCO}_{2}$ could be a sign for pulmonary embolism in the COPD group if a pre-existent blood gas analysis is available ${ }^{22}$. This observation, however, could not be confirmed by others ${ }^{23}$. The value of this finding could not be checked in our patient population, because we did not investigate a sufficient large number of COPD patients with pulmonary embolism.

Normal $\mathrm{pO}_{2}$ values are not uncommon in patients having less vascular obstruction. Some studies show that $9-15 \%$ of patients had a $\mathrm{pO}_{2}$ of $>10.5 \mathrm{kPa}(80 \mathrm{mmHg})^{24,25}$. In our patientgroups a $\mathrm{pO}_{2}$ of more than $10.5 \mathrm{kPa}$ was present in $9 \%$ of the pulmonary embolism group and in $11 \%$ of the COPD group.

The A-a gradient was abnormal in the majority of our patients in both groups with a statistically significant difference between them (the PE group showed a more abnormal A-a gradient than the COPD group). As already pointed out by Stein et al. a normal value of the A-a gradient was seen in $11-14 \%$ patients with pulmonary embolism, and therefore does not exclude the diagnosis of pulmonary embolism ${ }^{26}$. In our PE-population this was present in only $9 \%$.

The combination of RV-pressure overload on the echocardiogram and a $\mathrm{pCO}_{2}$ of less than $4.5-5 \mathrm{kPa}$ is highly suspect for pulmonary embolism as cause for the acute pulmonary hypertension.

\section{General remarks}

In several articles the value of echocardiography for the diagnosis of pulmonary embolism has been evaluated ${ }^{2,14,27}$. Surprisingly echocardiography still has not gained wide acceptance as a screening tool in patients suspected to have pulmonary embolism. This is mainly due to technical aspects of this technique and the required knowledge to interpret the images correctly. The echocardiogram is in many centers therefore not used as first line tool in acute patients. The technician (or the cardiologist) handling the equipment is not capable to achieve adequate images in the very sick. Optimal TR-velocities are not routinely measured in patients. Lung specialists are not used to look at ultrasound images. There is also misunderstanding about RV-dilatation and pulmonary pressures in COPD.

In general hypoxia is the main cause for pulmonary hypertension in patients with COPD ${ }^{\text {to }}$. In COPD-patients without arterial under-saturation in general no RV-dilatation is noticed. 
This is not known by most of the referring doctors. We are convinced that ultrasound is a tool which allows the diagnosis of the likelihood of pulmonary embolism within minutes after arrival in hospital. This technique is besides history, physical examination, electrocardiogram and blood gas analysis a real first line tool. Dependent on the total picture (clinical status plus outcome of ECG, blood gas analysis and echocardiogram) the patient can than be scheduled for immediate treatment, V/Q-scanning or pulmonary angiography. It would be of interest to perform a study to look at the value of these well-accepted techniques in patients who do have and do not have RV-overload on the echocardiogram. Transesophageal echocardiography (TEE) is clearly of value in patients with pulmonary embolism, increasing the amount of positive thrombus detection ${ }^{28,29}$. But TEE is not a non-invasive technique anymore, particularly in patients with severe dyspnea.

This study is one of the first which uses echocardiography as the initial diagnostic tool. After proving the presence of $R V$-overload the final diagnosis and outcome were retrospectively studied. The retrospective nature of this study is a potential disadvantage, because the whole diagnostic evaluation was sometimes incomplete and pulmonary embolism not convincingly ruled out in every patient. The echocardiographic database, however, was prospective in nature. Recently Mazeyrollas prospectively studied 840 patients having the clinical suspicion of pulmonary embolism, or recent onset ( $<4$ days) dyspnea or chest pain admitted to the first heart aid or cardiac care unit ${ }^{30}$. Based on a clinical evaluation using previous cardiac history, complaints, physical examination and ECG 708 patients were excluded for echocardiographic evaluation while 132 patients were considered to be candidates for pulmonary embolism. Seven died before an echocardiogram could be made. Bedside echocardiography revealed an other diagnosis than pulmonary embolism in $55 / 132$ patients. In the final group (70 patients) the investigators were able to perform an adequate echocardiogram in 64 (91 $\%$ ). Although not precisely described how, they diagnosed pulmonary disease in 17 patients, other cardiac pathology in 14 patients and mixed/other pathology in 6 patients. Pulmonary embolism was diagnosed in the 31 remaining patients. Abnormal tricuspid regurgitation velocity $(>2.5 \mathrm{~m} / \mathrm{s})$ and a right over left ventricular diameter ratio $(>0.5)$ measured with $\mathrm{M}$ mode were significant independent variables for the diagnosis. Blood gas analysis was not included in this study. We used RV dimensions measured in the apical 4 chamber. The normal value for the right ventricle we used was $<2.7 \mathrm{~cm}$. Kasper used a normal value of $<$ $3 \mathrm{~cm}$ for his study ${ }^{13}$. Some authors report higher normal values, but in our opinion in this specific acute population a cut-off point of an RV diameter of 3.5 or $4 \mathrm{~cm}$ is too large.

\section{Conclusions}

This study shows that Doppler-echocardiography is an important diagnostic tool in patients with pulmonary embolism. The clinical picture of patients with pulmonary embolism may be confusing. Patients with (an exacerbation of their pre-existent) pulmonary disease can also show RV-pressure overload. We therefore included in our study apart from RV-pressure overload other clinical variables to diagnose the presence of pulmonary emboli. 
This study shows that a combination of RV-pressure overload detected by Dopplerechocardiography as initial diagnostic tool and a $\mathrm{pCO}_{2}<4.5-5 \mathrm{kPa}$ at initial blood gas analysis is very suspect for an important pulmonary embolism. An A-a gradient of less than 20 was present in only $9 \%$ of patients with pulmonary embolism in this study. In $66 \%$ of patients with pulmonary embolism and electrocardiographic registrations serial changes were recorded. 


\section{References}

1. Sreeram N,Cheriex EC, Smeets JLRM, Gorgels APM, Wellens HJI. The value of the 12-lead electrocardiogram at hospital admission in the diagnosis of pulmonary hypertension. Am J Cardiol 1994;73:298-303.

2. Cheriex EC, Sreeram N, Eussen YFJM, Pieters FAA, Wellens HJJ. Cross-sectional echocardiography as the initial diagnostic tool in acute pulmonary embolism. Br Heart J 1994;72:298-303.

3. Mulleneers RGA. Cheriex EC, Dassen WRM, Bleijlevens BB, Wellens HJJ, Meester GT. CAESARS: The CArdiac Echo Storage And Retrieval network System. In: Computers in Cardiology. IEEE Computer Society Press, Chicago. 1990:211-214.

4. Sahn DJ, DeMaria A, Kisslo J, Weyman A. Recommendations regarding quantitation in Mmode echocardiography: Results of a survey of echocardiographic measurements. Circulation 1978;58:1072-1083.

5. Schiller NB, Shah PM, Crawford M, DeMaria A, Devereux R, Feigenbaum H, Gutgesell H, Reichek N, Sahn D, Schnittger I, Silverman NH, Tajik AJ. Recommendations for quantitation of the left ventricle by two-dimensional echocardiography. J Am Soc Echo $1989 ; 2: 358-367$.

6. Cheriex EC, Leunissen KML, Ianssen JHA, Mooy JMV, wan Hooff JP. Echography of the inferior vena cava is a simple and reliable tool for estimation of "Dry weight' in haemodialysis patients. Nephrol Dial Transplant 1989;4:563-568.

7. Jansen EWL, Janssen JHA, Cheriex EC, Penn OCKM. Use of a removable vena cava filter for prevention of recurrent embolism after emergency pulmonary embolectomy. Tex Heart Inst .J 1989;16:15-17.

8. Pouwels HMM, Smeets JLRM, Cheriex EC, Wouters EFM. Pulmonary hypertension and fenfluramine. Eur Respir J 1990;3:606-607.

9. Giuntini C, Di Ricco G, Marini C, Melillo E, Palla A. Epidemiology. Chest 1995;107:3S-9S.

10. Schulman DS, Matthay RA. The right ventricle in pulmonary disease. In: Remetz MS, Cabin HS, eds. Cardiology Clinics. The right ventricle. WB Saunders. Philadelphia. 1992;10:111-135.

11. McIntyre K, Sasahara A. The hemodynamic response to pulmonary ambolism in patients without prior cardiopulmonary disease. Am J Cardiol 1971;28:288-294.

12. Stool EW, Mullins CB, Leshin SJ. Dimensional changes of the left ventricle during acute pulmonary arterial hypertension in dogs. Am J Cardiol. 1974;33:868-874.

13. Kaspar W, Geibel A, Tiede N, Bassenge D, Kauder E, Konstantinides S, Just H. Distinguishing between acute and subacute massive pulmonary embolism by conventional and Doppler echocardiography. Br Heart J 1993;70:352-356.

14. Wolfe MW, Lee RT, Feldstein ML, Parker JA, Come PC. Prognostic significance of right ventricular hypokinesis and perfusion lung scan defects in pulmonary embolism. Am Heart J $1994: 127: 1371-1375$.

15. McConnell MV, Solomon SD, Rayan ME, Come PC, Goldhaber SZ, Lee RT. Regional right ventricular dysfunction detected by echocardiography in acute pulmonary embolism. Am $d$ Cardiol 1996;78:469-473.

16. Metz D, Nazeyrollas P, Maillier B, Jennesseaux C, Tassan S, Maes D, Elaerts J. Regression of right ventricular hypokinesis after thrombolysis in acute pulmonary embolism. Am I Cardiol $1996 ; 78: 1252-1254$.

17. Kinney EL, Wright R. Efficacy of treatment of patients with echocardiographically detected right-sided heart thrombi: A meta-analysis. Am Heart J 1989;11 18:569-573. 
18. Gasarza F, Cuccia $C$, Corrado $G$, Bongarzoni $A$, Centonze $F$, Campana $M$, Buffoli $F$, Turla $C$, Marzegalli $M$, Santarone $M$. 'In transit' right heart thrombi in acute pulmonary embolism. Eur Heant J 1996; 18:(abstract)p 1402;

19. Israel $\mathrm{HL}_{3}$ Goldstein $\mathrm{F}$. The varied clinical manifestation of pulmonary embolism. Ann Intern Med 1957,47:202-226.

20. Riedel $M$, Stanek V, Widimsky J, Prerovski I. Longterm follow-up of patients with pulmonary thromboembolism. Late prognosis and evolution of hemodynamic and respiratory data. Chest $1982 ; 81: 151-156$.

21. Bouchama A, Curley W, Al-Dossary S, Elguindi A. Refractory hypercapnia complicating mssive pulmonary embolism. Am Rev Respir Dis 1988;138:466-468.

22. Lippman $M$, Fein $A$. Pulmonary embolism in the patient with chronic obstructive pulmonary disease. Chest 1981;79:39-42.

23. Lesser BA, Leeper jr KV, Stein PD, Saltzman HA, Chen J, Tompson T, Hales CA, Popowich jr J, Greenspan RH, Reid JG. The diagnosis of acute pulmonary embolism in patients with chronic obstructive pulmonary disease. Chest 1992;102:17-22.

24. Urokinase Pulmonary Embolism Trial. Circulation 1973;47(suppl 1):86-90.

25. Bell WR, Simon TL, DeMets DL. The clinical features of submassive and massive pulmonary embolism. Am J Med 1977;62:355-360.

26. Stein PD, Goldhaber SZ, Henry JW. Alveolar-Arterial oxygen gradient in the assessment of acute pulmonary embolism. Chest 1995;107:139-143.

27. Kasper W, Meinertz T, Henkel B, Eisner D, Hahn K, Hofmann T, Zeiher A, Just H. Echocardiographic findings in patients with acute pulmonary embolism. Am Heart $J$ $1986 ; 112: 1284-1290$.

28. Wittlich N, Erbel R, Eichler A, Schuster S, Jakob H, Iversen S, Oelert H, Meyer J. Detection of central pulmonary artery thromboemboli in patients with severe pulmonary embolism. J Am. Soc Echo 1992;5:515-524.

29. Prusczyk P, Torbicki A, Kuch-Wocial A, Chlebus M, Miskiewicz ZC, Jedrusik P. Transoesophageal echocardiography for definitive diagnosis of haemodynamically significant pulmonary embolism. Eur Heart J 1995; 16:534-538.

30. Nazeyrollas P, Metz D, Jolly D, Maillier B, Jennesseaux C, Maes D, Chabert JP, Chapoutot L, Elaerts. Use of transthoracic Doppler echocardiography combined with clinical and electrocardiographic data to predict acute pulmonary embolism. Eur Heart J 17;779-786:1996. 


\section{Chapter 8 \\ Treatment of acute pulmonary embolism. Effect of therapy on pulmonary anatomy and pulmonary hemodynamics.}

Massive pulmonary embolism is a clinical entity with a high mortality. The sudden elevation of pulmonary artery pressure and subsequent right ventricular failure can lead to death within minutes to hours. It is estimated that $11 \%$ of fatal cases die within 1 hour, $43-80 \%$ within 2 hours and $85 \%$ in the first 6 hours after the initial event ${ }^{1}$. The mortality is determined by three important factors: the extent of the pulmonary arterial occlusion, the reflex-humoral factors and the condition of the patient before embolism ${ }^{2}$. It is clear that adequate recognition and therapy will influence mortality considerably. Heparinization and thrombolysis have proven to be effective in the early hours. Also surgery (embolectomy) has beneficial effects, although peri-operative mortality is known to be very high ${ }^{3}$.

\section{What happens beyond this point?}

In $30-50 \%$ of patients a pulmonary infarction will occur. In larger/gross emboli, as pointed out before (chapter 2), this is a non-necrotic hemorrhagic complication which will resolve in the majority of cases ("incomplete infarction"4), particularly in the right lower lobe". However, following smaller and microscopic emboli fibrosis may result and atrophic infarcts will develop in half of the patients. They tend to be located more in the upper lung-fields ${ }^{5}$. Several authors believe that pulmonary infarction is the most common acute pulmonary disease in patients admitted to general hospitals ${ }^{6}$. A statement which is in agreement with the high incidence of microscopic emboli in autopsy studies ${ }^{5}$.

Pulmonary emboli themselves tend to resolve. In animals fresh emboli will disappear rather rapidly (within 2 days) under the influence of endogenous fibrinolysis ${ }^{7}$. Aged emboli in dogs resolve completely within $2-4$ weeks. In humans this time course has not been studied extensively.

Without treatment two intrinsic mechanisms are involved; endogenous fibrinolysis and organization. Fibrinolytic dissolution is mainly dependent on the age of the thrombus before leaving the venous system. The extent of the thrombolytic response will, however, vary from patient to patient $t^{2}$. The organization of a thrombus may therefore require clays to weeks. The interplay between age of the thrombus, exogenous and endogenous fibrinolysis and organization will determine the final amount of obstruction in the pulmonary vessel. The end-result will thus vary from total obstruction with retraction of vessel walls to only a small zone of intimal thickening ${ }^{2}$. Both perfusion-scans and angiograms show that in general within a few days to 4-6 weeks a substantial decrease of obstruction has occurred. Moser reports that in only 10 percent of patients important perfusion defects remains ${ }^{2}$. Improvement 
particularly occurs in younger healthier patients, but is clearly diminished in patients with prior pulmonary and/or heart disease.

There are some classical studies looking to this aspect in man. In a period ranging from 1964-1968, Dalen et al looked to the resolution rate in 15 patients after acute (within maximally four days) pulmonary embolism treated with venous ligation of the inferior caval vein and heparin (in 5/15 patients $75-150 \mathrm{mg}$ intravenously every four hours for 1-7 days) ${ }^{8}$. In these patients only minimal resolution of emboli was present at seven days. By 10 to 21 days mean pulmonary artery pressure had decreased to "near" normal levels in $4 / 10$ patients and angiograms had returned to normal in only $2 / 10$ patients. The other patients showed persistent abnormalities, although in $5 / 10$ a moderate resolution was described. It is clear that these patients were under-treated by heparin and mainly dependent on there own fibrinolytic capacity.

Hall et al. (1965-1973 period) looked at this problem in 72 surviving patients ( $18 \%$ did not survive the acute episode $)^{9}$. In this study patients were admitted within 4 days after the onset of symptoms. Embolectomy was performed in $46 \%$ of patients, $43 \%$ received streptokinase and $14 \%$ patients received heparin. In $56 / 60$ patients follow-up was available ( 12 patients died after the acute episode, making the initial $(<1$ year) mortality $32 \%$ ). Resolution of embolism was judged as almost complete in all patients, based on symptoms, signs, electrocardiogram and chest X-ray. In $42 \%$ the perfusion scan was normal. In $42 \%$ scans were still showing multiple defects or a general decreased perfusion in one lung. In 14 angiographically studied patients only minor abnormalities were found. The relation between therapy (embolectomy), perfusion scan and angiogram was not described. Nearly half of the patients, however, were treated with surgical embolectomy.

In subacute massive (longer histories ( $>2$ weeks) without acute episode of collapse) and acute minor thromboembolism (short history ( $<2$ weeks) and less than $50 \%$ obstruction of lung vessels) the prognosis is reasonable. No patient developed major problems in a series of patients studied by Sutton ( $8 \%$ of patients surviving the initial event died during followup) $)^{10}$. The patients, however, with pulmonary hypertension after chronic thromboemboli had a poor prognosis. Fifty percent died during maximal 7 years follow-up and the others were severely symptomatic.

Paraskos reported that $32 \%$ of patients surviving acute pulmonary embolism died during follow-up (average 29 months), mainly determined by the pre-embolic status. In $65 \%$ of patients lung-scan normalized. Partial resolution was present in $23 \%$ and in $12 \%$ there was persistent unresolved embolism".

Riedel et al. studied 76 patients with proven pulmonary embolism in the absence of other heart or lung disease at least two months after the last clinically manifest episode of pulmonary embolism ${ }^{12}$. The patients were investigated because of symptoms and are therefore not representative for the total post-embolic group. They divided the patients in groups; isolated acute pulmonary embolism (14), isolated subacute (history progressing over 1-4 weeks) pulmonary embolism (26), recurrent emboli (23) and occult pulmonary embolism (gradual progression over long period) (13). Mean pulmonary artery pressure ranged from $15.8 \mathrm{mmHg}$ (acute group) to $46.3 \mathrm{mmHg}$ (group occult pulmonary embolism). Survival was 
strongly dependent on initial mean pulmonary artery pressure. A mean pulmonary artery pressure (studied after $>2$ months) of $21-30 \mathrm{mmHg}$ coincides with a 10 years survival of 75 $80 \%$. Pressures exceeding $30 \mathrm{mmHg}$ decreased 10 years survival to below $50 \%$. More than $70 \%$ of patients with mean pressures of more than $40 \mathrm{mmHg}$ did not survive 4 years.

\section{Different treatment modalities}

As partially mentioned above there are many ways to interfere with the naturall course of the thromboembolic disease. Prevention of occurrence of venous thrombosis will not be discussed in this section. The most relevant cardiological/surgical interventions will be reviewed briefly.

\section{A. Vena Cava interruption and the use of filter devices}

Recognized recurrent embolism of thrombotic material from veins to the heart after thrombolysis accurred in $19 \%$ of the heparin treated patient-group and in $15 \%$ of the urokinase treated group of the UPET study giving rise to $1.2 \%$ additional mortality ${ }^{13}$ and in $1-7 \%$ of patients in the USPET study ${ }^{14}$.

In 1893 Bottini suggested caval interruption to prevent recurrent pulmonary embolism. This method popularized by Ochsner gave rise to an unacceptable high morbidity, with venous stasis in two third of patients ${ }^{3}$. Later surgical "filtration" procedures have been developed but were gradually overtaken by catheter guided filter devices. Eichelter and Schenk developed the first transvenous approach ${ }^{3}$. The first umbrella device was introduced by Mobin-Uddin in 1970 and placed in the inferior caval vein by surgical exposure of the internal jugular vein ${ }^{15}$. This filter had a high incidence of migration. Subsequent filters were the Greenfield stainless steel and titanium devices, Bird's nest, Amplatz and Günther filters '6 (figure 1).

The indications for filter placement are:

1. Patients with venous thromboembolism with contraindications to anticoagulation or patients in whom anticoagulation failed to prevent recurrences of pulmonary embolism (definitive placement).

2. Patients receiving thrombolytics for acute pulmonary embolism in the presence of persistent proximal deep venous thrombosis in whom the caval filter is inserted to prevent recurrences during the first days of therapy (temporary placement).

Recently reported complications of definitive filter devices are: pulmonary embolism in 2.9 $\%$ (with death in $0.8 \%$ ), death attributable to filter $0.12 \%$, inferior caval vein perforation $9 \%$, inferior caval vein obstruction $6.2 \%$ with venous insufficiency in $5.3 \%$ (the last two figures from the stainless steel Greenfield filter pooled data) ${ }^{16}$.

Removable filter devices have mainly been used in France. Therry et al described the use of jugularly and femorally introduced temporarily placed filters in 174 patients with extensive venous thrombosis (above the level of the calf veins) with or without $(35 \%)$ pulmonary embolism ${ }^{17}$. These patients received streptokinase $100.000 \mathrm{U} /$ hour for an average of 2.8 days (0.5-7 days). Phlebograms showed 312 clots that occluded the proximal veins (caval + iliac + femoral) 196 times in the 174 patients. Non-occlusive clots were present 116 times. 
A
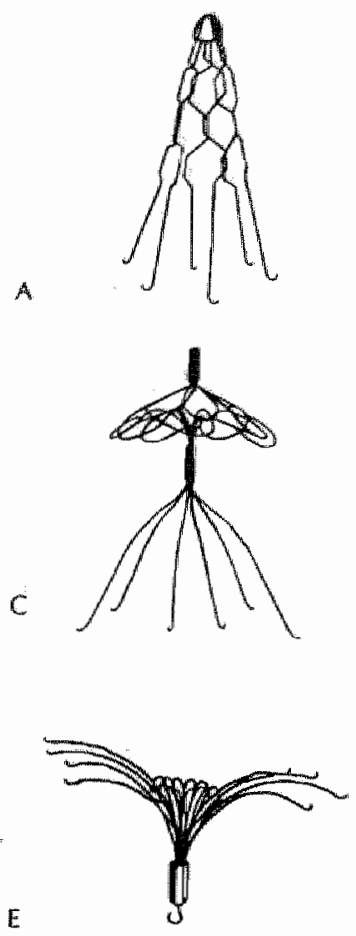

$\mathrm{G}$

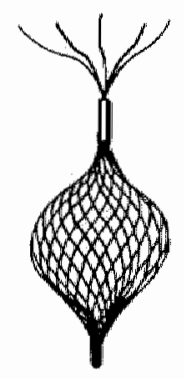

Bi

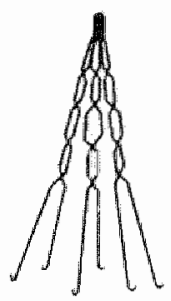

$\mathrm{D}$
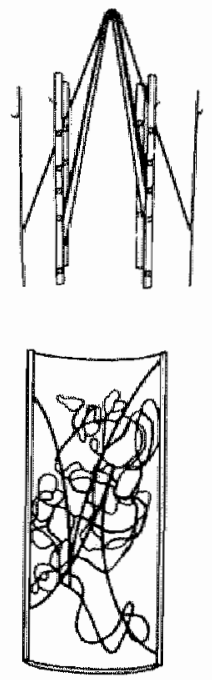

Figure 1: Examples of vena cava fitters: A. Stainless sted Greenfield fiter. B. Thtanium Greenfield fitter. C. Simon nithol filter. D. Vena Tech or LGM filter. E. Amplatz fitter. F. Bird's nest fitter. G. Gunther fihter" Copyright Anverican Medical Association (Arch Intern Med 1992;152;1987) with permission.

Complete lysis occurred in $76 \%$ of non-occlusive clots and in only $19 \%$ of occlusive clots. In 132 patients filter permeability was examined. In $29-33 \%$ of cases a thrombus was detected in the filter one day after the initiation of treatment, which disappeared during further treatment. The filter was successfully removed in all cases ${ }^{17}$. This study shows that during thrombolysis recurrent thromboemboli dislodge from the proximal veins in around $30 \%$ of cases. Seventy-six percent of thrombi found in the filter were smaller than $10 \mathrm{~mm}$, the longest of the remaining clots was $6.5 \mathrm{~cm}$. 


\section{B. Acute embolectomy}

Surgical and transvenous pulmonary embolectomy procedures have been developed. After the first surgical embolectomy without extra-corporeal circulatory support by Trendelenburg, in $1908^{18}$, Gibbon developed open cardiopulmonary bypass as adjunct to relieve the right ventricular overload ${ }^{3}$. The extreme variability of reported mortality (ranging from $24-93 \%$ ) suggest that patient selection is the main determinant of reported survival. Moser stated that based on current data "the only patients in whom acute embolectomy might be considered are those with hemodynamically unstable massive embolism who have an absolute contraindication to anticoagulant or thrombolytic therapy; those in whom aggressive medical therapy, including the use of thrombolytics, has proven to be ineffective in restoring hemodynamic integrity; and in those who have suffered cardiac arrest" 19. Mortality of an incorrect diagnosis approaches $100 \%$. Because all 'late' deaths (beyond the first hours) are due to recurrent embolism Moser advices to insert a temporary filter, and is not performing emergency embolectomy any more in recent years ${ }^{19}$.

Transvenous embolectomy have been used in small series with balloon and retractor devices but have not gained wide acceptance ${ }^{3}$. Suction catheter embolectomy has been used in 46 patients (in combination with a caval vein filter in 32/46 patients) from 1970 to 1992 by Greenfield et $\mathrm{al}^{20}$. Emboli were extracted in $76 \%$ of cases, with acute reduction in mean pulmonary artery pressure of $8 \mathrm{mmHg}$.

Also simultaneous mechanical clot fragmentation and thrombolysis can improve clot resolution markedly according to Essop ${ }^{21,22}$. They used standard catheters for this approach (multipurpose end-hole catheter with an .035 guidewire) and tried to perforate the occluding thrombus with the guidewire. If this was unsuccessful the catheter with the guidewire at its tip was advanced in the 'anticipated' direction with frequent contrast-injections to delineate distal anatomy. Thrombolytic therapy was started with a catheter in the main pulmonary $\operatorname{artery}^{21}$.

Recently a new type of catheter was used to remove thrombi from veins, arteriovenous fistula used for hemodialysis and coronary arteries ${ }^{23}$. This hydrolyser can potentially be used for the removal of emboli from the pulmonary circulation.

\section{Antithrombotic therapy. Available drugs (excluding drugs for chronic anticoagulation) ${ }^{24}$}

Vessel wall damage leads to a complex interaction between the vessel wall, blood-cells (mainly platelets), a number of coagulation factors and coagulation inhibitors to form a stabile hemostatic plug ${ }^{25,26}$. Although the hemostatic system in principle attempts to minimize blood loss from injured vessels, there is little difference between normal hemostasis and pathological events leading to thrombosis and embolism.

The coagulation cascade starts with activated platelets, generating potent mediators. Subsequent platelet aggregation forms a multicellular aggregate, a first line defense referred to as primary hemostasis. The secondary hemostatic system generates fibrin strands produced by the action of thrombin. Thrombin is generated from prothrombin.

Clot dissolution by the endogenous fibrinolytic system is a critically important component 
of the normal hemostatic system in restoring blood flow in obstructed blood vessels. The major protease of the fibrinolytic system is plasmin, generated from plasminogen. Activators like urokinase-type plasminogen activators (u-PA) and tissue-plasminogen activators (t-PA). are available to activate the plasminogen conversion into plasmin. After activation plasmin digests fibrin thrombi. Endogenous fibrinolytic activity is normally regulated at two levels. Plasminogen activator inhibitors (PAI) secreted by endothelial cells and platelets irreversibly inactivates plasmmogen activator. $\mathrm{Alpha}_{2}$-plasmin inhibitor binds to any free plasmin and rapidly neutralizes its action.

Heparin is the most effective anticoagulant for treatment of thromboembolic disorders. Heparin binds to and activates antithrombin. After formation of a protease-antithrombin complex heparin is released and bound to additional antithrombin. Heparin is thus active in preventing fibrin formation. Heparin can sometimes cause thrombocytopenia, and rarely leads to intra-vascular platelet-agglutination and paradoxical thrombosis. Only a small fraction of heparin in most commercially available solutions has anticoagulant activity. To reduce complications and improve efficacy low molecular weight, high antithrombin affinity heparin has been prepared using fractionation of commercial heparin.

\section{Thrombolysis/fibrinolysis}

There are two general classes; the endogenous agents derived from human sources, t-PA and U-PA, and the exogenous agents derived from non-human sources, streptokinase (SK) and anisoylated derivative complexed to plasminogen (APSAC).

$\mathrm{SK}$ is the oldest available plasminogen activator. It does not activate plasminogen directly but forms a complex with the proenzyme. Plasma half-life is 30 minutes. APSAC is an inactive derivative produced by acylation of the plasminogen active site. It works on site in plasma (spontaneous de-acylation) with a plasma lhalf-life of 70 minutes. APSAC and SK not being of human source give rise to allergic reactions and antibody formation. APSAC is not inhibited by Alpha $_{2}$-plasmin inhibitor.

UK is a pro-enzyme that is converted to a fully active low molecular weight two-chain form. The plasma half life is 10 minutes. Unglycosylated human-type high molecular weight single-chain urokinase-type plasminogen activator (scu-PA) has not been used in trials on pulmonary embolism.

Tissue-ty pe plasminogen activator. $\mathrm{t}-\mathrm{PA}$ is normally secreted by endothelial cells as a singlechain polypeptide. It is converted in the plasma to a two-chain species and is more than 300 fold more efficient at activating plasminogen in the presence of fibrin. Single chain $\mathrm{t}-\mathrm{PA}$ has an initial plasma half-life of 4 minutes.

Recombinant DNA technology is increasingly used to produce clinically valuable proteins. This biotechnological industry can produce and purify large-scale recombinant t-PA and is developing t-PA variants.

\section{Heparin and thrombolytics in pulmonary embolism}

The dose needed and the way to administer adequate anticoagulant therapy or thrombolysis is under continuing discussion ${ }^{27-29}$. It is clear that doses needed for recently formed small 
arterial thrombi are not necessarily the same as for venous thrombi of older ages. Using anticoagulants and thrombolytics there is always concern about creating severe hemorrhagic. complications. Heparin has never been used in dosages as high as needed for extra-corporeal circulation during open heart surgery. Usually doses leading to aPTT (activated partial thromboplastin time) levels of 2-3 times normal are used. The dose of the initial bolus in most studies was 5.000-10.000 U. In recent years subcutaneous low-molecular-weight heparin (LMWH) has been used and compared with intravenously given unfractionated heparin (UFH) in doses of $400 \mathrm{U}$ two times daily, resulting in comparable effects ${ }^{30}$.

Streptokinase has in general always been used as a constant infusion of $100.000 \mathrm{U} /$ hour over 24-72 hours (with an initial bolus of 250.000-600.000 U) ${ }^{31,32}$. A single large bolus (e.g. $1.500 .000 \mathrm{U}$ ), as used in myocardial infarction, has been used in solitary cases but never in pulmonary embolism trials ${ }^{33,34}$.

Urokinase has been used as bolus $4000-4400 \mathrm{U} / \mathrm{kg}$ followed by $4000-4400 \mathrm{U} / \mathrm{kg} / \mathrm{hour}$ over 12-24 hour or without bolus in a dose of $2000 \mathrm{U} / \mathrm{kg} /$ hour over 24 hour (total dose can exceed 4-8 millions U of UK) ${ }^{13,14,35}$. Several studies used $15.000-20.000 \mathrm{U} / \mathrm{kg}$ as single bolus (not in trial format) ${ }^{36,37}$. A higher initial dose regimen is given by Goldhaber ${ }^{38}: 1$ million U UK in 10 minutes, followed by 2 million in 110 minutes making a total dose of 3 million in 2 hours. Tilsner suggested to use 1.500.000-3.000.000 U as bolus followed 60.000-100.000 U/hour for 24 hours ${ }^{33,39}$.

Recombinant tissue-type plasminogen activator (rt-PA) has been given as $10 \mathrm{mg}$ bolus followed by a continuous infusion of in total 50-100 mg over maximally 2 hours or in a dose of maximally $50 \mathrm{mg}$ in 15 minutes $(0,6 \mathrm{mg} / \mathrm{kg})^{40-48}$.

The studies using heparin and thrombolysis in pulmonary embolism are listed in table 1. These data deserve the following comments:

The first study which looked at the effect of heparin in comparison with non-pharmalogic treatment was stopped when 19 patients not treated with heparin showed unacceptable high mortality and embolic recurrences. Heparin was clearly superior ${ }^{49}$.

Except for the UPET (1 year V/Q-scan) ${ }^{13}$, USPET ( 6 months V/Q-scan) ${ }^{14}$ and PAIMS 2 study ( 30 days V/Q-scan) ${ }^{42}$, no evaluation of pulmonary vascular function beyond 8 days is available. UPET, USPET showed that on average $67-93 \%$ of the initial percentage of perfusion defects resolved (with UK somewhat better than SK). PAIMS 2 showed 54-68\% improvement in segment score after 30 days ${ }^{42}$. No other $\mathrm{V} / \mathrm{Q}$-scan studies showed more improvement during the first 14 days than $56 \%$.

In most trials angiographic recovery was not studied beyond the first hours. Improvement was around $30-40 \%$. Ly studied his population (SK versus heparin) angiographically after 3 days and Théry (UFH versus LMWH) after 8 days ${ }^{30,31}$. Ly reported $53 \%$ and Théry $68 \%$ improvement within their follow-up period.

Pressure measurement and calculation of total pulmonary resistance showed that mean pulmonary artery pressure never normalized (below $16 \mathrm{mmHg}$ ) during follow-up, except in the study of Verstraete ${ }^{40}$. In that study only the group treated with $50 \mathrm{mg}$ rt-PA over 2 hours 
pius heparin, additionally receiving, because of insufficient first result, 50 mg over 5 hours, reached on average a mean pulmonary artery pressure of $12 \mathrm{mmHg}$. The same holds true for total pulmonary resistance. Sors showed that the average improvement was $26 \%$ in 30 minutes, $29-36 \%$ in 1 hour and $43-49 \%$ in 12 hours ${ }^{47}$.

In general the mortality of acute pulmonary embolism decreased dramatically after the start of using heparin. Using thrombolytics did not result in further reduction of mortality. The rate of lysis and pulmonary pressure lowering during the first hours is, however, clearly better in the thrombolysis groups compared with heparin ${ }^{13,31,44,45}$. In this respect $100 \mathrm{mg} \mathrm{rt-PA}$ (over longer periods?) seems to be best ${ }^{40,47}$.

It is surprising that there is hardly any study after 1980 evaluating the late effects on pulmonary vascular conditions, which seems to be a must to obtain information on optimal therapy. The only study looking at pulmonary capillary blood volume as expression of vital micro-circulation was performed as a sub-study of the UPET and USPET study. In this study, after one year, a clear beneficial effect was noted for treatment with urokinase in comparison to heparin (see table 1, Sharma 1980) s. $^{50}$.

In normal adults pulmonary artery pressure hardly increases when cardiac output increases. In patients with chronic pulmonary disease pulmonary pressures will increase during exercise more than twice the resting value. Thus a patient with a baseline mean pulmonary artery pressure of $25 \mathrm{mmHg}$ can exhibit severe pulmonary hypertension ( $50 \mathrm{mmHg}$, mean) during mild to moderate exercise. This means that during daily activities as walking and climbing stairs pronounced pressure elevation can cause right ventricular hypertrophy and even right ventricular failure ${ }^{51,52}$. No such studies have been undertaken in patients with pulmonary embolism after recovery from the acute event. It seems logical that also after embolization and (partial) resolution, changes in the pulmonary vasculature will cause an inappropriate response to an increase in flow. The observation of Sharma et al. on pulmonary blood volume in patients with pulmonary embolism treated with heparin illustrates that over time the micro-circulation can change considerably in this population ${ }^{50}$.

In our population (chapter 5) of 60 patients with pulmonary embolism and RV overload 10 patients ( $16.7 \%$ ) died. In 25 patients ( $41.7 \%$ ) follow-up echocardiography was performed. In $15 / 25$ patients the follow-up echocardiogram was performed more than 4 months after the event. In $9 / 15$ patients the tricuspid regurgitation velocity exceeded $2.7 \mathrm{~m} / \mathrm{s}$ indicating resting systolic pulmonary artery pressure of more than $30 \mathrm{mmHg}$. In these patients a steep pressure increase during exercise can be expected. It also shows that a considerable number of patients will have some form of pulmonary hypertension after the acute period. In patients not having elevated resting pulmonary pressures, still an inappropriate elevation of pressures during exercise could be present. Using echocardiography, however, it is very difficult to monitor tricuspid incompetence velocities during or immediately after exercise in patients who are in general short of breath, adipose and less mobile. 


\section{In conclusion:}

1. It is estimated that of all cases of pulmonary embolism approximately $10 \%$ will die within one hour ${ }^{52.53}$. After this initial event one third of cases will reach hospital. Acute in-hospital death in adequately diagnosed, therapy instituted, pulmonary embolism is around $8 \%$ \%2,5: Subsequent death in the two third of all non-diagnosed cases outside hospital (surviving the initial event) is estimated to be $30 \%{ }^{52,53}$. Non-diagnosed pulmonary embolism in the hospital population is also not unusual and accounts for a substantial amount of in-hospital morbidity and mortality (chapter 3 ).

2. Prognosis after pulmonary embolism is mainly dependent on age of thromboembolism (acute/subacute and chronic/occult) and pre-embolic status. $8-32 \%$ of patients will die mainly as a result of the underlying disease. In patients with deep venous thrombosis this can increase to $42 \%$ in 6-8 year (chapter 2$)^{55}$. In patients with persistent forms of pulmonary hypertension prognosis is dependent on the height of the mean pulmonary artery pressure.

3. A considerable amount of studies have been performed on therapy in patients with acute pulmonary embolism. Heparin is significantly better than no pharmacological therapy as to mortality and morbidity. Thrombolytics perform better in the early hours.

4. "Complete" resolution in acute/subacute pulmonary embolism is estimated to be present in around $65-75 \%$ of patients ${ }^{11,14}$. In $2-12 \%$ there is no resolution " More recent studies (1980 and later) looking at long-term effects (longer than 7-8 days) of therapy on resolution of pulmonary emboli and pulmonary pressures are not available. The latest study looking at long-term effects, investigated pulmonary-capillary blood volume one year after treatment, comparing patients treated with heparin with patients on thrombolytics (data from patients of the UPET and USPET studies) ${ }^{13,14}$. This study describes more complete resolution of thromboemboli in patients treated with thrombolytics than heparin and anticoagulants ${ }^{50}$.

5. In patients in a poor hemodynamic state due to massive pulmonary embolism the best approach is to give a thrombolytic agent to obtain the most rapid early resolution of emboli. To prevent new early embolic events insertion of a temporary vena cava filter should be considered.

\section{Practical cardiological approach to patients suspected of acute pulmonary embolism:}

Goldhaber divides patients presenting with thromboembolism into 6 categories $^{5 \%}$ :

\section{Massive:}

Presentation: Breathlessness, syncope and cyanosis with persistent systemic arterial hypotension (systolic blood pressure $<90 \mathrm{mmHg}$ ).

RV-dysfunction present.

Usually more than $50 \%$ obstruction of pulmonary vasculature.

\section{Moderate to large:}

Presentation: Normal systolic arterial blood pressure.

RV-dysfunction present. 
Perfusion defect on lung scan typically greater than $30 \%$.

3. Small to moderate:

Presentation: Normal systolic blood pressure.

No RV-dysfunction.

4. Pulmonary infarction (usually small peripheral emboli).

5. Paradoxical embolism.

6. Non-thrombotic pulmonary embolism (air, fat, tumor fragments, amniotic fluid).

The first two categories are treated with heparin plus thrombolytic therapy and/or a mechanical intervention. The small pulmonary emboli (syndromes 3 and 4) are only treated with heparin ${ }^{57,58}$.

As stated earlier the recently proposed pulmonary embolism diagnosis strategy does not include echocardiography and ECG as first line tools in the diagnosis ${ }^{57}$. Most studies using echocardiography are only studying RV dilatation and RV asynergy and not RV pressure increase using the tricuspid regurgitant velocity. RV-dysfunction in these studies is not the same as RV pressure overload. In our own strategy we will approach the problem as a cardiovascular problem.

Basically the most important steps to be undertaken in patients with suspected pulmonary embolism are (scheme on page 108):

1. Physical examination with emphasis on signs of diminished cardiac output and RV pressure overload or RV failure.

2. Rapid diagnosis of (the severity of) RV pressure overload using ECG and echocardiography. Combine echocardiography with blood gas analysis (emphasis on $\mathrm{pCO}_{2}$ ). A low $\mathrm{pCO}_{2}$ in the presence of echocardiographic $\mathrm{RV}$-overload is suggestive of pulmonary embolism. Higher $\mathrm{pCO}_{2}$ levels do not exclude pulmonary embolism but make a pulmonary cause also more likely.

3. In patients with $\mathrm{RV}$ overload and a low $\mathrm{pCO}_{2}$ pulmonary embolism is very likely. Conformation can be obtained using ventilation perfusion scanning or pulmonary angiography. If logistically possible perform pulmonary artery pressure measurements (figure 2).

4. Evaluate the site and the extent of venous thrombosis (not only helpful to confirm the diagnosis but also essential to recognize potentially lethal recurrences). If proximal deep venous thrombosis is present consider placement of a temporary vena cava inferior filter.

5. Treat patients with massive or moderate to large pulmonary emboli with heparin plus thrombolytic agents. The optimal treatment goal is normalization of resting pulmonary artery pressures. In patients with massive embolism and hypotension/shock consider mechanical pulmonary embolectomy or fragmentation using a catheter. 
The same scheme is followed if echocardiography and ECG or echocardiography allone are the only sign of RV pressure overload in patients presenting with complaints not suspect for pulmonary embolism.

D-dimer is not incorporated in this scheme. At present our experience with D-dimer is to limited to use it as a separate step.
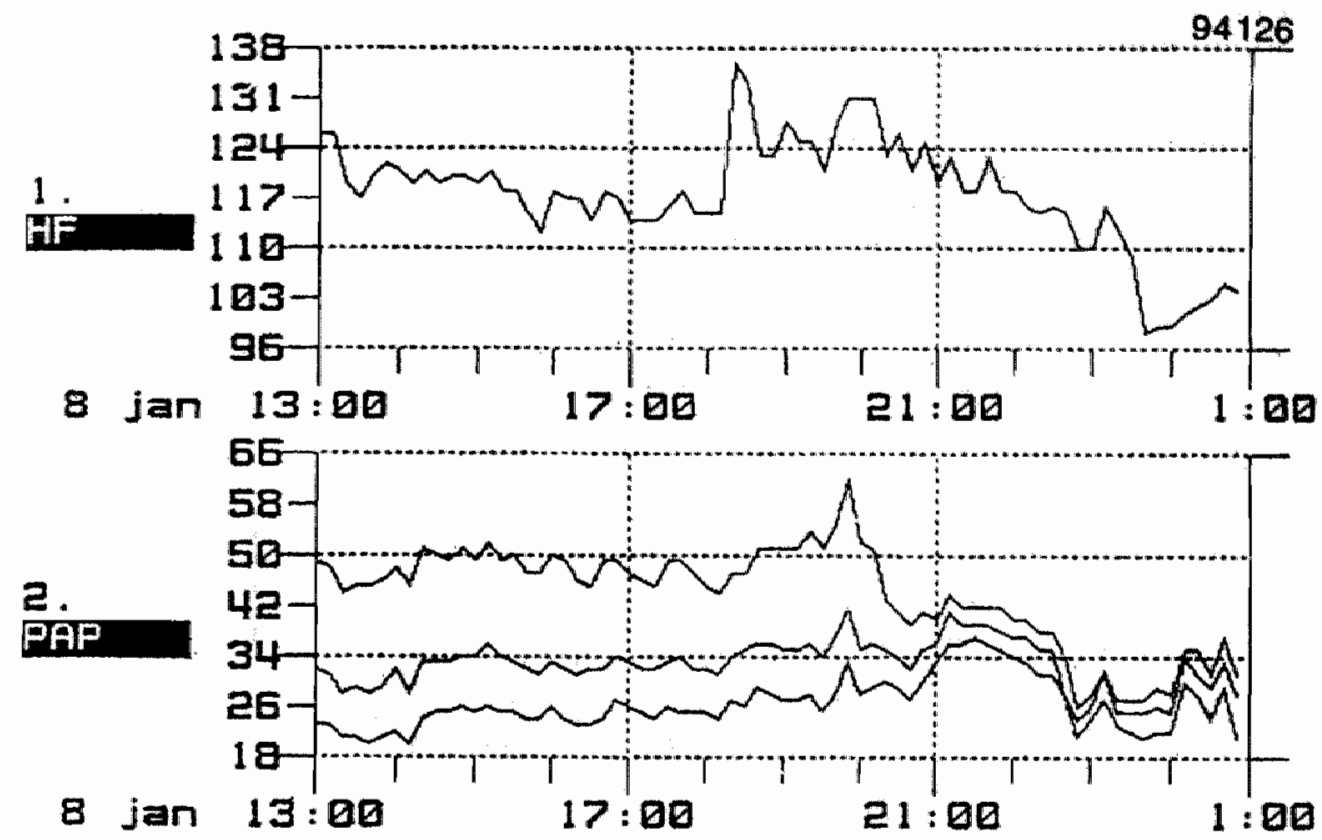

Figure 2: Example of heart rate (HF) and pulmonary artery pressure (PAP) behavior in a patient with pulmonary embolism treated with thrombolysis. The superior line in the PAP graph represents the systolic pressure, the lowest line represents the diastolic pressure and the middle line the mean pulmonary artery pressure. Heart rate decreases to around $100 / \mathrm{min}$ and mean pulmonary artery pressure to around $25 \mathrm{mmHg}, 12$ hours atter starting treatment. 


\begin{tabular}{|c|c|c|c|c|}
\hline Study & $\begin{array}{l}\text { Indusion / } \\
\text { number pat. }\end{array}$ & Diagnostic evaluation & Treatment & $\begin{array}{l}\text { Primary effect: } \\
\text { 1. Angiogram }\end{array}$ \\
\hline \multirow{3}{*}{$\begin{array}{l}\text { Barritt } \\
1960^{45}\end{array}$} & $<12 \mathrm{~d}$ after & \multirow{3}{*}{$\begin{array}{l}\text { Clinical. First Trial } \\
\text { "no heparin" versus } \\
\text { "heparin". } \\
\text { Trial was altered after } 35 \\
\text { pat, because of high } \\
\text { mortality in "no heparin" } \\
\text { group }\end{array}$} & $10 \mathrm{~d}$ confined to bed & - \\
\hline & & & & \\
\hline & $\begin{array}{l}<12 \mathrm{~d} \text { after } \\
\text { onset } P E / 16 \\
\text { (expanded to } \\
54 \text { ) }\end{array}$ & & $\begin{array}{l}\text { Heparin } 10,000 \text { U every } 12 \mathrm{~h} \text { for } 6 \\
\text { doses without laboratory control and } \\
10 \mathrm{~d} \text { confined to bed }\end{array}$ & - \\
\hline \multirow[t]{2}{*}{$\begin{array}{l}\text { LIPET } \\
1970^{12}\end{array}$} & all $P E / 82$ & \multirow{2}{*}{ 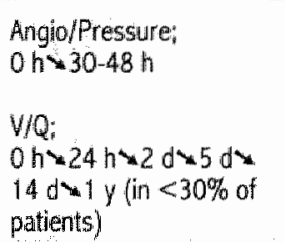 } & $\begin{array}{l}\text { UK } 4400 \text { U/kg bolus followed by } 4400 \\
\text { U/kg/h over } 12 \mathrm{~h} \text { and } 5 \text { days heparin } \\
\text { [Lee-White } 30-45 \mathrm{~min} \text { ). }\end{array}$ & $1.78^{*}$ \\
\hline & all PE/78 & & $\begin{array}{l}\text { Heparin } 165 \mathrm{U} / \mathrm{kg} \text { bolus followed by } 22 \\
\text { U/kg/h ower } 12 \mathrm{~h} \text { and } 5 \text { days heparin } \\
\text { (Lee-White } 30-45 \mathrm{~min} \text { ). }\end{array}$ & $0.54^{*}$ \\
\hline \multirow[t]{2}{*}{$\begin{array}{l}\text { Miller } \\
1974{ }^{2}\end{array}$} & $\begin{array}{l}<2 \mathrm{~d} \text { after } \\
\text { onset } \mathrm{PE} / 15\end{array}$ & \multirow[t]{2}{*}{$\begin{array}{l}\text { Angio/Pressure: } \\
0 \mathrm{~h} \times 24 \mathrm{~h}\end{array}$} & $\begin{array}{l}\text { SK } 600.000 \text { bolus followed by } 100.000 \\
\text { h over } 72 \mathrm{~h}\end{array}$ & $24.3 \times 9.7^{* *}$ \\
\hline & $\begin{array}{l}<2 \mathrm{~d} \text { after } \\
\text { onset } \mathrm{PE} / 8\end{array}$ & & Heparin over $72 \mathrm{~h}>2 \times$ aPTT & $23.9 \times 21.8 * *$ \\
\hline \multirow[t]{3}{*}{$\begin{array}{l}\text { USPET } \\
1974^{14}\end{array}$} & $\begin{array}{l}<5 d \text { after } \\
\text { onset } P E / 59\end{array}$ & \multirow{3}{*}{$\begin{array}{l}\text { Angio/Pressure; } \\
\text { o } \mathrm{h} \times 24-30 \mathrm{~h} \\
\text { W/Q; } \\
0 \mathrm{~h} \times 1 \mathrm{~d} \times 3 \text { mo } \times 6 \mathrm{mo} \\
\text { (in } 60 \% \text { of patients) }\end{array}$} & $\begin{array}{l}\text { UK } 4400 \text { U/kg bolus followed by } 4400 \\
\text { U/kg/h over } 12 \mathrm{~h}\end{array}$ & $1.66^{*}$ \\
\hline & $\begin{array}{l}<5 d \text { after } \\
\text { onset PE/54 }\end{array}$ & & $\begin{array}{l}\text { UK } 4400 \mathrm{U} / \mathrm{kg} \text { bolus followed by } 4400 \\
\text { U/kg/h over } 24 \mathrm{~h}\end{array}$ & $1.76^{*}$ \\
\hline & $\begin{array}{l}<5 \text { dafter } \\
\text { onset PE/54 }\end{array}$ & & $\begin{array}{l}5 K 250.000 \mathrm{U} / 20-30 \mathrm{~min} \text { bolus } \\
\text { followed by } 100.000 \mathrm{U} / \mathrm{h} \text { over } 24 \mathrm{~h}\end{array}$ & $1.70^{*}$ \\
\hline \multirow[t]{2}{*}{$1978^{31}$} & $\begin{array}{l}<5 d \text { after } \\
\text { onset } P E / 14\end{array}$ & \multirow[t]{2}{*}{ Angio $0 \mathrm{~h} \times 72 \mathrm{~h}$} & $\begin{array}{l}5 K 250.000 \text { U/20 min followed by } \\
100.000 \text { U/h over } 72 \mathrm{hll} \text { After } 5 K_{\text {n }} \\
\text { warflarin }\end{array}$ & $21.6 \times 10.2 *$ \\
\hline & $\begin{array}{l}<5 \mathrm{~d} \text { alter } \\
\text { onset } P E / 11\end{array}$ & & $\begin{array}{l}\text { Heparin } 15.000 \mathrm{U} / \text { bolus followed by } \\
30.000 \mathrm{U} / \mathrm{d} \text { over } 7 \mathrm{~d}(30.000-60.000 \\
\mathrm{U} / \mathrm{dl})\end{array}$ & $16.5 \times 13.1 * *$ \\
\hline \multirow[t]{2}{*}{$\begin{array}{l}\text { Sharma } \\
1980^{\text {sid }}\end{array}$} & all $P E / 21$ & \multirow{2}{*}{$\begin{array}{l}\text { Pulmonary diffusing } \\
\text { capacity (D) } \text { co and } \\
\text { Pulmonary capillary } \\
\text { bload volume }\left(V_{c}\right) \\
14 \mathrm{~d} \text { \#y }\end{array}$} & $\begin{array}{l}\text { Heparin (see UPET and USPET. } \\
\text { Patients from ane center underwent } \\
\text { this sub-study) }\end{array}$ & - \\
\hline & all PE/19 & & SK and UK (see UPET and USPET) & . \\
\hline \multirow[t]{2}{*}{$\begin{array}{l}\text { UKEP } \\
1987^{35}\end{array}$} & $\begin{array}{l}<5 \text { d after } \\
\text { onset PE/67 }\end{array}$ & \multirow[t]{2}{*}{ Angio $0 \mathrm{~h} \times 30-48 \mathrm{~h}$} & $\begin{array}{l}\text { UK } 2000 \text { U/kg/h } 24 \mathrm{~h}+\text { heparin/24h } \\
\text { (2.3 } 3 \text { aPTT) followed by heparin } 22 \mathrm{~d}\end{array}$ & $22.6 \times 17.0^{* *}$ \\
\hline & $\begin{array}{l}<5 d \text { after } \\
\text { onset PE/62 }\end{array}$ & & $\begin{array}{l}\text { UK } 4400 \mathrm{U} / \mathrm{kg} / \mathrm{h} 12 \mathrm{~h} \text { followed by } \\
\text { heparin } 22 \mathrm{~d}\end{array}$ & $22.6 \times 18.2$ \\
\hline
\end{tabular}


Treatment of pulmonary embolism

\begin{tabular}{|c|c|c|c|c|c|}
\hline $\begin{array}{l}\text { 11. PASP (P) or } \\
\operatorname{MPAP}(M)\end{array}$ & III. TPR & N. VIQ & $\begin{array}{l}\text { Important } \\
\text { bleeding }\end{array}$ & $\begin{array}{l}\text { Mortality of } \\
\text { ther apy }\end{array}$ & $\begin{array}{l}\text { Late evaluation } \\
\text { \# remarks }\end{array}$ \\
\hline$\infty$ & - & - & $0 \%$ & $0 \%$ & $\begin{array}{l}\text { Total mortality } 26.3 \% \\
\text { PE recurrence } 26.3 \%\end{array}$ \\
\hline- & - & - & $0 \%$ & $0 \%$ & $\begin{array}{l}\text { \# No mortality and no } \\
\text { recurrence in first } 16 \text { pat } \\
\text { and } 1 \text { recurrence in final } \\
54 \text { pat }\end{array}$ \\
\hline $\begin{array}{l}P 44.5 \times 3.4 .4 \\
M 26.3 \times 20.7\end{array}$ & $\begin{array}{l}5.8 \times 5.5 \\
\Delta \text { Dynes-sec- } \\
\mathrm{cm}^{-5}\end{array}$ & $\begin{array}{l}26.6 \times 20.4 \times 11.7 \\
\text { in } 0.1-14 \mathrm{~d} \text { (resp) }\end{array}$ & $\begin{array}{l}45 \% \text { (many } \\
\text { venesections) }\end{array}$ & $1 \%$ & W/Q25.7×6.6@ \\
\hline $\begin{array}{l}P 44.4 \times 41.2 \\
M 26.0 \times 24.8\end{array}$ & $\begin{array}{l}5.9 \times 5.9 \\
\begin{array}{l}\Delta \text { Dynes-sec- } \\
\mathrm{cm}^{-5}\end{array}\end{array}$ & $\begin{array}{l}25.4 \times 22.7 \times 10.7 \\
\text { in } 0-1-14 d(\text { resp) }\end{array}$ & $27 \%$ & $0 \%$ & WQ26×5.8@ \\
\hline$P 43 \times 27.8$ & $16.3 \times 7.0 \mathrm{U} / \mathrm{m}^{2}$ & - & $20 \%$ & $0 \%$ & \multirow[t]{2}{*}{ Absent } \\
\hline$P 43.5 \times 37.2$ & $\begin{array}{l}15.0 \times 11.2 \\
\mathrm{U} / \mathrm{m}^{3}\end{array}$ & - & $25 \%$ & $0 \%$ & \\
\hline $\begin{array}{l}P 47.8 \times 35.5 \\
M 27.4 \times 20.1\end{array}$ & $\begin{array}{l}5.96 \times 5.63 \\
\text { Dynes-sec-cm-5. }\end{array}$ & $33 \times 24 @$ & $\begin{array}{l}31 \% \text { (many } \\
\text { venesections) }\end{array}$ & $0 \%$ & V/Q33>4.4×2.5@ \\
\hline $\begin{array}{l}P 46.4 \times 35 \\
M 27.5 \times 20\end{array}$ & $\begin{array}{l}5.93 \times 5.49 \\
\text { Dynes-sec-cmis }\end{array}$ & 33721.4@ & $25 \%$ & $0 \%$ & V/Q3377×8.1@ \\
\hline $\begin{array}{l}P 45.6 \times 36.2 \\
M 26.2 \times 20.9\end{array}$ & $\begin{array}{l}5.18 \times 4.78 \\
\text { Dynes sec } \mathrm{cm}^{-5}\end{array}$ & $33 \times 26 @$ & $22 \%$ & $0 \%$ & W/Q 33×11.4×10.8@ \\
\hline - & - & - & $24 \%$ & $0 \%$ & \multirow[t]{2}{*}{$\begin{array}{l}\text { Absent } \\
\text { \# in } 72 \text { h less } \\
\text { improvement with heparin }\end{array}$} \\
\hline - & - & - & $18 \%$ & $0 \%$ & \\
\hline- & - & - & - & - & $\begin{array}{l}D I_{c \infty} 19 \times 20(\text { norm } \\
19-35) \\
V_{r} 30 \times 28(\text { norm } 47 \pm 5)\end{array}$ \\
\hline - & - & - & - & - & $\begin{array}{l}D P_{c \epsilon} 22 \times 24 \\
V_{c} 45 \times 49\end{array}$ \\
\hline $\begin{array}{l}P 45.1 \times 33.9 \\
M 27.3 \times 19.5\end{array}$ & - & 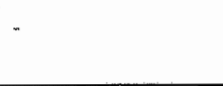 & $4.5 \%$ & $1.5 \%$ & \multirow[t]{2}{*}{ Absent } \\
\hline $\begin{array}{l}P 45.9 \times 35.4 \\
M 28.3 \times 21.6\end{array}$ & - & - & $3.2 \%$ & $1.6 \%$ & \\
\hline
\end{tabular}




\begin{tabular}{|c|c|c|c|c|}
\hline Study & $\begin{array}{l}\text { Indusion/ } \\
\text { no pat }\end{array}$ & Diagnostic enaluation & Treatment & $\begin{array}{l}\text { Primary effect: } \\
\text { 1. Anglogram }\end{array}$ \\
\hline \multirow[t]{2}{*}{$\begin{array}{l}\text { Verstraete } \\
1988^{\circ} \text { : }\end{array}$} & $\begin{array}{l}<5 d \text { after } \\
\text { onset } \\
\text { PE/19 }\end{array}$ & \multirow[t]{2}{*}{$\begin{array}{l}\text { Angio/Pressure: } \\
\text { o hw } 2 \mathrm{~h} \text { (and } 7.78 \mathrm{~h} \\
\text { if Miller index }>15 \text { after } \\
2 \mathrm{~h} \text { ) }\end{array}$} & $\begin{array}{l}\text { tt-PA } 10 \mathrm{mg} / \text { botus followed by } 20 \\
\text { mg/h over } 2 \mathrm{~h} \text { (total } 50 \mathrm{mg} \text { ) intra: } \\
\text { pulmonary }+ \text { heparin ( } 5000 \mathrm{U} \text { and } \\
1000 \mathrm{U} / \mathrm{h} \text { ) }\end{array}$ & $\begin{array}{l}25 \times 22 \\
(\times 16(14 \text { pat }))^{*}\end{array}$ \\
\hline & $\begin{array}{l}<5 d \text { after } \\
\text { onset } \\
\text { PElis }\end{array}$ & & $\begin{array}{l}\text { rt-PA } 10 \text { mg/bolus followed by } 20 \\
\text { mg/h over } 2 \mathrm{~h} \text { (total } 50 \mathrm{mg} \text { ) } \\
\text { intravenous + heparin ( } 5000 \\
\text { U/bolus and } 1000 \text { U/h). If Mller } \\
\text { score }>15 \text { than additionat } 50 \mathrm{mg} \\
\text { over } 5 \mathrm{~h} \text { (i.p. or li.w) }\end{array}$ & $\begin{array}{l}26 \times 22 \\
(\times 16(8 \text { pat }))^{* *}\end{array}$ \\
\hline \multirow[t]{2}{*}{$\begin{array}{l}\text { Goldhaber } \\
1988^{41}\end{array}$} & $\begin{array}{l}<14 \text { d after } \\
\text { onset } \\
\text { PE122 }\end{array}$ & \multirow{2}{*}{$\begin{array}{l}\text { Angio/Pressure; } \\
0 \mathrm{~h} \times 2 \mathrm{~h} \\
\mathrm{~V} / \mathrm{Q} \\
0 \mathrm{~h} \times 24 \mathrm{~h}\end{array}$} & nt-PA $100 \mathrm{mg} / 2 \mathrm{~h}$ (no heparin) & $\begin{array}{l}6.2 \times 4.8 \text { quantitative } \\
\text { score (UPET not } \\
\text { subtracted) }\end{array}$ \\
\hline & $\begin{array}{l}<14 d \text { after } \\
\text { onset } P E / 23\end{array}$ & & $\begin{array}{l}\text { UK } 4400 \text { U/kg ballus and } 4400 \\
\text { U/kg/h over } 24 \mathrm{~h} \text { (if } 2 \mathrm{~h} \text { angiogram } \\
\text { showed lysis UKK was stopped (in } 2 \\
\text { pts)) (no heparin) }\end{array}$ & $\begin{array}{l}6.0 \times 5.5 \text { quantitative } \\
\text { score }\end{array}$ \\
\hline \multirow{2}{*}{$\begin{array}{l}\text { PUOPED } \\
\text { (collabora } \\
\text { tive study) } \\
1990^{4+4}\end{array}$} & $\begin{array}{l}<7 \text { d after } \\
\text { onset } P E / 9\end{array}$ & \multirow{2}{*}{$\begin{array}{l}\text { Angio/Pressure; } \\
0 \mathrm{~h} \times 2 \mathrm{~h} \\
\text { V/Q; } \\
0 \mathrm{~h} \times 1 \mathrm{~d} \times 2 \mathrm{~d} \times 7 \mathrm{~d}\end{array}$} & $\begin{array}{l}\text { rttPA } 40(-80) \mathrm{mg} / 40(-90) \text { min }+ \\
\text { heparin (dose?) }\end{array}$ & $\begin{array}{l}12.2 / 10.0 \times \\
12.5 / 8.2 \\
\text { (score left/right) }\end{array}$ \\
\hline & $\begin{array}{l}<7 \text { dafter } \\
\text { onset } P E / 4\end{array}$ & & Heparin (dose?/periad?) & $\begin{array}{l}12.9 / 15.5 x \\
12.8 / 18\end{array}$ \\
\hline \multirow[t]{2}{*}{$\begin{array}{l}\text { Levine } \\
1990^{48}\end{array}$} & $\begin{array}{l}<14 \text { d after } \\
\text { onset } P E / 33\end{array}$ & \multirow[t]{2}{*}{$\begin{array}{l}V / Q_{i} \\
0 h \times 1 d \times 7 d\end{array}$} & $\begin{array}{l}5000 \text { U/bolus heparin }+30.000 \\
\text { U/24 h heparin + nt-PA } 0.6 \\
\text { mg/kg/2 min }\end{array}$ & - \\
\hline & $\begin{array}{l}<14 \mathrm{~d} \text { after } \\
\text { onset } \mathrm{PE} / 25\end{array}$ & & $\begin{array}{l}5000 \text { U/bolus heparin }+30.000 \\
\text { U/24 h heparin + Placebo }\end{array}$ & - \\
\hline \multirow[t]{2}{*}{$\begin{array}{l}\text { Goldhaber } \\
1992^{\text {th }}\end{array}$} & $\begin{array}{l}<14 \text { after } \\
\text { onset } P E / 46\end{array}$ & \multirow[t]{2}{*}{$\begin{array}{l}\text { Angio/Pressure: } \\
\text { oh } \times 2 \mathrm{~h} \\
\text { W/Qi } \\
0 \mathrm{~h} \times 24 \mathrm{~h}\end{array}$} & $\begin{array}{l}\text { UK } 1 \text { million } U / 10 \text { min followed by } 2 \\
\text { million U/1 } 10 \text { min followed by } \\
\text { heparin } 7 \mathrm{~d}(2 \times \text { aPT })\end{array}$ & $\begin{array}{l}6.43 \times 5.29 \\
\text { quantitative score. } \\
\text { Moderate to marked } \\
\text { improwement in } 42 \%\end{array}$ \\
\hline & $\begin{array}{l}<14 \text { d after } \\
\text { onset } P E / 46\end{array}$ & & $\begin{array}{l}\text { tt-PA } 100 \mathrm{mg} / 2 \mathrm{~h} \text { followed by } \\
\text { heparin for } 7 \mathrm{~d}(2 \times \text { aPTT) }\end{array}$ & $\begin{array}{l}6.04 \times 4.69 \\
\text { quantitative score. } \\
\text { Moderate to marked } \\
\text { improwement in } 33 \%\end{array}$ \\
\hline \multirow[t]{2}{*}{$\begin{array}{l}\text { Meyer } \\
1992^{43}\end{array}$} & $\begin{array}{l}<6 \mathrm{~d} \text { after } \\
\text { onset } \mathrm{PE} / 29\end{array}$ & \multirow[t]{2}{*}{$\begin{array}{l}\text { Angio/Pressure; } \\
0 \mathrm{~h} \times 12-18 \mathrm{~h}\end{array}$} & $\begin{array}{l}\text { UK } 4.000 \mathrm{U} / \mathrm{kg} \text { bolus and } 4.000 \\
\mathrm{U} / \mathrm{kg} / \mathrm{h} \text { over } 12 \mathrm{~h} \text { and heparin if } \\
\text { needed for } 0-6 \mathrm{~h} \text { (Angio) }\end{array}$ & $25 \times 17.5^{* *}$ \\
\hline & $\begin{array}{l}<6 \mathrm{~d} \text { after } \\
\text { onset } \\
\text { PE } 134\end{array}$ & & $\begin{array}{l}\mathrm{rt} . \mathrm{PA} 10 \mathrm{mg} \text { bolus and } 90 \mathrm{mg} / 2 \mathrm{~h} \\
\text { followed by heparin } 20 \mathrm{U} / \mathrm{kg} \text { over } \\
10-18 \mathrm{~h}\end{array}$ & $24 \times 18.1 * *$ \\
\hline
\end{tabular}


Treatment of pulmonary embolism

\begin{tabular}{|c|c|c|c|c|c|}
\hline $\begin{array}{l}\text { Il. PASP (P) or } \\
\text { MPAP (M) }\end{array}$ & HII.TPR & NV. V/Q & $\begin{array}{l}\text { Important } \\
\text { bleeding }\end{array}$ & $\begin{array}{l}\text { Mortality of } \\
\text { therapy }\end{array}$ & $\begin{array}{l}\text { Late evaluation } \\
\text { remarks }\end{array}$ \\
\hline$M 31 \times 22 \times 18$ & - & - & $15 \%$ & $0 \%$ & \multirow{2}{*}{$\begin{array}{l}\text { Absent } \\
\text { \#Befter effect with longer infusion. } \\
\text { \#no additional benefit } \\
\text { intrapulmonary infusion } \\
\$ \text { Petitpretz et al. Circ } 70 ; \\
861 ; 1984 \text { uses } 15.000 \mathrm{U} / \mathrm{kg} \text { UK as } \\
\text { bolus with fast result (case reports) }\end{array}$} \\
\hline$M 31 \times-21 \times 12$ & - & - & $0 \%$ & $0 \%$ & \\
\hline $\begin{array}{l}P 50 \times 39 \\
M 31 \times 24\end{array}$ & - & $\begin{array}{l}32 / 41 \times 22 / 29 @ \\
\text { (AP/Segmental } \\
\text { views) }\end{array}$ & $23 \%$ & $0 \%$ & \multirow{2}{*}{$\begin{array}{l}\text { Absent } \\
\text { \# rt-PA faster than UK } \\
\text { \# bleeding not needing blood } \\
\text { transfusions was present in } 12 / 23 \\
\text { UK pat and needed discontinuation } \\
\text { of UK in } 8 \text { ( } 5 / 8 \text { groin-related) }\end{array}$} \\
\hline $\begin{array}{l}P 46 \times 49 \\
M 26 \times 27\end{array}$ & - & $\begin{array}{l}33 / 42 \times 21 / 30 @ \\
\text { (AP/Segmentall } \\
\text { views) }\end{array}$ & $4 \%$ & $0 \%$ & \\
\hline$M 28 \times 25$ & $\begin{array}{l}550 \times 360 \\
\text { Dynes-sec- } \\
\mathrm{cm}^{-5}\end{array}$ & $\begin{array}{l}39 \times 29 \times 28 \times 19 \\
@\end{array}$ & $11.1 \%$ & $11.1 \%$ & \multirow[t]{2}{*}{$\begin{array}{l}\text { Absent } \\
\text { \# dose finding and comparison } \\
\text { with heparin }\end{array}$} \\
\hline$M 33 \times 33$ & $770 \times 760$ & $\begin{array}{l}41 \times 41 \times 40 \times 34 \\
@\end{array}$ & $0 \%$ & $0 \%$ & \\
\hline- & - & $\begin{array}{l}27.4 \times 17.7 \times 11.4 \\
@\end{array}$ & $0 \%$ & $0 \%$ & \multirow{2}{*}{$\begin{array}{l}\text { Absent } \\
\text { \# Inclusion: also (not reporting) } \\
\text { subgroups < }<48 \mathrm{~h} \text { and } \geq 48 \mathrm{~h} \text { after } \\
\text { onset of PE } \\
\text { \# Exclusion: heparin use }>72 \mathrm{~h} \\
\text { (tailled heparin!) }\end{array}$} \\
\hline - & - & $\begin{array}{l}21.3 \times 16.1 \times 10.3 \\
@\end{array}$ & $0 \%$ & $0 \%$ & \\
\hline $\begin{array}{l}P 44.4 \times 43.2 \\
M 28.5 \times 28.3\end{array}$ & - & $\begin{array}{l}34.2 / 40.4 x \\
25.2 / 31 @ \\
\text { (AP/segmental } \\
\text { views) }\end{array}$ & $13 \%$ & $0 \%$ & \multirow[t]{2}{*}{$\begin{array}{l}\text { Absent } \\
\text { \# similar effects of } 2 \mathrm{~h} \text { rt-PA and } \\
\text { UKK }\end{array}$} \\
\hline $\begin{array}{l}P 47.4 \times 44.2 \\
M 27.8 \times 28.1\end{array}$ & - & $\begin{array}{l}31.2 / 37.5 x \\
22.1 / 27 @ \\
\text { (AP/segmental } \\
\text { views) }\end{array}$ & $18 \%$ & $2.3 \%$ & \\
\hline $\begin{array}{l}P 48 \times 30 \\
M 28 \times 17\end{array}$ & $\begin{array}{l}14.1 \times 6.4 \\
\mathrm{U} / \mathrm{m}^{2}\end{array}$ & - & $21 \%$ & $29 \%$ & \multirow[t]{2}{*}{$\begin{array}{l}\text { Absent } \\
\text { \# no differences between study- } \\
\text { groups }\end{array}$} \\
\hline $\begin{array}{l}P 47 \times 30 \\
M 28 \times 17\end{array}$ & $\begin{array}{l}11.9 \times 5.9 \\
\mathrm{U} / \mathrm{m}^{2}\end{array}$ & - & $28 \%$ & $3.4 \%$ & \\
\hline
\end{tabular}




\begin{tabular}{|c|c|c|c|c|}
\hline Study & $\begin{array}{l}\text { lindusion / tho } \\
\text { pat }\end{array}$ & Dignostic evaluation & Treatiment & $\begin{array}{l}\text { Primary effect: } \\
\text { I. Anigiogram }\end{array}$ \\
\hline \multirow[t]{2}{*}{$\begin{array}{l}\text { PAIMS2 } \\
1992^{42}\end{array}$} & $\begin{array}{l}<10 \text { d atter } \\
\text { onset PE / } 20\end{array}$ & \multirow{2}{*}{ 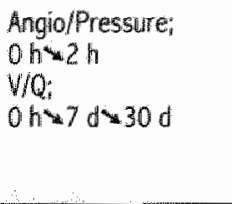 } & $\begin{array}{l}\text { Heparin } 10.000 \text { U/bolus and } \mathrm{rt}-\mathrm{PA} \\
10 \mathrm{mg} \text { bolus and } 90 \mathrm{mg} / 2 \mathrm{~h} \text {. } \\
\text { Heparin } 7-10 \mathrm{~d} \text {. }\end{array}$ & $28.3 \times 24.8$ \\
\hline & $\begin{array}{l}<10 \mathrm{~d} \text { after } \\
\text { onset } \mathrm{PE} / 16\end{array}$ & & $\begin{array}{l}\text { Heparin } 10.000 \text { U/bolus and } 7-10 \\
\mathrm{~d}(2-3 \times \text { aPTI })\end{array}$ & $25.3 \times 25.2$ \\
\hline \multirow[t]{3}{*}{ Thery $^{30}$} & $\begin{array}{l}<30 \text { after } \\
\text { onset PE / } 33\end{array}$ & \multirow{3}{*}{$\begin{array}{l}\text { Angio: } \\
\text { O hy } 8 d \\
\text { Phlebography: } \\
0 d \times 8 d\end{array}$} & $\begin{array}{l}\text { Heparin (UF) bolus } 50 \mathrm{U} / \mathrm{kg} \text { and } \\
600 \mathrm{U} / \mathrm{kg} \text { iv for } 14 \mathrm{~d}(2.5-3 x \\
\mathrm{aPTI})\end{array}$ & $\begin{array}{l}34.7 \times 11.0 \% \\
\text { obstruction }\end{array}$ \\
\hline & $\begin{array}{l}<30 \text { after } \\
\text { onset PE } / 35\end{array}$ & & $\begin{array}{l}\text { WWW Hepanin } 400 \mathrm{l} / \mathrm{kg} \text { bi.d sc for } \\
14 \mathrm{~d}\end{array}$ & $\begin{array}{l}31.7 \times 11.2 \% \\
\text { obstruction }\end{array}$ \\
\hline & $\begin{array}{l}<3 D \text { after } \\
\text { onset PE/26 }\end{array}$ & & $\begin{array}{l}\text { LMW heparin } 600 \mathrm{U} / \mathrm{kg} \text { ti.d, sc for } \\
14 d\end{array}$ & $\begin{array}{l}32.4 \times 11.4 \% \\
\text { obstruction }\end{array}$ \\
\hline \multirow[t]{2}{*}{$\begin{array}{l}\text { Goldhaber } \\
1993^{45}\end{array}$} & $\begin{array}{l}<14 \text { d after } \\
\text { onset } P E / 46\end{array}$ & \multirow{2}{*}{$\begin{array}{l}\text { Angio }(21 \%) \\
\text { oh } \\
\text { V/Q }(94 \%) \\
\text { o h } \times 24 \mathrm{~h} \\
\text { Echo }(88 \%) \\
\text { Oh } \times 3 \mathrm{~h} \times 24 \mathrm{~h}\end{array}$} & $\begin{array}{l}\text { nt-PA } 100 \mathrm{mg} / 2 \mathrm{~h} \text { lollowed by } \\
1000 \mathrm{~b} / \mathrm{h} \text { for } 4 \mathrm{~h} \text { and than } 5 \mathrm{~d} \\
\text { heparin }(1.5-2.5 \mathrm{x} \text { aPTT) }\end{array}$ & ” \\
\hline & $\begin{array}{l}<1.4 \text { di after } \\
\text { onset PE / } 55\end{array}$ & & $\begin{array}{l}\text { Heparin } 5000 \text { U followed by } 1000 \\
\text { U/h for } 4 \mathrm{~h} \text { and than } 5 \mathrm{~d} \text { heparin } \\
(1.5-2.5 \times \mathrm{aPT})\end{array}$ & - \\
\hline \multirow[t]{2}{*}{$\begin{array}{l}\text { Goldhaber } \\
1994^{46}\end{array}$} & $\begin{array}{l}<14 \mathrm{~d} \text { after } \\
\text { onset } \mathrm{PE} / 61\end{array}$ & \multirow{2}{*}{ 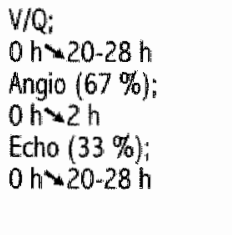 } & $\begin{array}{l}\mathrm{tt}-\mathrm{PA} 0.6 \mathrm{mg} / \mathrm{kg} / 15 \mathrm{~min} \text { ( } \mathrm{max} 50 \\
\mathrm{mg} \text { ) followed by heparin }(2 \times \\
\text { aPTT) for? }\end{array}$ & $\begin{array}{l}6.43 \times 5.83 \\
\text { (quantitative score } \\
0=\text { no dot } \\
9=\text { massive dot) }\end{array}$ \\
\hline & $\begin{array}{l}<14 \text { d after } \\
\text { onset PE } / 29\end{array}$ & & $\begin{array}{l}\text { rt-PA } 100 \mathrm{mg} / 2 \mathrm{~h} \text { followed by } \\
\text { heparin }(2 \times \text { aPTा) for? } \mathrm{d}\end{array}$ & $\begin{array}{l}5.77 \times 4.45 \\
\text { (quantitative score) }\end{array}$ \\
\hline \multirow[t]{2}{*}{$\begin{array}{l}\text { Sors } \\
1994^{47}\end{array}$} & $\begin{array}{l}<5 \mathrm{~d} \text { after } \\
\text { onset } \mathrm{PE} / 36\end{array}$ & \multirow{2}{*}{$\begin{array}{l}\text { Angio: } \\
\text { oh } \\
\text { Pressure: } \\
0 \mathrm{~h} \times 1 \mathrm{~h} \times 12 \mathrm{~h} \\
V / \mathrm{Q}_{\mathrm{i}} \\
0 \mathrm{~h} \times 20-28 \mathrm{~h}\end{array}$} & $\begin{array}{l}\mathrm{rt}-\mathrm{PA} 0.6 \mathrm{mg} / \mathrm{kg} / 15 \mathrm{~min}(\max 50 \\
\mathrm{mg}) \text { followed by heparin } 3-5 \mathrm{~d}(2- \\
2.5 \times \mathrm{at} P T T)\end{array}$ & $25 \times$ not performed \\
\hline & $\begin{array}{l}<5 d \text { after } \\
\text { onset PE/117 }\end{array}$ & & $\begin{array}{l}\text { rt.PA } 100 \mathrm{mg} / 2 \mathrm{~h} \text { followed by } \\
\text { heparin } 3.5 \mathrm{~d}(2-2.5 \times \text { aPTT })\end{array}$ & 24 anct performed \\
\hline
\end{tabular}

Table 1: Major studies using heparin or thromboltics in pulmonay embolism. The table summarizes the entrance criteria (interval between onset of complain's and start of treatment) and number of pattients in each group (column 2). In column 3 diagnostic tools used are thited and the use of each of these lools in the is given (separated by an $\times$ icon). The results of the measurements are shown in collumn 5.8 and 11 . Wh column 4 treatment is given. In column 9 bleeding complications are listed fin general those biedings needing bibad transfuisions or causing major problems (e.g. intra-cranial)). In column 10 mortallty related to therapy is Histed. 
Treatment of pulmonary embolisin

\begin{tabular}{|c|c|c|c|c|c|}
\hline $\begin{array}{l}\text { II. PASP (P) or } \\
\text { MPAP (M) }\end{array}$ & III. TPR & N. NOQ & $\begin{array}{l}\text { Important } \\
\text { bleeding }\end{array}$ & $\begin{array}{l}\text { Mortality of } \\
\text { therapy }\end{array}$ & $\begin{array}{l}\text { Late evaluation } \\
\text { \# remarks }\end{array}$ \\
\hline$M 30.2 \times 21.4$ & - & $\begin{array}{l}12 \times 7 \times 5.5 \\
\text { segment score }\end{array}$ & $15 \%$ & $10 \%$ & \multirow[t]{2}{*}{$\begin{array}{l}\text { Absent } \\
\text { \# cardiogenic shock excluded }\end{array}$} \\
\hline M $22.3 \times 24.8$ & - & $\begin{array}{l}8.5 \times 5.3 \times 2.7 \\
\text { segment score }\end{array}$ & $12.5 \%$ & $0 \%$ & \\
\hline- & - & - & $6 \%$ & $0 \%$ & \multirow{3}{*}{$\begin{array}{l}\text { Absent } \\
\text { \# } 8 d \text { analysis shows that Low } \\
\text { Molecular Weight Heparin } \\
\text { (LWMH) } 400 \text { U/kg b.i.d. is as } \\
\text { good as unfractionated } \\
\text { Heparin (LFH) }\end{array}$} \\
\hline$\infty$ & - & $\infty$ & $0 \%$ & $0 \%$ & \\
\hline- & - & - & $19.2 \%$ & $0 \%$ & \\
\hline - & - & $\begin{array}{l}\text { 42.9v28.3@ } \\
14.6 \% \text { improwement }\end{array}$ & $6.5 \%$ & $0 \%$ & \multirow{2}{*}{$\begin{array}{l}\text { Absent } \\
\text { \# Echo RV area }(\mathrm{AP} 4 \mathrm{CH}) \text { and } \\
\text { WM improved at } 24 \mathrm{~h} \text { in } 39 \% \\
\text { of 'rt-PA' compared with } 17 \% \\
\text { of "heparin' }\end{array}$} \\
\hline - & - & $\begin{array}{l}36.0 \times 34.5 @ \\
1.5 \% \text { improvement }\end{array}$ & $1.8 \%$ & $0 \%$ & \\
\hline- & - & $46.3 \times 37.4 @$ & $13 \%$ & $8.3 \%$ & \multirow[t]{2}{*}{$\begin{array}{l}\text { Absent } \\
\text { \# less fibrinolysis with bolus rt- } \\
\text { PA compared with } 2 \mathrm{~h} \text { group } \\
\text { \# inconclusive (partially } \\
\text { technically inadequate) }\end{array}$} \\
\hline - & - & 34.8×24.0@ & $22 \%$ & $3.7 \%$ & \\
\hline $\begin{array}{l}\text { P. } 57 \times ? \\
M 33 \times 25 \times 20\end{array}$ & $\begin{array}{l}15.2 \times 10.2 \\
\times 8.7 \mathrm{U} / \mathrm{m}^{2}\end{array}$ & $14 \%$ improvement & $6 \%$ & $0 \%$ & \multirow[t]{2}{*}{$\begin{array}{l}\text { Absent } \\
\text { \# TPR decreased initially faster } \\
\text { in the } 2 \text { h group }\end{array}$} \\
\hline $\begin{array}{l}P 51 \times ? \\
M 31 \times 26 \times 21\end{array}$ & $\begin{array}{l}16.2 \times 9.8 \\
\times 8.3 \mathrm{U} / \mathrm{m}^{2}\end{array}$ & $13 \%$ improvement & $8 \%$ & $0 \%$ & \\
\hline
\end{tabular}

Abbreviations: $P E=$ pulmonary embolism, UK= $=$ urokinase, $S K=$ sireptokinase, it $-P, A=$ =recombinant tissue type plasminogen activator, $h=$ hour, $d=d a y$, mo=month, $y=y e a r$, Angio=pulmonary angiogram, Pressure=pressure measurements in pulmonary artery (in mmilg), $P A S P=$ pulmonary artery systolic pressure, MPAP= mean pumonary antery pressure, TPR=total pulhonary vascular

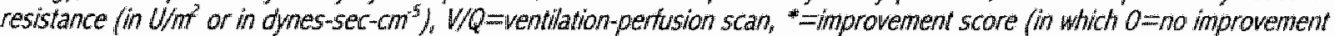

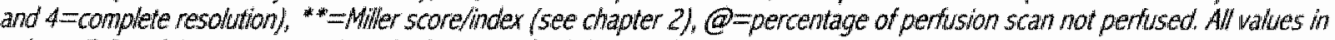
column $5-8$ and $1 /$ are mean values (without standard deviation).

Example Sors study: Pressure (column 3); oh $\times 1 \mathrm{~h} \times 12 \mathrm{~h}$ and results in column $6.431 \times 26 \times 21$ are mean pulmonary artery pressures in minth on start study (o hour), after 1 hour and after 14 hours. 


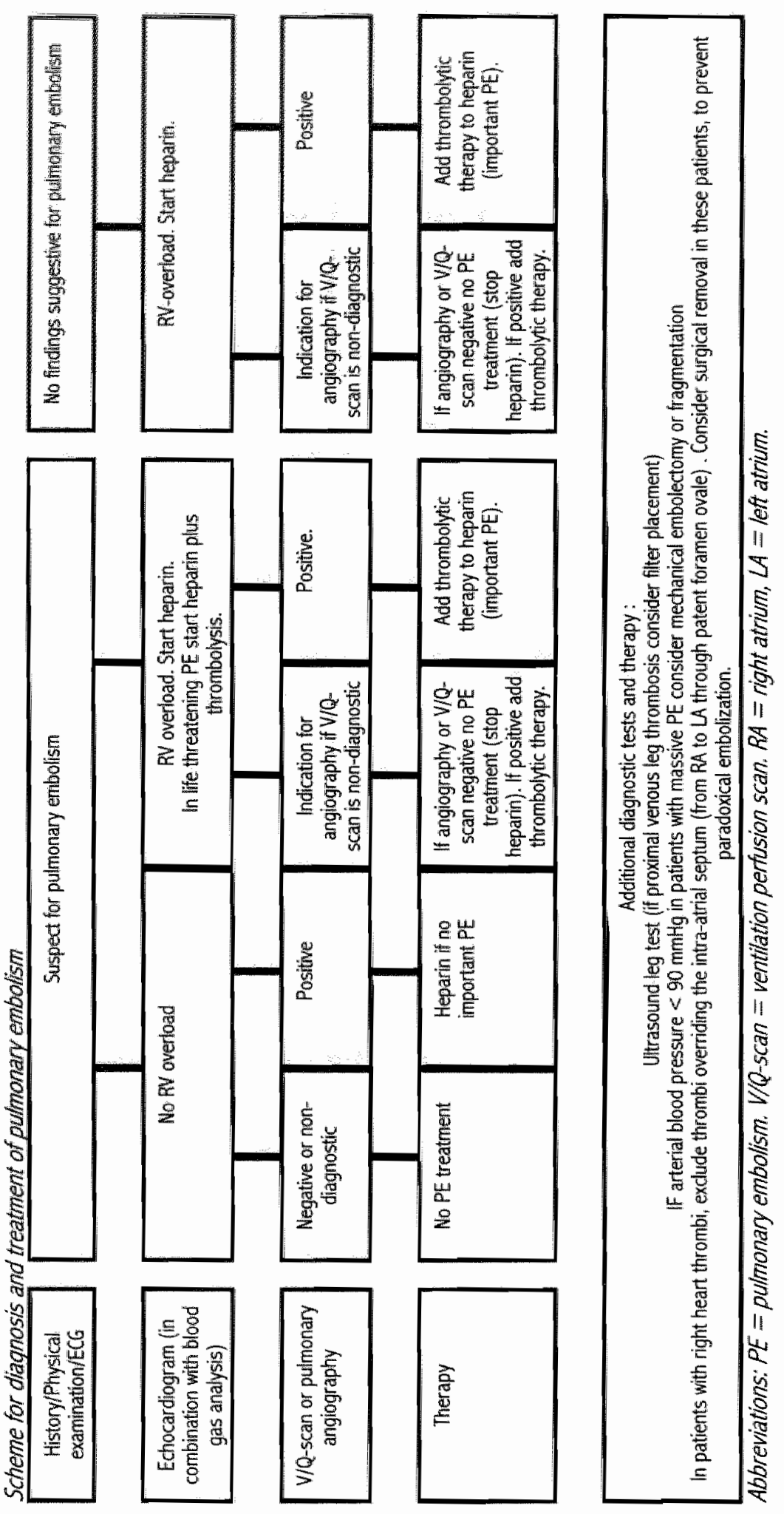




\section{References}

1. Tapson VF, Witty LA. Massive pulmonary embolism. Diagnostic and therapeutic strategies. Clin Chest Med 1995;16:329-340.

2. Moser KM. State of the art. Pulmonary embolism. Am Rev Respir Dis 1977;115:829-852

3. Greenfield LJ. Vena caval interruption and pulmonary embolectomy. Clin Chest Med $1984 ; 5: 495-505$.

4. Hampton AO, Castleman B. Correlation of post-mortem chest teleröntgenograms with autopsy findings (with special reference to pulmonary embolism and infarction). Am J Roentgenol 1940;43:305-326.

5. Havig Ö. Deep vein thrombosis and pulmonary embolism. Acta Chir Scand 1977(suppl):478..192.

6. Short DS. A survey of pulmonary embolism in a general hospital. Brit Med J 1952;1:790-796.

7. Moser KM, Guisan M, Bartimmo EE, Longo AM, Farsanyi PG, Chiorazzi N. In vivo and postmortem dissolution rates of pulmonary emboli and venous thrombi in the dog. Circulation 1973;48:170-176.

8. Dalen JE, Banas JS, Brooks HL, Evans GL, Paraskos JA, Dexter L. Resolution rate of acute pulmonary embolism in man. N Engl J Med 1969;280:1194-11 199.

9. Hall RJC, Sutton GC, Kerr IH. Long-term prognosis of treated acute massive pulmonary embolism. Brit Heart J 1977;39:1128-1134.

10. Sutton GC, Hall RJC, Kerr IH. Clinical course and late prognosis of treated subacute massive, acute minor, and chronic thromboembolism. Brit Heart J 1977;39:1135-1142.

11. Paraskos JA, Adelstein SJ, Smith RE, Rickman FD, Grossman W, Dexter L, Dalen JE. Late prognosis of acute pulmonary embolism. N Engl I Med 1973;289:55-62.

12. Riedel M, Stanek V, Widimsky J, Prerowsky I. Longterm follow-up of patients with pulmonary hypertension. Chest 1982;81:151-158.

13. Urokinase Pulmonary Embolism Trial. Phase 1 results. A cooperative study. JAMA $1970 ; 214: 2163-2172$.

14. Urokinase-Streptokinase Embolism Trial. Phase 2 results. A cooperative study. JAMA 1974,229:1606-1613.

15. Mobin-Uddin $K$, Utley JR, Bryant LR. The inferior vena cava umbrella filter. Prog Cardiovasc Dis 1975;18:391-399.

16. Ballew KA, Philbrick JT, Becker DM. Cava filter devices. Clin Chest Med 1995;16:295-305.

17. Thery C, Bauchart JJ, Lesenne M, Asseman P, Flajollet J-G, Legghe R, Marache P. Predictive factors of effectiveness of streptokinase in deep venous thrombosis. Am $J$ Cardiol $1992 ; 69: 117-122$.

18. Trendelenburg F. Uber die operative behandlung der embolie der lungenarterie. Arch Klin Chir $1908 ; 86: 686-700$.

19. Moser KM, Fedullo PF. Acute and chronic pulmonary embolism. In; Pulmonary circulation. Peacock AJ, ed. Chapman \& Hall, London, 1996:391-422.

20. Greenfield LJ, Proctor MC, Williams DM, Wakefield TW, AbuRhama AF, Clagett GP, Lumsden AB. Long-term experience with transvenous catheter pulmonary embolectomy. J Vase Surg 1993;18:450-458.

21. Essop MR, Middlemost S, Skoularigis J, Sareli P. Simultaneous mechanical clot fragmentation and pharmacological thrombolysis in acute massive pulmonary embolism. Am J Cardiol $1992 ; 69: 427-430$. 
22. Brady AJB, Crake T, Oakley CM. Simultaneous mechanical clot fragmentation and pharmacological thrombolysis in acute massive pulmonary embolism. Readers' comments. Am J Cardiol 1992;69:836.

23. Wan Ommen VG, van den Bos AA, Pieper $M$, den Heyer P, Thomas MR, Ozbeck S, Bär F, Wellens HJ. Removal of thrombus from aortocoronary bypass grafts and coronary arteries using the 6F hydralyser. Accepted Am J Cardiol 1997.

24. Handin RI, Loscalzo J. Iemostasis, thrombosis, fibrinolysis, and cardiovascular disease. In: Braunwald $\mathrm{E}$, ed. Heart disease. A text book of cardiovascular medicine. Fourth edition. WB Saunders Philadelphia, 1992:1767-1789.

25. Becker RC, Ansell J. Antithrombotic therapy. An abbreviated reference for clinicians. Arch Intern Med 1995:155:149-161.

26. Kessler CM. Anticoagulation and thrombolytic therapy. Practical considerations. Chest 1989 (suppl); $95: 245 \mathrm{~S}-256 \mathrm{~S}$.

27. Goldhaber SZ. Bolus and accelerated thrombolysis. Experimental observations and clinical management of myocardial infraction and pulmonary embolism. Chest 1995;107:889-892.

28. Editorial Lancet. Thrombolysis for pulmonary embolism. Lancet 1992;340:21.

29. Böttiger BW, Böhrer H.. Thrombolysis for pulmonary embolism. Lancet 1992;340:852.

30. Théry $\mathrm{C}$, Simonneau $\mathrm{G}$, Meyer $\mathrm{G}$, Hélénon $\mathrm{O}$, Bridey $\mathbb{F}$, Armagnac $\mathrm{C}$, d'Azemar $\mathrm{P}$, Coquart JP. Randomized trial of subcutaneous low-molecular-weight heparin CY 216 (Fraxiparine) compared with intravenous unfractionated heparin in the curative treatment of submassive pulmonary embolism. A dose-ranging study. Circulation 1992;85:1380-1389.

31. Ly B, Armesen H, Eie H, Hol R. A controlled trial of streptokinase and heparin in the treatment of major pulmonary embolism. Acta Med Scand 1978;203:465-470.

32. Miller GAH, Sutton GC, Kerr IH, Gibson RV, Honey M. Comparison of streptokinase and heparin in treatment of isolated massive pulmonary embolism. Brit Med J 1971;2:681-684.

33. Böttiger BW, Bach A, Böhrer H, Martin E. Die akute thromboembolie der lunge, Anesthesist 1993;42:55-73.

34. Heinrich F, Fenn K, Spörri R, Klink K. Fibrinolysetherapie der lungenembolie. Verh Dtsch Ges Inn Med 1990;96:356-364.

35. The UKEP study research group. The UKEP study: Multicenter clinical trial on two local regimens of urokinase in massive pulmonary embolism. Eur Heart $\mathbb{1} 1987 ; 8: 2-10$.

36. Petitpretz $P$, Simmoneau $G$, Cerrina $J$, Musset $D$, Dreyfus $M$, Vandenbroek MD, Duroux P. Effects of a single bolus of urokinase in patients with life-threatening pulmonary emboli: A descriptive trial. Circulation 1984;70:861-866.

37. Stern M, Meyer $\mathrm{G}$, Sors H. Urokinase versus tissue plasminogen activator in pulmonary embolisn. Lancet 1988;11:691-692.

38. Goldhaber SZ, Kessler CM, Heit JA, Elliott SG, Friedenberg WR, Heiselman DE, Wilson DB, Parker JE, Bennett D, Feldstein ML, Selwyn AP, Kim D, Sharma GVRK, Nagel JS, Meyerovitz MF. Recombinant tissue-type plasminogen activator versus a novel dosing regimen of urokinase in acute pulmonary embolism: A randomized controlled multicenter trial. J Am Coll Cardiol $1992 ; 20: 24-30$.

39. Tilsner $\mathrm{V}$. Thrombolytic therapy in fulminant pulmonary thromboembolism. Thorac Cardiovase Surg 1991;39:357-359.

40. Verstraete M, Miller GAH, Bounameaux H, Charbonnier B, Colle IP, Lecorf G, Marbet GA, Mombaerts $\mathrm{P}$, Olsson $\mathrm{CG}$. Intravenous and intrapulmonary recombinant tissue-type plasminogen activator in the treatment of massive pulmonary embolism. Circulation $1988 ; 77: 353-360$. 
41. Goldhaber SZ, Heit J, Sharma GVRK, Nagel JS, Kim D, Parker JA, Drum D, Reagan K, Anderson J, Kessler GM, Markis J, Dawley D, Meyerovitz M, Vaughan DE, Tumeh SS, Localzo J, Selwyn AP, Braunwald E. Randomized controlled trial of recombinant tissue plasminogen activator versus urokinase in the treatment of acute pulmonary embolism. Lancet 1988;2:293-298.

42. Dalla-Volta $\mathrm{S}$, Palla $\mathrm{A}$, Santolicandro A, Giutini $\mathrm{C}$, Pengo V, Visioli $\mathrm{O}$, Zonzin $\mathrm{P}$, Zanutini D, Barabaresi F, Agnelli G, Morpurgo M, Marini MG, Visani L. PAIMS 2: Alteplase combined with heparin versus heparin in the treatment of acute pulmonary embolism. Plasminogen Activator Italian Multicenter Study 2. J Am Coll Cardiol 1992;20:520-526.

43. Meyer G, Sors $\mathrm{H}$, Charbonnier B, Kaspar W, Bassand J-P, Kerr IH, Lesaffre E, Vanhove P, Verstraete $M$. Effects of intravenous urokinase versus alteplase on total pulmonary resistance in acute massive pulmonary embolism: A european multicenter double-blind trial. J Am Coll Cardiol 1992;19:239-245.

44. PIOPED investigators. Tissue plasminogen activator for the treatment of acute pulmonary embolism. A collaboratiwe study. Chest 1990,97:528-533.

45. Goldhaber SZ, Haire WD, Feldstein ML, Miller M, Toltzis R, Smith IL, Taveira da Silva AM, Come PC, Lee RT, Parker JA, Mogtader A, McDonough TJ, Braunwald E. Alteplase verus heparin in acute pulmonary embolism: randomised trial assessing right-ventricular function and pulmonary perfusion. Lancet 1993;341:507-511.

46. Goldhaber SZ, Agnelli G, Levine MN. BAPE study group. Reduced dose bolus alteplase vs conventional alteplase infusion for pulmonary embolism thrombolysis. Chest $1994 ; 106: 718$ 724.

47. Sors H, Pacouret G, Azarian R, Meyer G, Charbonnier B, Simonneau G. Hemodynamic effects of bolus vs 2 -h infusion of alteplase in acute massive pulmonary embolism. A randomized controlled multicenter trial. Chest 1994;106:712-717.

48. Levine $M$, Hirsch $J$, Weitz $J$, Cruickshank M, Neemeh $J$, Turpie AG, $_{3}$ Gent M. A randomized trial of a single bolus dosage regimen of recombinant tissue plasminogen activator in patients with acute pulmonary embolism. Chest 1990;98:1473-1479.

49. Barritt DW, Jordan SC. Anticoagulant drugs in the treatment of pulmonary embolism. A controlled trial. Lancet 1960; 1309-1312.

50. Sharma GVRK, Burleson VA, Sasahara AA. Effect of thrombolytic therapy on pulmonary capillary blood volume in patients with pulmonary embolism. N Eng $\mathbb{J}$ Med 1980;303:842-845.

51. Weiztzenblum E, Chaouat A, Oswald M. Pulmonary hypertension due to chronic hypoxic llung disease. In: Pulmonary circulation. Peacock AJ, ed. Chapman \& Hall, London, 1996;157-179.

52. Matthay RA, Arrigola AC, Wiedemann HP, Schulman DS, Mahler DA. Right ventricular function at rest and during exercise in chronic obstructive pulmonary disease. Chest 1992 (suppl); $101: 255 \mathrm{~S}-262 \mathrm{~S}$.

53. Dalen JE, Alpert JS. Natural history of pulmonary embolism. Prog Cardiovasc Dis 1975;17:259-269.

54. Benotti JR, Dalen JE. The natural history of pulmonary embolism. Clin Chest Med 1984;5:403410 .

55. Beyth RJ, Cohen AM, Landefeld S. Long term prognosis of deep venous thrombosis. Arch Intern Med 1995;155:1031-1037.

56. Goldhaber SZ. Pulmonary embolism. In: Braunwald E, ed. Heart disease. WB Saunders. Philadelphia. 1996;1582-1603.

57. Cannon $\mathrm{CP}$, Goldhaber SZ. Cardiovascular risk stratification of pulmonary embolism. Am J Cardiol 1996;78:1149-1151. 
58. Becker DM, Philbrick JT, Selby JB. Inferior vena cava filters: Indications, safety, effectiveness. Arch Intern Med 1992:152:1985-1994. 


\section{Chapter 9}

\section{Summary}

The aims of this thesis are to give insight into the effects of thromboembolism on pulmonary hemodynamics, to address the role of specific cardiological tools, as electrocardiography and echocardiography, for diagnosing right ventricular pressure overload suggestive for pulmonary embolism and to discuss the cardiological aspects of treatment of pulmonary embolism.

In chapter 2 the anatomy of the pulmonary circulation is described and the effect of pulmonary embolism on the circulation is discussed. Large emboli do not give rise to pulmonary infarctions due to collateral circulation, mainly provided by the bronchial artery system. The obstruction of pulmonary vessels will lead to increased afterload to the right ventricle and a decrease in cardiac output. Hypoxemia will develop in $90 \%$ of patients with obstructions of more than $10 \%$. Deep venous thrombosis is the main cause for pulmonary embolism. More than half of the patients with deep venous thrombosis will develop pulmonary embolism (including clinically silent emboli). Patients with deep venous thrombosis, not due to transient risk factors, have a high likelihood to have or develop overt cancer, during follow up. Diagnostic techniques to proof the presence of deep venous thrombosis are discussed. Ultrasound is the most used technique nowadays with a sensitivity of more than $90 \%$.

Major advantages and disadvantages of well known techniques to diagnose pulmonary embolism, as pulmonary angiography and pulmonary scintigraphy are discussed. It is shown that ventilation-perfusion scanning is onlly of value if the conclusion is "normal" or "high probability". Other techniques as Computer Tomography (CT) and Magnetic Resonance Imaging (MRI) are shown to have a high diagnostic yield for central (and thus important) pulmonary emboli.

The most recent advocated strategy for cost-effective diagnosis of pulmonary embolism is reported: serial noninvasive leg tests for deep venous thrombosis, ventilation perfusion scan and in the selected remaining subgroup pulmonary angiography. These strategies, however, are not looking at costs made to come to an alternative diagnosis in the patient population with a negative diagnosis pulmonary embolism, are not evaluating the time delay to reach the diagnosis and are not using standard cardiological tools.

In chapter 3 we tried to get insight in the amount of patients dying as a result of pulmonary embolism in the region surrounding the Academic Hospital of Maastricht. 2398 post-mortem examinations were performed in 5309 patients dying in hospital (about $45 \%$ of all persons dying in the region). In $4.4 \%$ of the post-mortem examinations gross pulmonary embolism was found. In $57 \%$ pulmonary embolism was massive or submassive and considered to be the main cause for death. In only $38 \%$ of cases pulmonary embolism was considered or diagnosed before death, a finding which is in agreement with the literature. Forty patients 
had an echocardiographic examination hours to years before death. In 10 of 24 patients with pulmonary embolism as their main cause of death an echocardiographic examination was made within 4 days. Eight of these 10 patients did show pressure elevation in the right sided circulation.

Chapter 4 describes the database system used to store the echocardiographic reports on line. This system is in use from September 1986 and contains at present more than 47.000 echocardiographic reports of more than 37.500 patients. All echocardiographic examinations are stored and authorized directly after the examination using a fixed mnemonic coding system. $0.6 \%$ of the population of 16.465 patients investigated until the end of 1992 showed signs of right sided pressure overload or floating thrombi in the right heart chambers. This subgroup is investigated in the chapters 5 to 7 . The database itself and the correlations between other used databases are discussed in chapter 4 .

In chapter 5 the use of cross sectional Doppler echocardiography as initial tool for the diagnosis is described in a population of 60 patients without previous lung disease and with acute complaints of chest pain, worsening dyspnea, palpitations or cardiovascular collapse in whom the combination of history, physical examination, electrocardiography and echocardiography did lead to the working diagnosis pulmonary embolism. The sequelae of these patients and the corroborative investigations to confirm the diagnosis are described. In 46 patients the diagnosis was additionally proven using scintigraphic ventilation perfusion scanning or pulmonary angiograms. Thrombi within the right side of the circulation were visualized in 9 patients. Indices of acute right ventricular pressure or volume overload that were present included an increased right ventricular end-diastolic diameter (56 patients), paradoxical diastolic septal motion ( 56 patients), tricuspid valve regurgitation with the peak velocity of regurgitation exceeding $2.6 \mathrm{~m} / \mathrm{sec}$ ( 56 patients), and a decreased collapse index of the inferior caval vein ( 46 patients). Fourteen patients were treated on the basis of echocardiographic findings alone. Three of them (with visible thrombi) recovered while 11 died. Pulmonary emboli were confirmed in four of five patients in whom an autopsy was performed.

The conclusion of this chapter is that two-dimensional Doppler echocardiography is a sensitive technique for the identification of pulmonary hypertension and acute right ventricular dysfunction associated with pulmonary embolism, and is ideal for serial followup.

In chapter 6 , in 49 consecutive patients with subsequently proven pulmonary embolism the 12 lead electrocardiograms obtained at hospital admission were reviewed in a blinded fashion, to identify ECG features suggestive of right ventricular overload. Pulmonary embolism was considered probable in 37 patients ( $76 \%$ ), from the presence of at least three of the following abnormalities: (1) Incomplete or complete right bundle branch block. This was associated with ST segment elevation and positive $T$ wave in $V_{1}$. (2) $S$ waves in leads $\mathrm{I}$ and aVL of $>1.5 \mathrm{~mm}$. (3) A shift in the transition zone in the precordial leads to $\mathrm{V}_{5}$. (4) Q waves in leads III and aVF, but not in lead II. (5) right axis deviation, with a frontal QRS axis of $>90^{\circ}$, or an indeterminate axis. (6) A low voltage QRS complex of $<5 \mathrm{~mm}$ in the limb leads. (7) $T$ wave inversion in leads III and aVF or leads $V_{1}$ to $V_{4}$, which occurred more 
commonly in patients with symptoms for $>7$ days. In the 12 patients with normal ECG's at admission, serial ECG's revealed diagnostic features of embolism in a further three patients.

There was no significant difference in the echocardiographically derived peak right ventricular systolic pressure or the right ventricular end-diastolic diameter between patients with and without abnormal ECG's respectively. On subdividing the patients with abnormal ECG's into three groups depending on the number of ECG abnormalities ( 7 or more abnormalities, 5-6 abnormalities, 3-4 abnormalities), there was no significant difference between any of the subgroups in right ventricular systolic pressure or end-diastolic diameter. Reviewing the electrocardiographic reports stored in the database (chapter 4) showed reports of patients with signs of pressure overload in whom the final clinical diagnosis was not pulmonary embolism. This total subgroup also included patients with chronic pulmonary disease in whom the attending physician excluded pulmonary embolism (with corroborative investigations or on clinical grounds only). The fact that the echocardiographic parameters described in chapter 5 and electrocardiographic signs of chapter 6 are specific for RVpressure overload but not necessarily for pulmonary embolism, and could also be seen in patients with exacerbations of pulmonary disease, will continue to make non-cardiologists sceptic to use these tools!

In chapter 7 this population with right sided pressure overload is studied as to echocardiographic features, clinical characteristics, additional investigations (particularly, blood gas analysis) and treatment. 50 patients had clearly proven pulmonary embolism. 22 patients were regarded, mainly on clinical grounds, to have pulmonary disease as cause for their (acute) pressure overload. The blood gas analysis in these two patient groups showed a clear distinction in $\mathrm{pCO}_{2}$ levels at hospital admission. $\mathrm{A} \mathrm{pCO}_{2} \leq 4.5-5 \mathrm{kPa}$ in combination with echocardiographic $\mathrm{RV}$-overload is highly suspect for pulmonary embolism. $\mathrm{A} \mathrm{pCO}_{2}>$ $4.5 \mathrm{kPa}$ was present in $76 \%$ of the patients with clinically suspected pulmonary disease as cause for the pressure overload. The electrocardiogram (discussed already in chapter 6) also showed serial changes in $31 \%$ of patients with pulmonary disease, probably, suggesting improvement in hemodynamics as a result of treatment.

In chapter 8 the treatment of pulmonary embolism is discussed after giving insight in the natural history of emboli in the pulmonary circulation. Endogenous thrombolysis and organization of thrombi can cause spontaneous decrease in amount of obstructed vessels, particularly in the young patient, without other diseases. The different classes of agents used for thrombolysis are reviewed. The trials performed to prove their effect are listed, especially on hemodynamics and long term results. These studies show that heparinization of patients improved prognosis (mortality) significantly. Fibrinolysis did not improve mortality further, but shows a significantly faster initial improvement in hemodynamics and thrombus resolution. One study suggests that fibrinolysis is better than heparin in restoring pulmonary capillary function long-term. On average the improvement in pulmonary obstructions is around $67-93 \%$ after 6 months using V/Q-scans and $68 \%$ after 8 days using angiography. Average mean pulmonary artery pressures are not returning to normal in all but one study (using prolonged infusions of recombinant tissue plasminogen activator). 
In conclusion, patients with larger pulmonary emboli, leading to circulatory problems (tachycardia, dyspnea, collapse, chest pain) are often coming to the attention of the cardiologist. The cardiologist has tools, which he/she can operate him/herself, on a 24 hour base and can help him/her to make the diagnosis right ventricular pressure overload due pulmonary emboli as very likely. The combination of electrocardiographic and echocardiographic findings discussed above in combination with a low $\mathrm{pCO}_{2}$ is in our view highly diagnostic. 


\section{Hoofdstuk 10}

\section{Samenvatting}

Dit proefschrift heeft als doel inzicht te geven in de cardiovasculaire aspecten van veneuze trombo-embolieen. Vele specialisten houdten zich bezig met patiênten met deze aandoening en benaderen dit probleem elk op hun eigen wijze. De chirurg is dagelijks bezig te voorkomen dat zijn patiënten in de peri- en postoperatieve periode een diepe veneuze trombose oplopen en probeert op deze wijze een longembolie te voorkomen. De internist ziet veelal de patiënt met een diepe veneuze trombose en onderzoekt de onderliggende oorzaak voor dit probleem. Veel intermisten behandelen ook de circulatoire aspecten van longembolieën. De longarts ziet de patiënt met kortademigheid of pijn bij het ademen en gaat op zoek naar de verklarende factor. De cardioloog wordt geconfronteerd met patiènt met een collaps, een shock, een tachycardie of pijn op de borst en probeert op de snelst mogelijke manier de oorzaak te achterhalen. Elk van de bovengenoemde specialisten heeft een eigen diagnostisch protocol ter bevestiging van de diagnose. Veelall wordt hiervoor gebruik gemaakt van beeldvormende technieken, die uitgevoerd en beoordeeld worden door de radioloog en de nucleair geneeskundige. Met name het scintigrafisch onderzoek wordt frequent gebruikt, maar is veelal alleen maar binnen normale werktijden als diagnosticum beschikbaar.

Een deel van de patiënten wordt op basis van het verhaal (de anamnese) en/of de wijzę van presentatie direct herkend als hebbende een longembolie. Een deel van de patiënten wordt op indirecte wijze (bij toeval) herkend of wordt niet herkend en overlijdt aan de gevolgen van de embolie (waarna de patholoog de diagnose stelt bij de obductie).

De patiënt, waarbij de diagnose vermoed wordt op basis van zijn klinische presentatie, is onderdeel van vele studies in de medische literatuur. De diagnostische ampak tijn behandeling is een continue bron voor nieuwe studies. Het is echter duidelijk dat opname in een bepaalde studie bepaald wordt door het primaire vermoeden van de medicus.

De cardioloog is een specialist, die een groot aantal diagnostische en beeldvormende technieken zelf beheert en beheerst. Deze technieken zijn 24 uur per dag beschikbaar. Een deel van deze technieken hebben (naast anamnese en lichamelijk onderzoek) het vermogen om een specifieke aandoening hoog op een differentiaal diagnose lijst te kunnen plaatsen, ook zonder een primair vermoeden van de medicus. Electrocardiografie en echocardiografie behoren tot deze technieken en zijn als niet invasieve technieken, voor het stellen van de diagnose longembolie, het onderwerp van dit proefschrift. Daarnaast beschikt de cardioloog over de mogelijkheid om pulmonalis angiogrammen te maken en drukmetingen in het pulmonaalcircuit te verrichten. Tevens is de hartbewaking bij uitstek de plaats waar hemodynamische monitoring van de patiënt uitgevoerd kan worden en de behandeling van de longembolie met trombolytische en antistollingstherapie kan worden verricht. 
Om de circulatoire gevolgen van een trombo-embolie beter te kunnen begrijpen wordt in hoofdstuk 2 gestart met een beschrijving van de anatomie van de long en haar bloedvoorziening en wordt het effect beschreven van longembolieẻn op deze circulatie. Eveneens wordt ingegaan op de relatie tussen diepe veneuze trombose en longembolieẽn.

De algemeen aanvaardde en gebruikte diagnostiek van diepe veneuze trombose en longembollieen wordt besproken. Het ultrageluid is momenteel de meest gebruikte techniek voor het vaststellen van een diepe veneuze trombose met een sensitiviteit van meer dan $90 \%$.

De scintigrafische ventilatie-perfusie scan, eventueel gevolgd door een pulmonalis angiogram, is de meest geèigende techniek voor de diagnostiek van de longembolie zelf. Bij een patiënt, met het vermoeden op een longembolie, zijn diagnostische kosten-baat strategieên ontwikkeld. Op deze manier wordt, gebruik makend van het ultrageluidsonderzoek van de benen en een ventilatie-perfusie scan, gepoogd het aantal invasieve (en dure) pulmonalis angiogrammen te beperken. Tevens wordt geprobeerd het aantal patiënten dat onnodig in het ziekenthuis verblijft zo laag mogelijk te houden. Uit de literatuur blijkt dat 25-35\% van de patiënten, met een klinisch vermoeden op een longembolie, echt een longembolie hebben. Deze patienten hebben dus veelal (meerdere) ultrageluids onderzoeken van de benen en een ventilatie-perfusiescan achter de rug. Wat de werkelijke diagnose bij deze patiënten met klachten en hun navolgende behandeling (en kosten) dan wel was wordt helaas in geen van deze studies duidelijk gemaakt.

In hoofdstuk 3 wordt inzage gegeven in het aantal patiënten dat in het Academisch Ziekenhuis Maastricht overleden zijn aan een (fatale) longembolie in de periode 1986 en 1992. Tevens is gekeken naar de mate waarin de diagnose door de behandelende arts herkend is, gerelateerd aan de ernst van de longembolie (wel/niet oorzaak voor overlijden). In deze periode werden 2398 obducties uitgevoerd bij 5309 patiënten die in het ziekenhuils overleden (ongeveer $45 \%$ van alle personen die in de regio Maastricht en omgeving overleden zijn). Bij $105(4.4 \%$ ) van de obducties werden longembolieën aangetroffen. Hiervan was de longembolie in $57 \%$ van de gevallen de doodsoorzaak. In $38 \%$ van alle fatalle gevallen was de diagnose longembolie gesteld of overwogen voor het overlijden. Een literatuur-onderzoek toont aan dat het niet herkennen van de longembollie in het Academisch Ziekenhuis Maastricht niet afwijkt van de rest van de wereld.

In het cardiologische echocardiografische databestand waren 40 van deze patiènten bekend (24 hiervan overleden aan een fatale embolie). Bij slechts 10 gevallen echter had dit echocardiografische onderzoek plaatsgevonden binnen 4 dagen voor het overlijden. $\mathrm{Bij} 8$ van de 10 onderzoeken was toen drukverhoging in de rechter hartshelft geconstateerd, wijzend op reeds aanwezige embolisatie.

Hoofdstuk 4 beschrijft het elektronische opslagsysteem gebruikt voor de echocardiografische verslagen. Dit opslagsysteem werd ontwikkeld in 1986 en maakt, naast een getalsmatige opslag van de hart-dimensies, gebruik van een opslag van diagnoses via een vast coderingssysteem. Sinds 1987 wordt dit systeem gebruikt voor directe rapportage aan de aanvragend arts. De codering wordt direct gekoppeld aan het verslag en nadien niet meer aangepast. Vanaf 1991 is het systeem beschikbaar als netwerksysteem en is de authorisatie geformaliseerd. Op dit moment bevat het systeem meer dan 47.000 echocardiografische 
verslagen van meer dan 37.500 patiënten. Bij $0.6 \%$ van 16.465 patiënten onderzocht tot eind 1992 werden aanwijzingen gevonden voor een drukoverbelasting van de rechter hartcirculatie, die niet verklaard kon worden door een afwijking van de linker harthelft, of werd een mobiel stolsel aangetroffen in het rechter hart of de longslagader. Bij deze bevindingen werd de echocardiografische diagnose "verdacht voor longembolie" of "longembolie niet uitgesloten" gesteld. Deze patiëntengroep is het onderwerp van studie in de hoofdstukken 5 tot en met 7 .

In hoofdstuk 5 wordt beschreven dat bij 46 van 60 patiënten zonder bekend longlijden met, mede dank zij echocardiografisch vastgestelde, rechter kamer belasting longembolieën konden worden aangetoond. Bij 9 van de 60 patiënten werden mobiele stolsels aangetroffen. Bij 14 patiënten werd de behandeling ingezet op basis van de echocardiografische bevindingen alleen. De reden hiervoor was het spoedeisende karakter van bevinding (reanimatie, shock). Bij 56 van de 60 patiènten werd een verwijde rechter kamer en een tricuspidalis insufficiëntie van meer dan $2.6 \mathrm{~m} / \mathrm{sec}$ (wijzend op een drukverschil van groter of gelijk aan $30 \mathrm{mmHg}$ tussen rechter kamer en rechter boezem) gevonden. Bij 46 patiënten was er een onvoldoende respiratoire collaps van de onderste holle lichaamsader wijzend op verhoogde rechter boezemdruk.

De conclusie van hoofdstuk 5 is dat echocardiografisch onderzoek als initieel diagnostisch onderzoek bij patiënten zonder pre-existent longlijden de waarschijnlijkheidsdiagnose longembolie met een grote mate van zekerheid kan stellen.

In hoofdstuk 6 worden de electrocardiografische registraties beschreven van 49 patiënten, die zich presenteerden met (acute) klachten en echocardiografisch aangetoonde rechter kamer belasting hadden. Deze 49 ECG's werden geblindeerd (tussen 170 andere ECG's) beoordeeld door 3 cardiologen op de anwezigheid van rechter kamer belasting. In het totaal 37 ECG's ( $76 \%$ ) gaven aanleiding tot de mogelijke diagnose longembolie op basis van de volgende criteria:

(1) Een incompleet of compleet rechter bundeltakblok (RBTB). Dit ging gepaard met STelevatie en een positieve T-top in $V_{1}$.

(2) $S$ toppen in afleidingen $I$ en aVL van meer dan $1.5 \mathrm{~mm}$.

(3) Een verschuiving van de overgangs zone van de precordiale afleidingen naar $V_{\varsigma}$.

(4) Q toppen in afleiding III en aVF, maar niet in II.

(5) Rechter as deviatie (QRS as in frontale vlak $>90^{\circ}$ ).

(6) Laag voltage in de extremiteitsafleidingen $(<5 \mathrm{~mm})$.

(7) T-top inversie in afleiding III en aVF of $V_{1}$ tot $V_{4}$, meestal voorkomend bij patienten met symptomen beginnend langer dan 7 dagen voor presentatie.

Bij 3 van de 12 patiënten met een normaal ECG bij opname werd het ECG tijdens opname alsnog diagnostisch. Er bleek geen relatie aanwezig tussen de hoogte van de druk en/of de mate van rechter kamer verwijding en de aanwezigheid en/of de totaal score van ECGafwijkingen. 
Deze ECG criteria zijn inmiddels overgenomen in "Heart disease. A textbook of cardiovascular medicine" onder de redactie van E.Braunwald (5de editie, 1996).

Bij de 100 patiënten met echocardiografische tekenen voor rechter kamer belasting of stolsels in het rechter hart waren ook patiềnten met een andere klinische diagnose dan longembolie. Vooral bij patiënten met exarcerbatie van pre-existent aanwezig chronisch longlijden bleek ook een acuut rechter kamer belastingsbeeld waargenomen te kunnen worden. Deze 100 patiënten vormen onderwerp van evaluatie in hoofdstuk 7. Deze evaluatie probeert duidelijk te maken waarom de echocardiografische diagnose acute rechter kamer belasting niet altijd tot de conclusie longembolie mag leiden. Gezien het retrospectieve karakter van deze evaluatie werd de diagnose (exarcerbatie) chronisch longlijden alleen op klinische grondslag gesteld (en retrospectief in veel gevallen aan-nemelijk geacht). Opvallend was dat de bloedgassen bij de patiëntengroep met bewezen longembolieën (45) en bij een groep met chronisch longlijden (19) een opvallend (en statistisch significant verschil) te zien gaven in $\mathrm{pCO}_{2}$. De combinatie van een $\mathrm{pCO}_{2} \leq 4.5-5 \mathrm{kPa}$ en een echocardiografische rechter kamer drukoverbelasting was zeer suspect voor longembolie. Een $\mathrm{pCO}_{2}$ wan $>4.5$ was aanwezig bij $76 \%$ van de patiënten met longlijden als oorzaak voor de rechtsbelasting. Het ECG toonde bij $31 \%$ van de patiënten met longlijden eveneens seriêle veranderingen aan, passend bij veranderingen in RV-drukken in de loop van de behandeling.

In hoofdstuk 8 wordt het natuurlijk beloop van embolieèn in de pulmonale circulatie beschreven. Embolieën verdwijnen (zeker bij gezonde jonge mensen) deels onder invloed van endogene trombolyse. Daarnaast treedt er recanalisatie op. Bij oudere en ziekere patiënten gebeurt dit in een veel mindere mate. Persisterende pulmonale drukverhoging met vermindering van inspanningstolerantie is dan niet ongebruikelijk in deze populatie en is mede afhankelijk van leeftijd van de trombo-embolie en het aantal recidieven. Een overzicht wordt gegeven over de behandelingsmogelijkheden bij longembolieën en de effecten daarvan op de stoisels en de pulmonaaldrukken. Heparinisatie heeft de mortaliteit van longembolieern dramatisch doen dalen. Trombolyse met behulp van urokinase, streptokinase of plasminogeen activatoren heeft de sterfte niet verder doen dalen, maar heeft bewezen het oplossen van embolieën wel te versnellen. Goede studies over het effect van de therapie (heparine of trombolyse) op langere termijn gevolgen voor de longcirculatie zijn onvoldoende voorhanden.

Op basis van de gegevens in de literatuur is het duidelijk dat bij patiënten met duidelijke hemodynamische gevolgen van een longembolie trombolyse de voorkeur verdiend.

De conclusie van dit proefschrift is dat, wanneer evaluatie van een patiënt, met een verscheidenheid aan klachten en/of symptomen, met behulp van een electrocardiogram en/of een echocardiogram, tekenen van rechter kamer belasting oplevert, de diagnose longembolie zeer waarschijnlijk is. Een lage $\mathrm{pCO}_{2}$ aanwezig bij analyse van arteriële bloedgassen versterkt deze diagnose aanzienlijk. 


\section{Nawoord}

Het leerproces binnen de klinische cardiologie en echocardiografie houdt niet op na het verkrijgen van een staflidmaatschap. Gestimuleerd werd ik door professor Hein Wellens. Zijn vermogen om het vak in de totale breedte te blijven overzien en de geprogrammeerde levenswijze die hier achter moet zitten hebben mij al die jaren geintrigeerd. Zijn bereidheid alles wat onder zijn ogen kwam te herschrijven, al die jaren lang, is bewonderenswaardig. Dit heb ik met name mogen ervaren bij de uitwerking van dit proefschrift.

Een groot probleem bij het tot stand komen van dit proefschrift was het structureel tijd maken voor het schrijven, naast de vaak drukke klinische dagtaak. Het effectueren hiervan vond te laat plaats en alleen met hulp van collegae Chris de Zwaan, Jan-Melle van Dantzig en Jan Heijmeriks.

De overige collegae hebben tijdens hun diensten allen te maken gehad met het onderwerp van dit proefschrift en hebben hun steentje bijgedragen.

Narayanswami Sreeram, kindercardioloog, destijds werkzaam als fellow op de electrofysiologie had het vermogen om zich in korte tijd in te werken in de ideeën achter electrocardiografie en echocardiografie bij rechter kamer overbelasting. De twee centrale hoofdstukken van dit proefschrift zijn mede door hem tot stand gekomen.

Ondersteuning bij het verzamelen van statussen en rangschikken van de vele data ondervond ik van Yvonne Eussen, student-assistente.

De afgelopen jaren heb ik van velen te horen gekregen dat ik met de echodatabase zonder enige twijfel moeiteloos zou moeten kunnen promoveren. De echodatabase was opgezet met het idee een praktische kaartenbak te vormen, die middels directe verslaglegging verzekerd zou moeten zijn van betrouwbare gegevens. Mijn eerste versie van de echodatabase werd in 1986 met hulp van Jan Heijmeriks opgebouwd. Vanuit dit systeem hebben Rob Mulleneers en Berto Bleijlevens het cardiologisch informatie systeem opgebouwd. Zij waren altijd bereid een helpende hand uit te steken.

Een groot deel van mijn tijd heb ik doorgebracht rond ultrageluidsapparatuur. Andrea Palmans-Meulemans is hierbij uitgegroeid tot steun en toeverlaat. De ondersteuning van de "oude garde" laboranten Edith Wijenberg en Patricia Jansen-Klomp versterkt met de "nieuwe garde" Jos Habets en Dominique Theuns is niet te verwaarlozen.

Secretariële ondersteuning is al die jaren in vertrouwde handen geweest van Nicole Cochrane. Jacqueline Janssen heeft het laatste jaar deze taak deels overgenomen. Ook Birgit van der Burg heeft waardevolle adviezen gegeven. Het secretariaat van de hartfunctie vergeet ik hierbij niet.

Pim Dassen bedankt voor de "cijfers" en de "wezen".

Simon Braat zonder jouw "scouting" was ik nooit in Maastricht gekomen. Ook jouw "technische ondersteuning" kwam op het juiste moment. 
Miek Havenith bedankt voor je bijdrage.

De verpleegkundigen, met name de verpleegkundigen van de CCU, zijn essentieel geweest voor de opvang van patiënten die het onderwerp vormen van dit proefschrift. Hun prettige wijze van samenwerking waardeer ik bijzonder. Met name Jean Partouns is altijd bereid iets extra's te doen.

Net als verpleegkundigen krijgen arts-assistenten veelal niet de waardering, die ze verdienen. Zij vangen dag en nacht de patiënten op, stellen de waarschijnlijkheidsdiagnose en bepalen vaak de snelheid van diagnostiek. Zonder hun werk kan geen klinisch proefschrift tot stand komen. Het doorworstelen van statussen laat vele handschriften zien. Velen hebben Maastricht reeds verlaten.

Bij dit soort nawoord komt het gezin altijd op de laatste plaats. "Mam, wie is die man die "s ochtends in de badkamer staat, is dat nu mijn vader?" is een kreet, die door mijn jongste dochter gebruikt werd. Deze opmerking ging steevast gepaard met mijn verweer dat ik het proefschrift niet aan haar, Caren, en haar zussen, Liane en Edine, zou opdragen maar aan Tobias, de hond, die de geboorte van dit proefschrift het meest van nabij heeft mogen meemaken. Toch bedank ik mijn kinderen, dat zij mijn computer in de laatste fase niet meer ontregeld hebben.

Edith blijft de echte spil van het gezin. Pol bedankt. 


\section{Curriculum vitae}

21 augustus 1952

1971

1971

1972-1973

10 mei 1977

7 december 1979

1980-1981

$1981-1982$

1982-1986

1 maart 1986
Geboren in Bandung (voormalig Nederlands Indiè).

Diploma HBS-B. Stedelijk Lyceum, Maastricht.

Start studie Geneeskunde aan de

Katholieke Universiteit Nijmegen.

Militaire dienst, Seedorf, Duitsland.

Doctoraalexamen Geneeskunde

Katholieke Universiteit Nijmegen.

Artsexamen

Assistentschap interne geneeskunde St Jozef ziekenhuis (Dr. J. Scherpbier).

Opleiding interne geneeskunde St Annadal ziekenhuis, Maastricht (Dr. J. Coenegracht).

Opleiding cardiologie St Annadal ziekenhuis, Maastricht (Prof. dr. H.J.J. Wellens).

Geregistreerd als Cardioloog. Sindsdien staflid vakgroep cardiologie, academisch ziekenhuis Maastricht. 